\author{
UNIVERSIDADE DE SÃO PAULO \\ FACULDADE DE ZOOTECNIA E ENGENHARIA DE ALIMENTOS
}

WALTER DA SILVA LEICK

Tecnologia computacional de apoio a rastreabilidade biométrica de bovinos

Pirassununga

2016 
Tecnologia computacional de apoio a rastreabilidade biométrica de bovinos

(Versão corrigida)

Dissertação apresentada a Faculdade de Zootecnia e Engenharia de Alimentos da Universidade de São Paulo, como parte dos requisitos para obtenção do Título de Mestre em Gestão e Inovação na Indústria Animal.

Área de Concentração: Gestão e Inovação na Indústria Animal.

Orientador: Prof. Dr. Ernane José Xavier Costa 
Ficha catalográfica elaborada pelo

Serviço de Biblioteca e Informaçāo, FZEA/USP,

com os dados fornecidos pelo(a) autor(a)

Leick, Walter da Silva

L526t Tecnologia computacional de apoio a rastreabilidade biométrica de bovinos / Walter da Silva Leick ; orientador Ernane José Xavier Costa. - Pirassununga, 2016. $73 \mathrm{f}$.

Dissertaçāo (Mestrado - Programa de Pós-Graduação em Engenharia de Alimentos) -- Faculdade de Zootecnia e Engenharia de Alimentos, Universidade de são Paulo.

1. rastreabilidade. 2. biometria. 3. celular. 4. web services. I. Costa, Ernane José Xavier, orient. II. Título. 


\section{Tecnologia computacional de apoio a rastreabilidade biométrica de bovinos}

Dissertação apresentada a Faculdade de Zootecnia e Engenharia de Alimentos da Universidade de São Paulo, como parte dos requisitos para obtenção do Título de Mestre em Gestão e Inovação na Industria Animal.

Área de Concentração: Gestão e Inovação na lindústria Animal.

Orientador: Prof. Dr. Ernane José Xavier Costa

Data de aprovação:

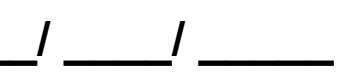

Banca Examinadora:

Prof. Dr. Ernane José Xavier Costa, USP/FZEA

Prof. Dr. César Gonçalves de Lima, USP/FZEA

Prof. Dr. Sérgio Paulo Amaral Souto, USP/FZEA 


\section{AGRADECIMENTOS}

À minha esposa Maria Hilda, que sempre me apoiou e incentivou a conquistar os meus sonhos.

Aos filhos Thomas, Hugo e Arthur por compreenderem minha ausência em momentos que gostariam que estivesse com eles.

Ao meu netinho Yuri que me ajudou a ter forças para tocar em frente.

A toda equipe do LAFAC pelo companheirismo, apoio e amizade.

A todos os professores e coordenadores que me ajudaram ensinando e corrigindo para que pudesse completar este trabalho.

Ao meu orientador e amigo Ernane, que sempre me apoiou e incentivou a fazer uma pós-graduação. 
"A mente que se abre a uma nova ideia jamais voltará ao seu tamanho original." Albert Einstein 


\section{RESUMO}

LEICK, W.S. Tecnologia computacional de apoio a rastreabilidade biométrica de bovinos. 2016. 68 f. Dissertação (Mestrado) - Faculdade de Zootecnia e Engenharia de Alimentos, Universidade de São Paulo, Pirassununga, 2016.

O Brasil é um dos maiores produtores e exportadores de carne bovina do planeta e com a expectativa de ser responsável por $45 \%$ do consumo mundial sendo que a maior parte de seu consumo ainda é local. Para se manter nesta posição e expandir suas vendas tanto no mercado interno como externo é importante que se garanta a qualidade do produto. Esta qualidade só é conseguida quando se consegue gerenciar todo o processo da cadeia produtiva, de forma a permitir o registro de todos os dados do animal na cadeia de produção. Tanto o governo através do SISBOV como grandes distribuidores possuem sistemas de gerenciamento que através de técnicas de rastreabilidade permitem ter este controle. A identificação do animal é ponto chave para a rastreabilidade que hoje é feita através de bottons, transponders, brincos entre outros. Todos estes métodos são invasivos e suscetíveis a perdas e adulterações. Esta dissertação mostra a viabilidade de inserir em sistemas de rastreabilidade existentes ou não a inclusão de identificação biométrica e usa como exemplo o focinho nasal do bovino. Para tanto desenvolveu-se programas para entrada de informações através de um celular com sistema operacional Android que em conjunto com programas desenvolvidos para rodarem na WEB pudessem cadastrar e confirmar a identidade do animal. Os testes mostraram a capacidade do aplicativo Android em localizar o espelho nasal e coletar o mesmo. Com os dados coletados foi possível armazenar as informações ou confirmar a identidade do animal por meio dos serviços do servidor. Mostrou-se desta forma viável a utilização deste tipo de identificação em sistemas de gerenciamento novos ou já existentes.

Palavras-chave: rastreabilidade, biometria, celular, web services. 


\begin{abstract}
LEICK, W. S. Computer technology to support bovines biometric traceability. 2016. 68 f. Thesis (MA) - Faculty of Animal Science and Food Engineering, University of São Paulo, Pirassununga, 2016.

Brazil is one of the largest producers and exporters of beef in the world and with the expectation of being responsible for $45 \%$ of global consumption and the largest part of consumption is still locall. To stay in this position and to expand its sales both in domestic and foreign markets is important to ensure product quality. This quality is achieved only when you can manage the entire process of the production chain in order to allow the registration of all animal data in the production chain. The government through SISBOV and large distributors have been working with management systems through traceability techniques. Animal identification is key to the traceability and nowadays is made via bottoms, transponders, earrings among others. All these methods are invasive and susceptible to loss and tampering. This work shows the feasibility of entering into existing traceability systems or not the inclusion of biometric identification and uses as an example the nasal muzzle beef. For both developed programs to input information through a mobile phone with Android operating system in conjunction with programs designed to be web based solution could register and confirm the identity of the animal. All results was able to shown the system performance by showing that it was possible to store the information or confirm the identity of the animal through the server services. The methodology proposed could be useful in commercial applications focusing in bovine traceability,
\end{abstract}

Key words: traceability, biometrics, mobile, web services 


\section{LISTA DE FIGURAS}

Figura 1 - Operação básica do LBP, com valor decimal resultante $184 \ldots \ldots \ldots 19$

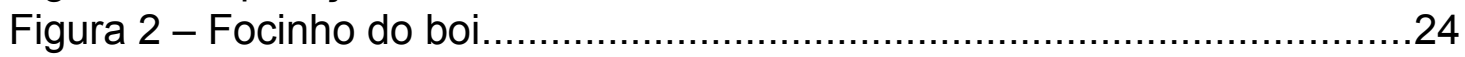

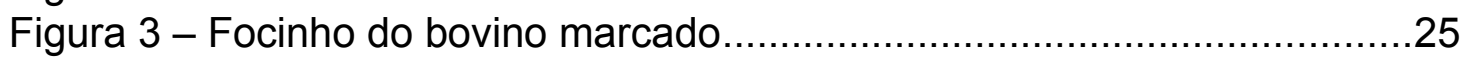

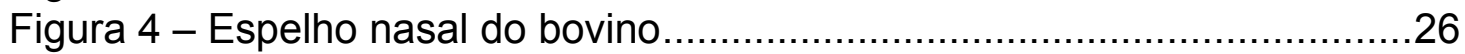

Figura 5 - Fluxo do Sistema............................................................... 30

Figura 6 - Tela de cadastramento e verificação......................................33

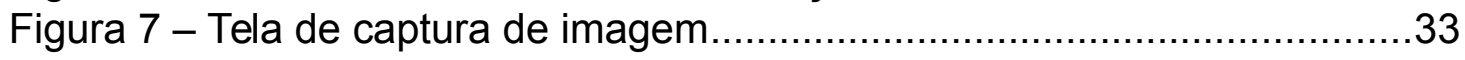

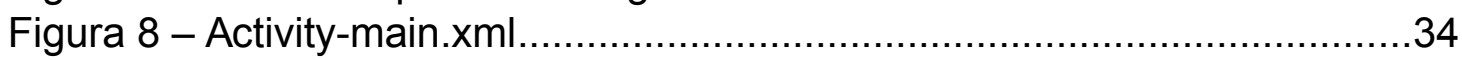

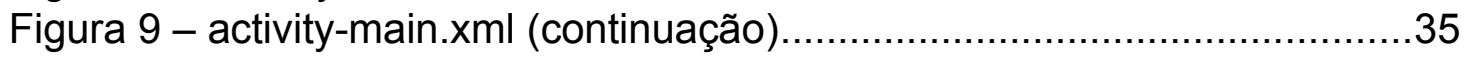

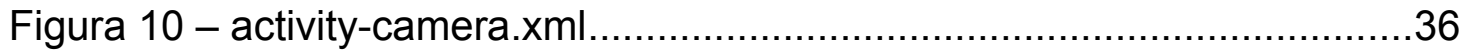

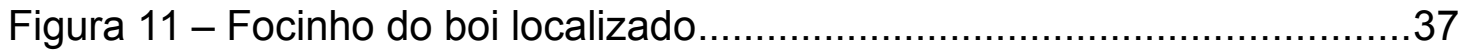

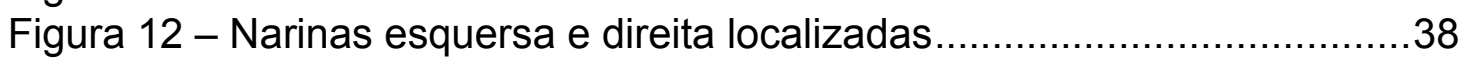

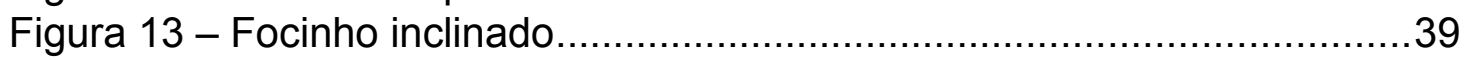

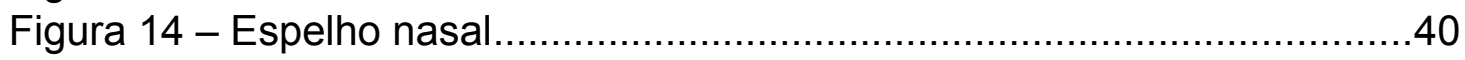

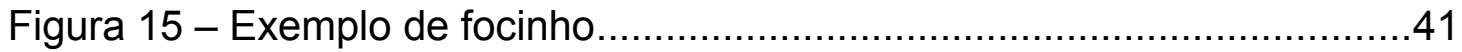

Figura 16 - Contra exemplo de focinho ................................................. 42

Figura 17 - Exemplo de narina direita..................................................42

Figura 18 - Contra exemplo de narina direita........................................43

Figura 19 - Exemplo de narina esquerda....................................................43

Figura 20 - Contra exemplo de narina esquerda.........................................44

Figura 21 - Estrutura Android Studio - Realce para os cascades..................46

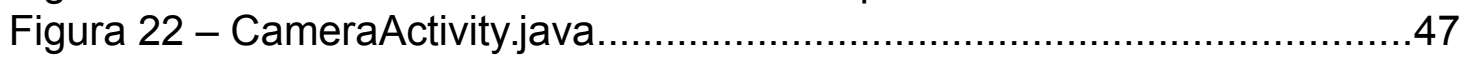

Figura 23 - Função initializeOpenCVDependencies................................48

Figura 24 - Função onCreate....................................................................49

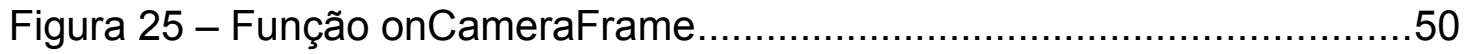

Figura 26 - Determinação do espelho nasal...........................................51

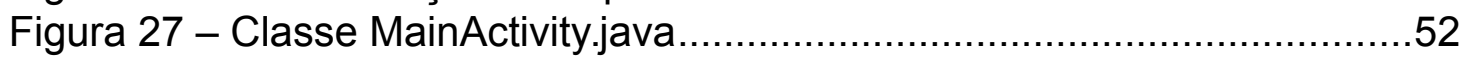

Figura 28 - Função onCreate da classe MainAvtivity.java..............................53

Figura 29 - Função capturelmage .......................................................54

Figura 30 - Função cadastrarlmagem................................................. 54

Figura 31 - Função verificarlmagem.................................................... 54

Figura 32 - WebService.java - Cliente................................................ 55

Figura 33 - Função involk da classe WebService.java - Cliente...................56

Figura 34 - Função enviaEnvolope da classe WebService.java - Cliente .......57

Figura 35 - Estrutura do projeto NetBeans................................................58

Figura 36 - Pacote org.me.biometricserver.............................................. 59

Figura 37 - Biometric Server (Web Service) ........................................59

Figura 38 - Função addAnimallmage - Serviço BiometricServer..................60

Figura 39 - Estrutura da tabela "animal" .................................................61

Figura 40 - Retorno Geração APK.....................................................62

Figura 41 - Pasta contendo app-release.apk ..........................................62

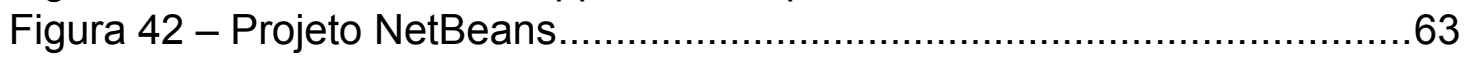

Figura 43 - BiometricServer na aba Serviços do Netbeans........................64

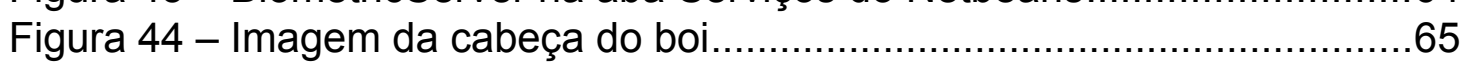

Figura 45 - Imagem da tela do celular focando o espelho nasal...................65 
Figura 46 - Tela do celular com espelho nasal capturado..........................66

Figura 47 - Linha da tabela "animal".........................................................67

Figura 48 - Imagem espelho nasal - Aplicativo Pinta..............................67 


\section{LISTA DE SIGLAS}

MAPA Ministério da Agricultura, Pecuária e Abastecimento

LBP

Local Binary Patterns

OpenCV

Open Source Computer Vision

WSDL

Web Service Description Language

$\mathrm{XML}$

Extensible Markup Language

SOAP

Simple Object Application Protocol

SISBOV

Sistema Brasileiro de Identificação e Certificação de Bovinos e

Bubalinos 


\section{SUMÁRIO}

1 INTRODUÇÃO

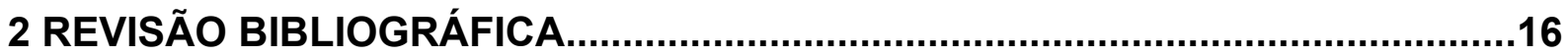

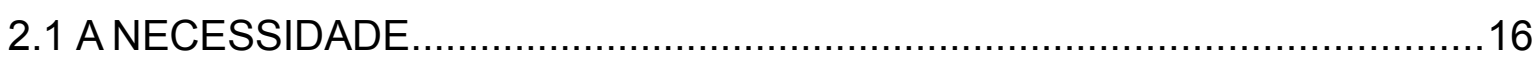

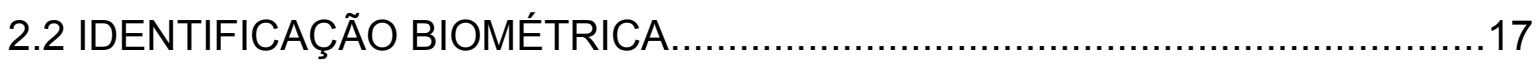

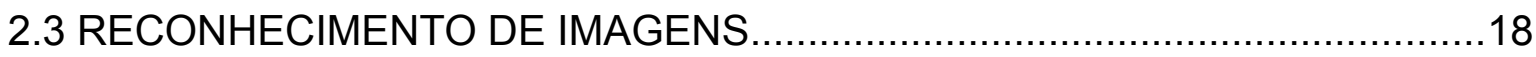

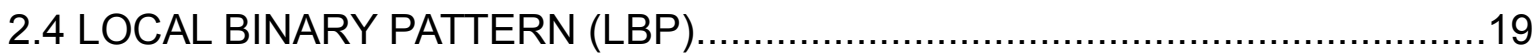

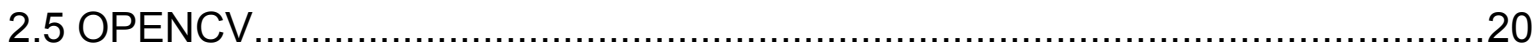

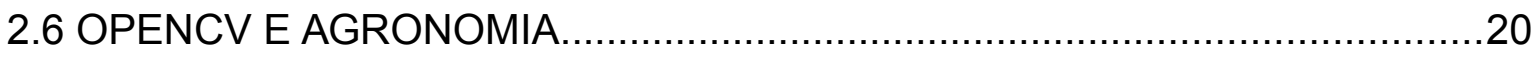

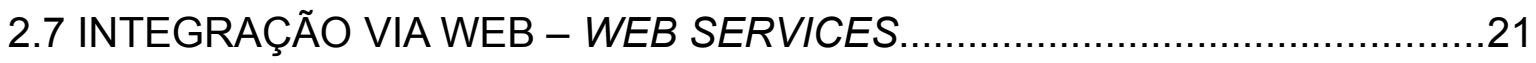

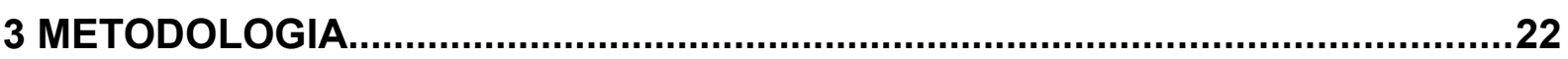

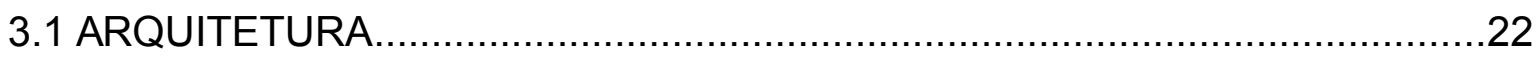

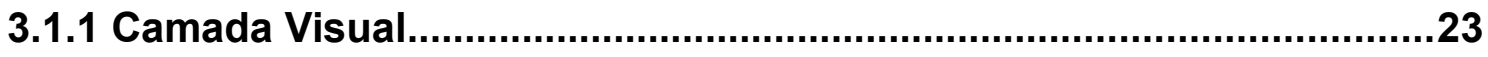

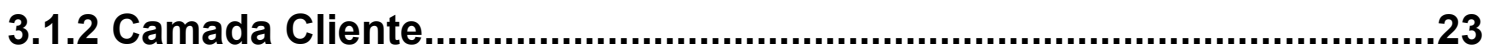

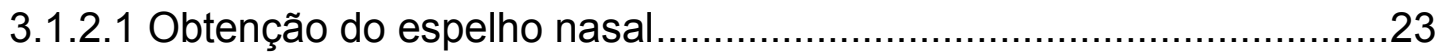

3.1.2.2 Obter o espelho nasal via OpenCV..............................................26

3.1.2.3 Comunicação com o Web Service...................................................27

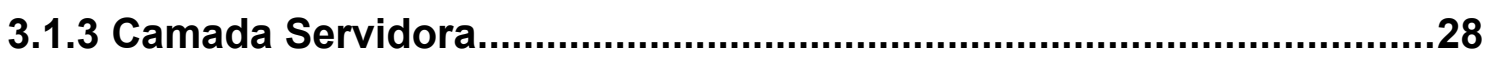

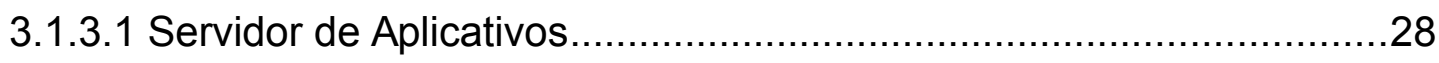

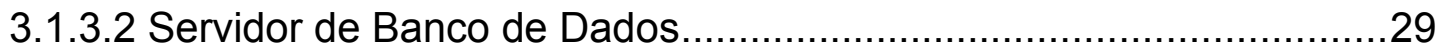

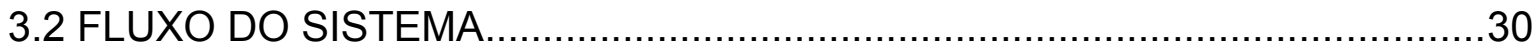

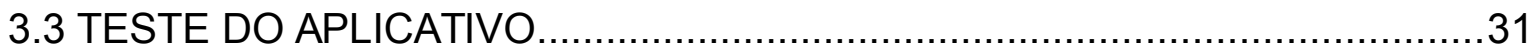

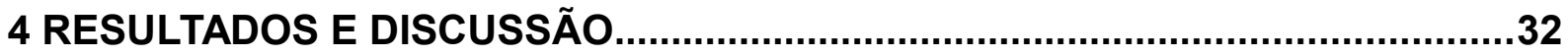

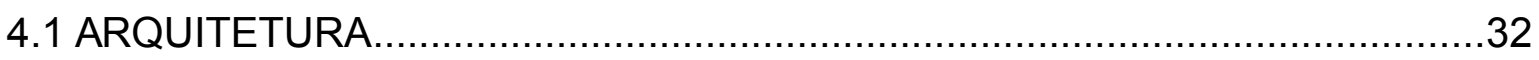

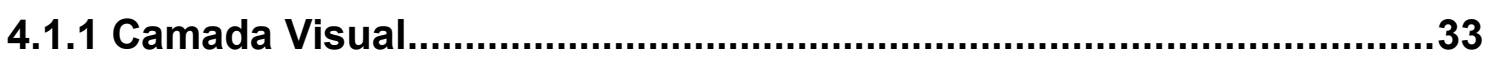

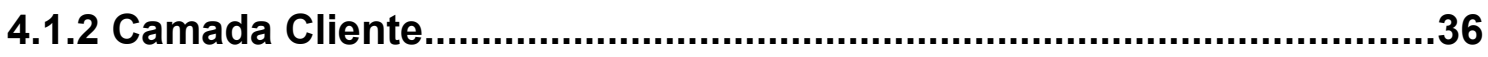

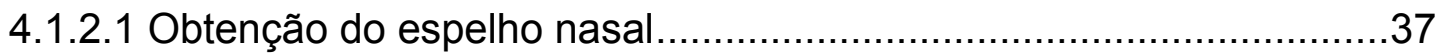

4.1.2.2 Identificação do espelho nasal pelo OpenCV ...................................40

4.1.2.3 Comunicação com Web Service ....................................................52

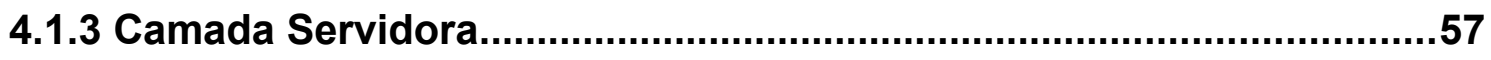

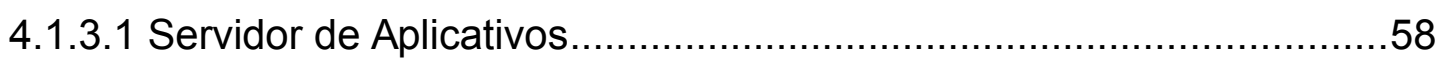

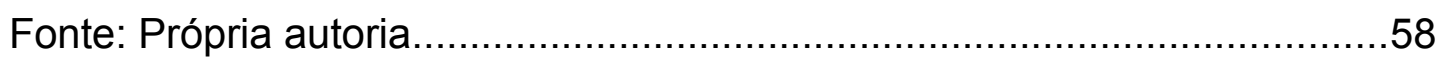

4.1.3.2 Servidor de Banco de Dados........................................................ 


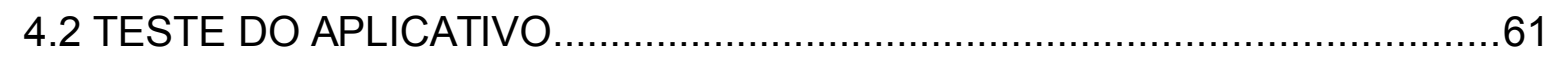

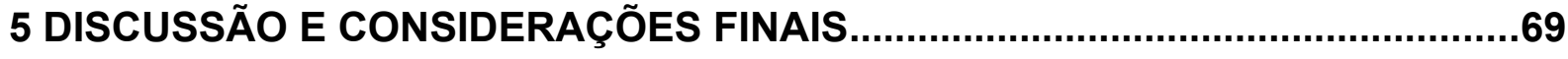

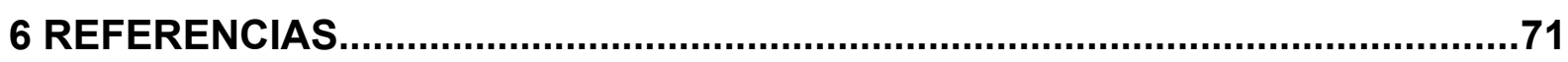




\section{INTRODUÇÃO}

O Brasil assumiu, desde 2004 a liderança nas exportações com vendas em mais de 180 países, tendo ainda no mercado interno, a maior parte de seu consumo. Dados de 2014 indicaram que o país possui o segundo maior rebanho de bovinos do mundo, com aproximadamente 212,3 milhões de cabeças de gado (Portal Brasil, 2015). A exportação brasileira vem crescendo nos últimos anos e a expectativa do Ministério da Agricultura é que o Brasil seja responsável por $44,5 \%$ do consumo de carne bovina mundial (MAPA, 2016). Para que o país possa atender as expectativas internas e externas de qualidade da carne é primordial que existam mecanismos eficientes para gerenciar as informações que permitam conhecer a origem do produto (FRANCO, 2002).

Existe um consenso na literatura científica que para que um alimento seja seguro o mesmo deve ser acompanhado de um conjunto de informações que permitam avaliar sua procedência e com isso garantir sua qualidade (Silva, 2004). Isto implica, no caso da produção de proteína animal, que cada segmento da cadeia produtiva seja controlado e monitorado de forma a permitir o registro coerente e sistemático das informações dos animais durante todo manejo, incluindo dados de doenças, nutrição e bem-estar. Sendo assim, existe a necessidade de se estabelecer formas de identificação e metodologias de busca destas informações a fim de garantir o gerenciamento de todos os eventos envolvidos no processo garantindo assim a qualidade e segurança do produto.

Todo este processo requer o uso de sistemas capazes de adquirir e processar a informação do animal, permitindo que se tenha dados de sua origem, de como foi manuseado e das regiões onde esteve confinado. Para tal controle existem sistemas de softwares de carácter privado e governamental. O SISBOV desenvolvido pelo Ministério da Agricultura, Pecuária e Abastecimento teve como objetivo garantir a origem e processos envolvidos na cadeia produtiva destinada a exportação. Com a obrigatoriedade do uso do SISBOV para comercialização de carne bovina ao exterior iniciou-se um processo de difusão do uso deste tipo de sistema e uma crescente importância foi dada a carne rastreada que passou a ser mais valorizada. 
Neste contexto esta dissertação apresenta uma forma de se avaliar o uso da biometria como um parâmetro de identificação animal, uma vez que a identificação é base para a rastreabilidade e a biometria uma forma de identificação não invasiva e com alto grau de confiabilidade.

Esta dissertação cria uma estrutura de desenvolvimento que permite inserir em sistemas de rastreabilidade existentes um serviço de identificação biométrico. Utiliza como meio de identificação biométrica o espelho nasal, mas está estruturado para atender a qualquer outra tecnologia. Tem como objetivo também mostrar que a coleta de imagens para cadastramento e identificação podem ser feitas de forma automática, viabilizando assim seu uso comercial.

Esta dissertação está estruturada com as seguintes sessões:

Revisão de Literatura que conceituará a base para o desenvolvimento dos trabalhos.

Metodologia, definindo as estruturas, linguagens, softwares de apoio e técnicas para o desenvolvimento.

Resultados e Discussão, será apresentado o que foi constatado na preparação de imagens, geração de padrões de identificação e nos testes de utilização do sistema.

Considerações Finais, aqui faz-se as últimas análises levando-se em conta o objetivo geral da dissertação versus os resultados obtidos.

Referências. 


\section{REVISÃO BIBLIOGRÁFICA}

\subsection{A NECESSIDADE}

Dada a importância do Brasil no mercado de carne bovina do planeta, embargos frequentes de países que competem por este mesmo mercado causam um impacto direto na economia. Gimenez (2011) descreve o fato de que os embargos surgem geralmente com a falha no gerenciamento de informações, pois, segundo a autora, a ausência de intercâmbio de dados "ambientais", "sociais" e "sanitários" na maioria das vezes permite que ocorram falhas nas tomadas de decisões dos gestores envolvidos e estes fatos reduzem a força do produto brasileiro o que pode diminuir sua competitividade. Isto mostra uma aparente preocupação mundial em relação a maneira como a gestão da produção de alimento é realizada no Brasil. Para se garantir um mínimo de gerência é necessário o acompanhamento do animal desde seu nascimento até $\mathrm{o}$ abate e registrar corretamente todos os eventos ocorridos com o mesmo conforme discutido por Barcelos (2003) e neste ponto um sistema desenvolvido para gerenciar estes dados, conforme a proposta desta dissertação, é fundamental.

O gerenciamento da cadeia de suprimentos é primordial para a garantia da qualidade do produto e segundo DIAS (2012) este gerenciamento agrega valor e melhora a competitividade no mercado e este fato justifica a criação de softwares que auxiliem no gerenciamento de dados como o proposto nesta dissertação.

No que diz respeito à produção de proteína animal de origem bovina, o Governo Brasileiro visando mitigar os efeitos da má gestão no setor e buscar uma melhor qualidade da gerência de informações criou o SISBOV (Sistema Brasileiro de Identificação e Certificação de Bovinos e Bubalinos). Estudos realizados por Furquim (2012) mostraram que ao implantar o sistema notou-se que no mercado interno havia uma baixa adesão dos pecuaristas ao sistema devido principalmente aos custos adicionais e insegurança quanto ao retorno financeiro. Entretanto Paz et. al. (2005) verificaram que devido as sobras das exportações e a exigência de carne 
rastreada por parte de grandes redes do varejo, este tipo de carne acabou se valorizando. O SISBOV, assim como outros sistemas utilizados no mercado permite a inserção de dados obtidos com o uso de dispositivos de identificação que vão desde os mais simples como brincos e bottons até os mais sofisticados como transponders e biometria. Ferreira e Meirelles (2002) demostraram que apesar dos brincos e bottons serem os mais comumente usados, a perda destes identificadores pode chegar a $15 \%$ em um ano.

Analisando este cenário verifica-se que a identificação biométrica pode ser o caminho para assegurar a identificação do animal e que de alguma forma a mesma deve ser inserida nos sistemas atualmente em produção e dentro deste contexto se insere os estudos realizados nesta dissertação.

\subsection{IDENTIFICAÇÃO BIOMÉTRICA}

No que se refere à biometria, estudos recentes como os realizados por Mahmoud (2015), demonstram que identificação biométrica é uma realidade tecnológica, principalmente o reconhecimento do espelho nasal.

Em relação ao espelho nasal, Ebert (2006) demostrou que as linhas e sulcos do focinho dos animais são únicos e estes formam padrões que nenhum outro animal possui sendo que estas características não se alteram com a idade do animal (GIMENEZ, 2011).

Segundo Barry (2007) através de fotografias digitais de focinhos e uso de um programa de reconhecimento de imagem o mesmo obteve uma média de sucesso de $98,85 \%$ na identificação do gado, mostrando desta forma a potencialidade do processo na validação da identidade.

Torna-se evidente que para a utilização destas técnicas de identificação em um ambiente de produção é necessário que a coleta, envio e retorno de informações dos dados biométricos sejam muito facilitados e preferencialmente automatizados a fim de viabilizar o seu uso durante todo o processo da cadeia produtiva e este aspecto é explorado nesta dissertação. 


\subsection{RECONHECIMENTO DE IMAGENS}

O ser humano desde o princípio dos tempos se utiliza da visão para reconhecer a face de outro homem para poder se relacionar. Uma tarefa muito fácil para nós mas uma tarefa que exige utilização de algoritmos complexos quando executada por um computador conforme descrito por Graça et. al. (2008). Em vários dos ramos do conhecimento é muito importante os métodos e técnicas no tratamento de imagens. Seja para obtenção de uma imagem de uma estrela ou de uma pequena célula cada vez mais o tratamento de imagens se torna essencial e quanto maior a qualidade deste resultado tão maior é o desenvolvimento dos produtos e serviços relacionados a ele (FEDOTOV e MOKSHANINA, 2011, p.27). Para que se possa reconhecer uma face ou outro objeto qualquer é necessário que identifiquemos padrões nestas imagens e que assim se consiga identificar o objeto em questão. No final dos anos 90 e início da última década estudaram-se várias técnicas de obtenção destas características. Uma delas e que está sendo muito utilizada atualmente é conhecida como LBP e mostra-se muito eficiente no reconhecimento destes padrões e com baixo custo computacional conforme reportado por Amaral et. al (2013).

Para que se possa executar rotinas de reconhecimento de imagens é necessário primeiramente que se capture a mesma e depois com ferramentas computacionais apropriadas fazer os tratamentos necessários para o reconhecimento conforme discute trabalho recente de Zaorálek et. al. (2016). Esta captura pode ser feita usando-se uma câmera fotográfica digital ou mesmo a câmera de um celular que é o mecanismo de aquisição usado nesta dissertação. 


\subsection{LOCAL BINARY PATTERN (LBP)}

Como citado acima o LBP é muito empregado na extração de padrões com o propósito de reconhecimento e classificação de imagens. Ele consiste basicamente em se dividir a imagem, previamente convertida em tons de cinza, em regiões onde tomando-se um pixel faz-se a comparação de intensidade com os pixeis vizinhos obtendo um valor binário. Quando o pixel vizinho for menor o valor atribuído será 0 (Zero) caso contrário o valor atribuído é $1(\mathrm{Um})$. Como o pixel em estudo juntamente com seus vizinhos formam uma matriz $(3,3)$ o resultado final desta comparação será um número binário de oito dígitos que é ati buído para o pixel em estudo. Este processo é feito para todos os pixeis da imagem em estudo. Podemos verficar o resultado observando a figura a seguir (Figura 1). Estes valores binários obtidos podem ser utilizados pelos softwares de reconhecimento que através de técnicas de relevância possam determinar um padrão (AMARAL et. al, 2013).

Figura 1 - Operação básica do LBP, com valor decimal resultante 184.
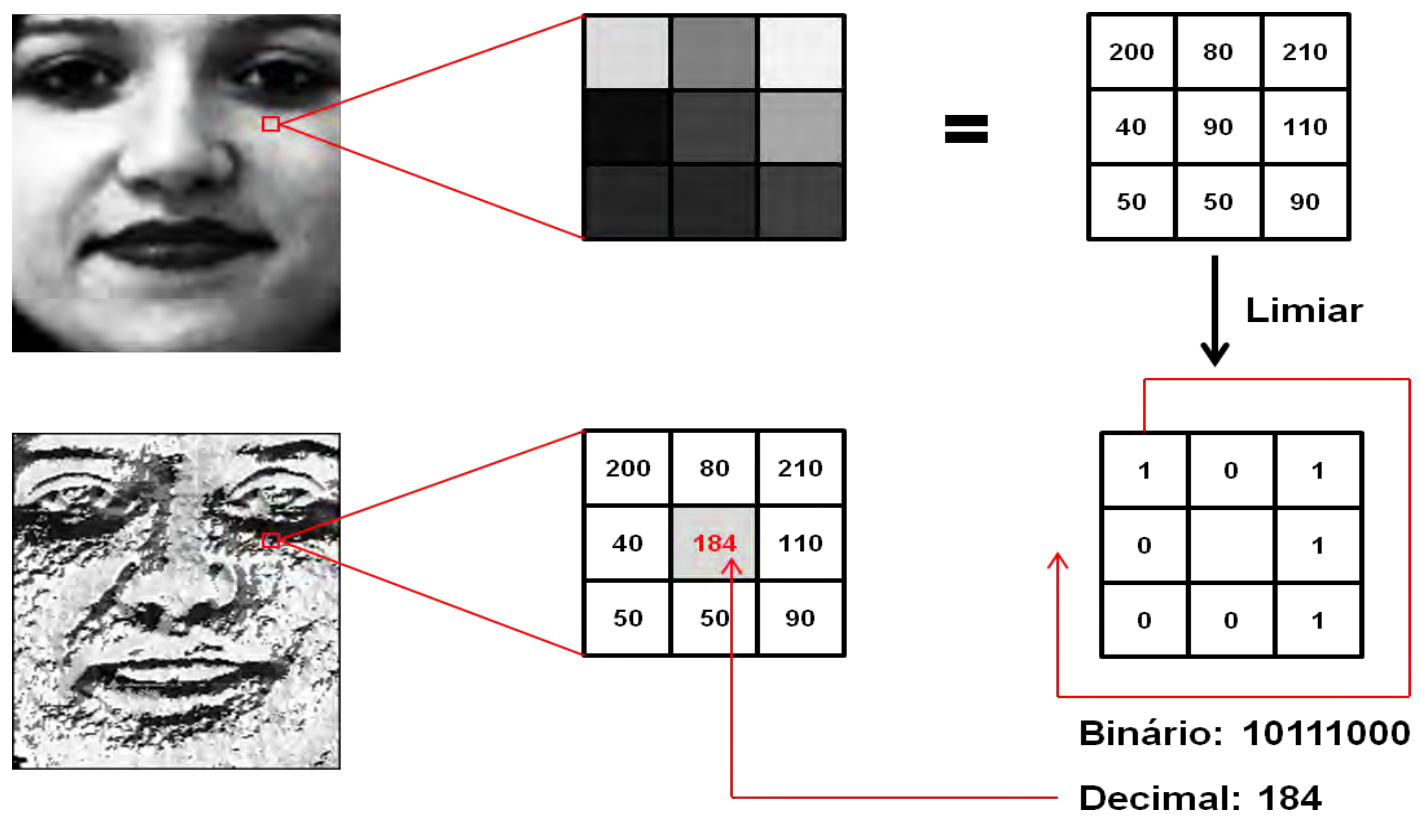

Fonte: (AMARAL et. al, 2013). 


\subsection{OPENCV}

Uma das ferramentas para tratamento de imagens com capacidade para resolver problemas complexos e uso relativamente simples é o OpenCV. Construído em $\mathrm{C}$ e $\mathrm{C}++$ pode ser utilizado em sistemas operacionais Windows, Linux e Mac OS (VISHWAKARMA; AKASH; YADAV, 2015). O OpenCV implementa técnicas de tratamento de imagems que permitem identificar faces humanas, segmentação de objetos e outros tipos de processamento digital de imagens. O OpenCV também pode ser implementado em celulares e assim utilizar a câmera do mesmo para obter e trabalhar as imagens, uma vez que os celulares atuais têm alto poder de processamento (JENQ et. al, 2011).

\subsection{OPENCV E AGRONOMIA}

Identificação de imagens na Agronomia e mais especificamente utilizando o OpenCV pode ser observado em alguns trabalhos de pesquisa. Exemplos disto são: a pesquisa sobre Postura de Vacas da Universidade de Catania (PORTO et. al, 2013) ou a pesquisa de comportamento de animais do jornal "Nature communications" onde o OpenCV foi utilizado para localizar a posição de ratos em imagens gravadas (WEISSBROD et. al, 2013). 


\subsection{INTEGRAÇÃO VIA WEB - WEB SERVICES}

Como citado por Kaneshima (2012), os Web Services permitem a integração de sistemas distintos e localizados em diferentes locais via internet. Os mesmos permitem encapsular serviços existentes de forma que qualquer outro que tenha permissão para tal possa acessar os mesmos. Desta forma um sistema pode ser cliente dos serviços de um Web Service e também pode ser provedor de serviços através de seu Web Service. Para esta comunicação deve ser utilizado um protocolo de comunicação e um destes protocolos muito utilizado é o SOAP que se utiliza do WSDL como descritor dos serviços.

- SOAP: Protocolo utilizado em alguns Web Services permite definição ampla dos serviços providos através do uso de descritores WSDL.

- WSDL: Linguagem baseada na utilização de XML que possui muitas opções de configuração e é independente do tipo de protocolo. Nele são informados as interfaces, os tipos de dados, protocolo e endereço do serviço.

O uso de WEB services para a plataforma Android tem sido reportado em trabalhos onde dados podem ser gerenciados em celulares como por exemplo o trabalho de Mantas et al. (2015). 


\section{METODOLOGIA}

Esta dissertação tenta mostrar a viabilidade de integração de métodos de identificação biométrica a sistemas novos ou já existentes de rastreabilidade bovina. Utiliza-se nesta dissertação especificamente a identificação através do espelho nasal do animal. Sendo assim, e baseado no capítulo anterior que embasa este estudo, define-se aqui as estruturas, linguagens, softwares de apoio e técnicas para o desenvolvimento.

\subsection{ARQUITETURA}

Para que o desenvolvimento de um software consiga obter os resultados esperados é necessário o entendimento do problema para o qual o mesmo está proposto. Considerando-se que o objetivo desta dissertação é mostrar a viabilidade de integração de técnicas de identificação biométrica em sistemas de rastreabilidade e que mais especificamente neste caso esta identificação se faz através do espelho nasal do bovino. Tem-se o seguinte problema:

Um usuário em algum momento poderá cadastrar um novo animal ou confirmar a identidade de um já existente. Em ambos os casos o usuário deverá obter a imagem do espelho nasal do bovino para que possa tomar uma das duas ações previstas. Depois de obter esta imagem o usuário escolherá a opção desejada e informará através do software o código de identificação do animal. Em qualquer uma das escolhas a imagem e o código de identificação serão enviados para um servidor que processará as informações, cadastrando ou validando a identidade do animal. Após esta ação o servidor enviará mensagem para o software do usuário informando o resultado de sua solicitação.

O sistema aqui proposto deverá permitir que um usuário remoto acesse o sistema de identificação localizado na internet e através dele consiga cadastrar o espelho nasal do animal ou confirmar a identidade do mesmo. Como a premissa é que o produto aqui desenvolvido possa ser utilizado por sistemas já existentes ou 
novos implementa-se entre a camada cliente e a camada servidora uma comunicação através de Web Services. Especificamente nesta dissertação o usuário se utiliza de um aparelho celular como forma de acesso a estes serviços.

Esta arquitetura está baseada em três camadas conforme abaixo descritas.

\subsubsection{Camada Visual}

Nesta camada é feita a interação do usuário com o sistema. Ela será responsável pela apresentação de telas, imagens e informações para o usuário. Nela o usuário digitará suas solicitações, enviará imagens e receberá as respostas esperadas.

\subsubsection{Camada Cliente}

Esta camada recebe as informações da camada visual e transmite para a camada servidora, assim como recebe da camada servidora e devolve para a camada visual. Nesta camada estarão contidas as normas, padrões e regras de comunicação. Sendo que estas estarão encapsuladas em uma biblioteca de forma a facilitar o desenvolvimento da camada cliente. Esta camada será responsável por duas atividades importantes no contexto do problema, que são: a obtenção do espelho nasal que permitirá a identificação e a comunicação com o Web Service que permitirá a integração com outros sistemas.

\subsubsection{Obtenção do espelho nasal}

A coleta de imagem é o processo onde obtêm-se de uma fotografia a parte da 
mesma capaz de identificar o bovino. Os seguintes itens devem ser realizados em sequência para obtenção as imagens:

1. Obter a imagem através de uma câmera fotográfica digital. Como no nosso caso faremos a identificação através do espelho nasal do bovino, esta foto será do focinho do boi (Figura 2).

Figura 2 - Focinho do boi

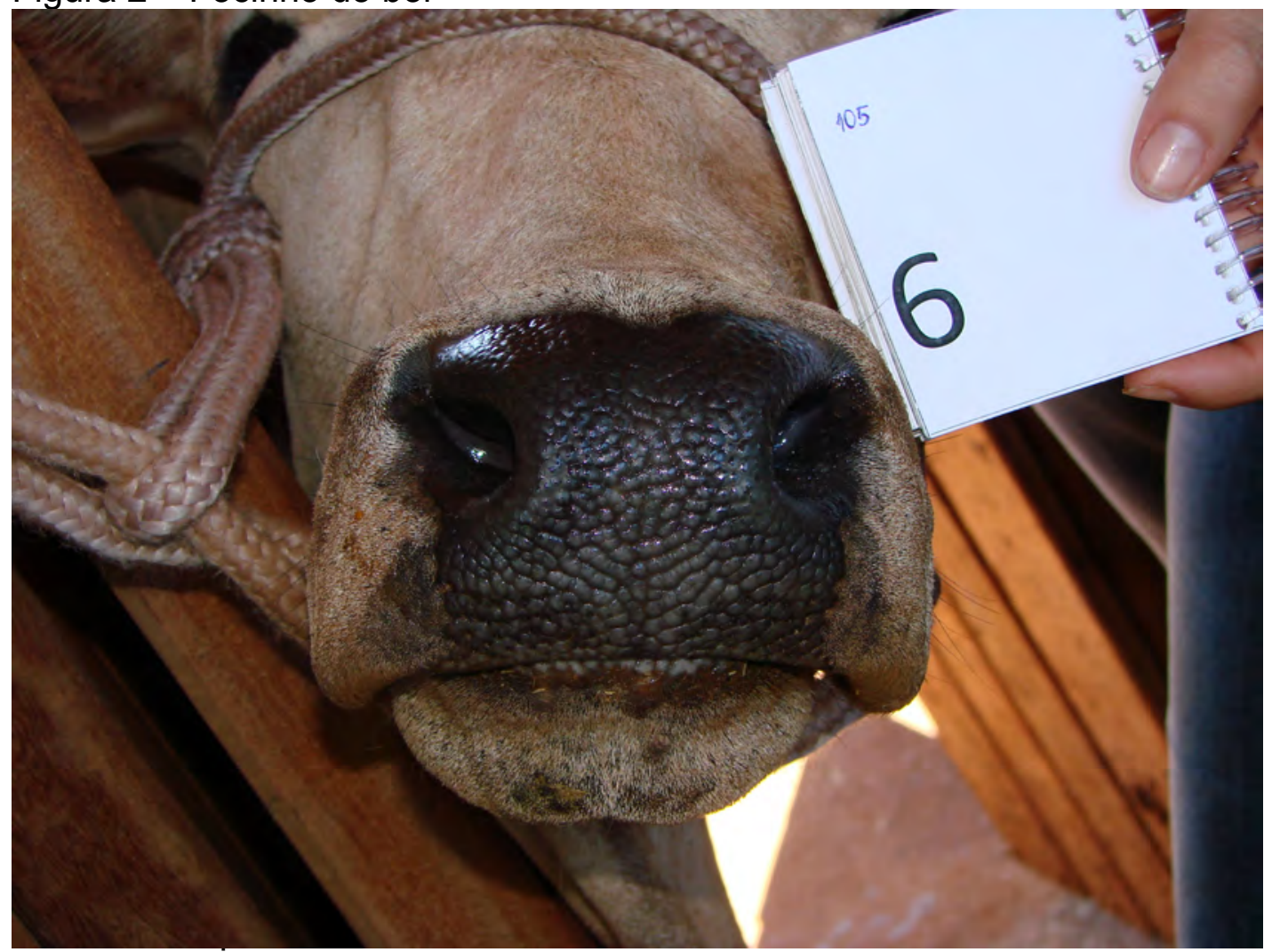

Fonte: Base de dados do Laboratório de Física Aplicada e Computacional, FZEA-USP, Pirassununga, SP, 2015.

2. Separar desta imagem o espelho nasal (Figura 3). Para este trabalho pode ser utilizado qualquer ferramenta de manipulação de imagens que permita recortar da imagem a parte desejada. Nesta dissertação utilizou-se o editor de imagens de nome "Pinta" (PINTAPROJETCT, 2016) devido a sua simplicidade e atender as necessidades inerentes a mesma. 
Figura 3 - Focinho do bovino marcado

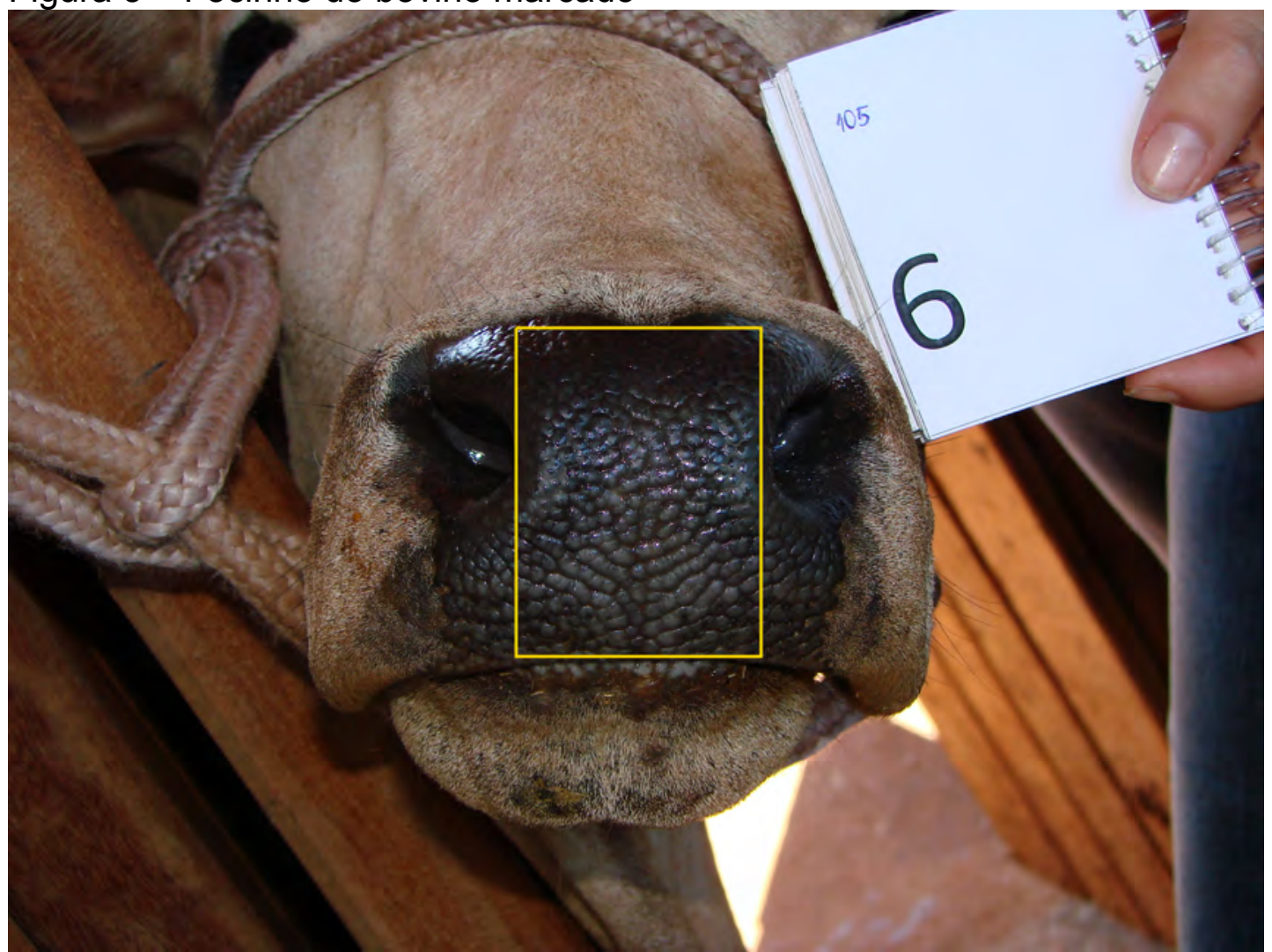

Fonte: Imagem alterada do Base de dados do Laboratório de Física Aplicada e Computacional, FZEA-USP, Pirassununga, SP, 2015. 
3. Depois de selecionado o espelho nasal, salvar a imagem (Figura 4).

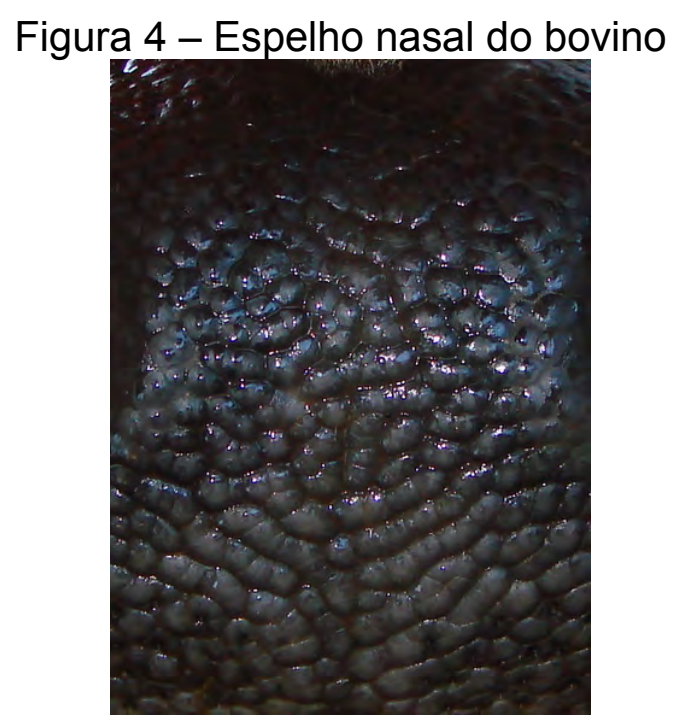

Fonte: Imagem alterada do Base de dados do Laboratório de Física Aplicada e Computacional, FZEAUSP, Pirassununga, SP, 2015.

Estes passos são meramente ilustrativos, para que se tenha o entendimento do que deve ser realizado a fim de se obter a imagem do espelho nasal que será utilizada para identificar o animal. Como refere-se a um sistema para cadastro e identificação do bovino é importante que tenha-se formas práticas de se obter esta imagem sem grandes manipulações por parte do usuário.

\subsubsection{Obter o espelho nasal via OpenCV}

Com o objetivo de tornar viável a utilização do software entendeu-se que seria necessário que a manipulação da imagem fosse o mais simples possível para o usuário. Definiu-se então que para o experimento utilizar-se-ia de um celular de quatro núcleos de processamento e sua câmera para obter as imagens. Para que seja possível fazer esta coleta automaticamente deve-se ter o controle da câmera 
do celular através de aplicativo desenvolvido e para se ter o controle e fazer as manipulações de imagens necessárias optou-se pelo software OpenCV utilizando-se de uma técnica de identificação de imagem utilizada pelo mesmo chamada "LBP" que foi adaptada nesta dissertação para o espelho nasal de bovinos. Este procedimento foi realizado segundo as seguintes etapas:

1. Identificar na imagem o focinho de forma bem definida. Pede-se a atenção novamente ao fato de que todas as identificações de imagens demonstradas a partir de agora estão sendo feitas pelo programa rodando no celular com uso das bibliotecas do OpenCV e que apenas aquela referente ao espelho nasal poderá ser vista pelo mesmo.

2. Identificar na região encontrada no item anterior as narinas do bovino. A determinação das narinas é importante pois ela determina a inclinação do focinho do bovino e a distância entre as mesmas define a dimensão do espelho nasal.

3. Obter a imagem entre as narinas que é determinada em sua largura pelo centro das narinas e em sua altura pelo lábio do animal e o ponto mais alto do focinho. Esta área é denominada Espelho Nasal.

A identificação de imagem pelo OpenCV através do "LBP" consiste na utilização de um arquivo de parâmetros que contem informações de exemplos e contraexemplos. Este arquivo tem um formato específico e é gerado pelo próprio OpenCV. Para a geração do arquivo de parâmetros é necessário que se forneça as imagens exemplos e contraexemplos e portanto a necessidade de se manipular várias fotografias e de cada uma delas obter os exemplos e contraexemplos que permitam a localização do espelho nasal do bovino.

\subsubsection{Comunicação com o Web Service}

Estas rotinas são responsáveis por enviar os pacotes contendo as solicitações para o Servidor remoto. Estas solicitações (mensagens) seguem um padrão defino no Web Service e são enviadas ao servidor no formato XML. Neste trabalho a mesma é composta por um método (rotina) a ser executada pelo Web 
Service e os parâmetros necessários para sua execução, "código de identificação" e "imagem do espelho nasal".

\subsubsection{Camada Servidora}

Esta camada é composta inicialmente por dois servidores. Um de banco de dados e outro de aplicativos.

\subsubsection{Servidor de Aplicativos}

Neste servidor é criado um Web Service que atende as requisições enviadas para este serviço. Este Web Service contém as rotinas que são acionadas pela camada cliente conforme a solicitação do usuário. Estas rotinas conterão as regras do negócio. Neste Web Service estão implementadas as chamadas necessárias ao servidor de Banco de Dados para que seja possível ao usuário conseguir inserir, atualizar, excluir e consultar com segurança e controle as informações. Neste trabalho foi implementado na camada cliente apenas as rotinas de cadastramento e validação de identidade. Sendo assim detalha-se as mesmas abaixo:

1. Cadastramento do animal. Para esta ação o Web Service após receber o código de identificação e a imagem do animal prepara estes dados para que os mesmos sejam enviados ao servidor de banco de dados onde estas informações são persistidas.

1. Validação de identidade. Assim que o Web Service recebe a solicitação o mesmo prepara o código de identidade e solicita ao servidor de Banco de Dados que busque a imagem persistida para aquele código. Assim que a imagem persistida estiver disponível o Web Service fará a comparação da imagem recebida como parâmetro e a imagem retornada do Banco de Dados. 


\subsubsection{Servidor de Banco de Dados}

Este servidor conterá todas as informações que deverão ser mantidas (persistidas). Três destas informações e que são base para esta dissertação são: a imagem do espelho nasal, o código identificador do animal e o momento da atualização da informação no formato data, hora, minuto, segundo e milésimos de segundos. 


\subsection{FLUXO DO SISTEMA}

No fluxo abaixo (Figura 5) existem as camadas Visual, Cliente e Servidora além da Internet como meio de comunicação entre elas. Neste fluxo o usuário através um "smartphone" inicia o processo pela camada Visual e neste momento a camada Cliente começa interagir com esta camada e a Servidora.

Figura 5 - Fluxo do Sistema

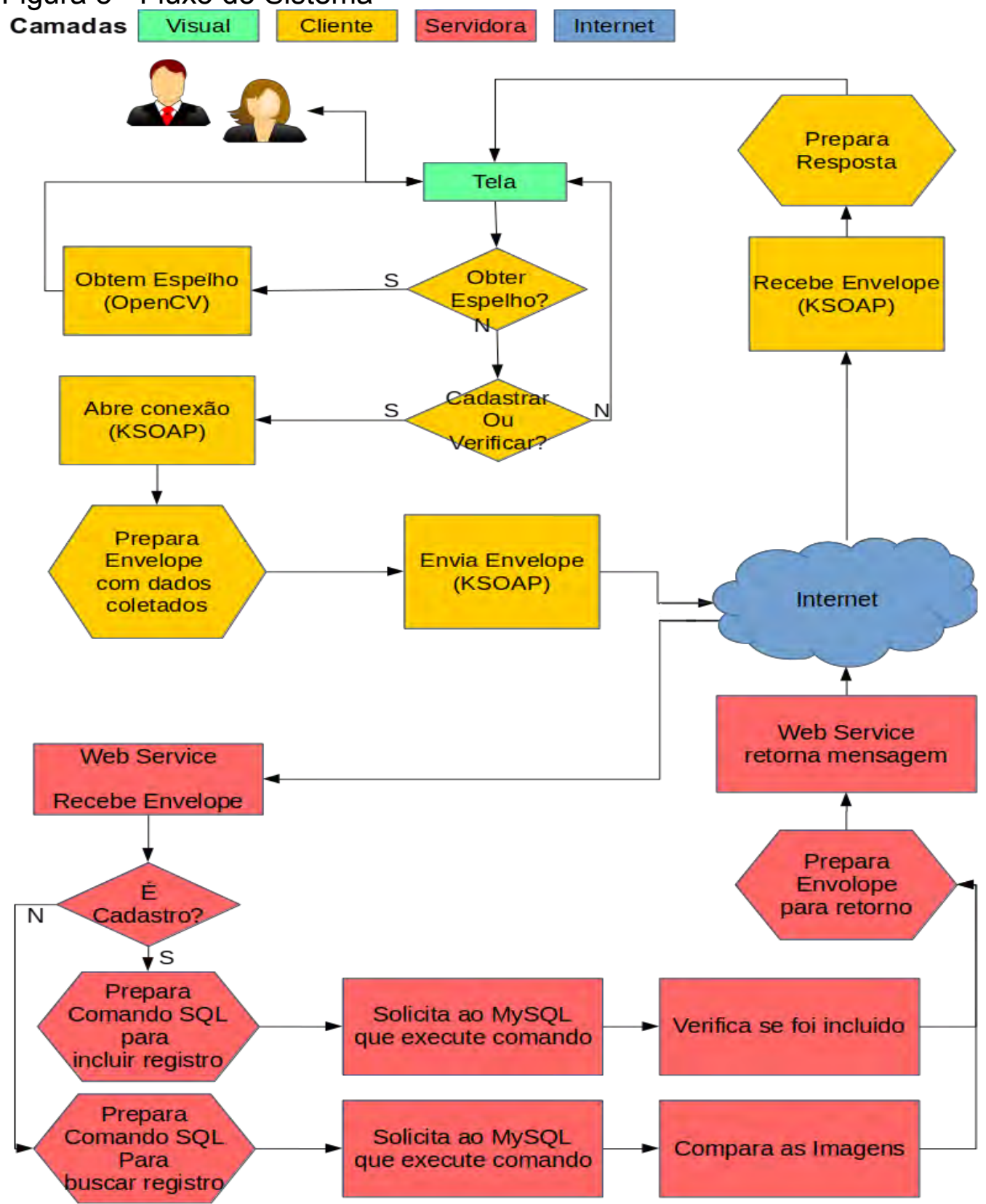

Fonte: Própria autoria. 


\subsection{TESTE DO APLICATIVO}

Para a realização dos testes será necessário que o aplicativo cliente esteja instalado em um celular e o aplicativo servidor instalado e em execução em local que o celular tenha acesso. Caso haja a possibilidade o servidor deve ser instalado em um local com IP Fixo, desta forma permitindo que o mesmo possa ser acessado de qualquer lugar onde haja comunicação com a Internet. Para a realização dos testes seguir os seguintes passos:

1. Preparar o animal (bovino) de forma que fique o mais imóvel possível a fim de se poder focar seu focinho com a câmera. Para efeito de demonstração podese usar fotos da cabeça do animal com o focinho bem visível.

2. De posse da câmera entrar no aplicativo e clicar no botão "OBTER ESPELHO NASAL". Neste momento o aplicativo deverá habilitar a câmera para que o usuário possa focalizar o espelho nasal.

3. Com a câmera habilitada focar o animal até perceber um retângulo na área onde denominamos "Espelho Nasal". Neste momento clicar no botão "SELECIONAR". Quando este botão é acionado o mesmo retorna para tela anterior do celular com a imagem do espelho nasal.

4. Preencher o campo "Código do Animal" com o identificador do animal.

5. Escolher uma das ações inseridas nos botões do aplicativo. Uma de cadastramento através do botão" CADASTRAR" e outra de verificação através do botão "VERIFICAR".

6. Na opção de cadastramento analisar no Banco de Dados do Servidor se a linha com as informações do animal foram inseridas com sucesso. Caso a opção tenha sido de verificação retornará para o aplicativo cliente a informação se a imagem correspondente ao código informado pertence ao animal cadastrado. 


\section{RESULTADOS E DISCUSSÃO}

\subsection{ARQUITETURA}

Para implementar a arquitetura descrita nesta dissertação fez-se necessário a instalação de um servidor de aplicações, instalação e configuração de um servidor de banco de dados, uma camada cliente para acesso ao serviço e uma camada servidora para atender as requisições. Para atingir este objetivo foram escolhidos os produtos e ferramentas abaixo, tendo como critério atenderem as necessidades do sistema e serem ferramentas gratuitas e que rodassem em múltiplas plataformas.

Servidor de Aplicações: GlassFish. Escolhido por sua robustez e facilidade de integração com a plataforma de desenvolvimento Java NetBeans.

Servidor de Banco de Dados: MySQL. Escolhido por sua confiabilidade, robustez, gratuidade e facilidade de suporte e desenvolvimento.

Plataforma de Desenvolvimento do Servidor de Aplicações: NetBeans. Dentre as plataformas para desenvolvimento Java esta se mostrou a mais adequada entre aquelas que possuíam os requisitos necessários para o desenvolvimento da camada servidora na linguagem Java. Desenvolvida pela Sun MicroSistems e agora pertencente a Oracle Inc, esta plataforma possui muita documentação, exemplos e usuários para esclarecimentos de dúvidas. Outra plataforma que mostrou-se igualmente selecionável foi a plataforma Eclipse, plataforma esta apoiada pela IBM.

Plataforma de Desenvolvimento das Camadas Visual e Cliente: Android Studio. Plataforma de desenvolvimento Java para celulares com sistema operacional Android. Escolhida por sua facilidade de desenho de telas e documentação disponível para pesquisa. O Sistema Android, por ser a plataforma mais utilizada em nosso país nos celulares, a mesma foi escolhida para exemplificar o acesso à camada cliente de acesso ao sistema.

Softwares de Apoio: OpenCV. É uma biblioteca para desenvolvimento na Área de Visão Computacional. Foi escolhida para os tratamentos das imagens devido sua 
versatilidade e quantidade de algorítimos disponíveis. Pode ser usada com Java, C, C++, Python e MatLab e roda nos sistemas operacionais Windows, Linux, Android e Mac Os.

\subsubsection{Camada Visual}

Para a interação do usuário com o aplicativo criou-se duas telas. Uma onde é incluído o código de identificação, imagem do espelho nasal e dois botões que permitem cadastrar e identificar o animal (Figura 6) e outra tela que permite ao usuário tirar a foto do espelho nasal do bovino (Figura 7).

Figura 6 - Tela de cadastramento e verificação

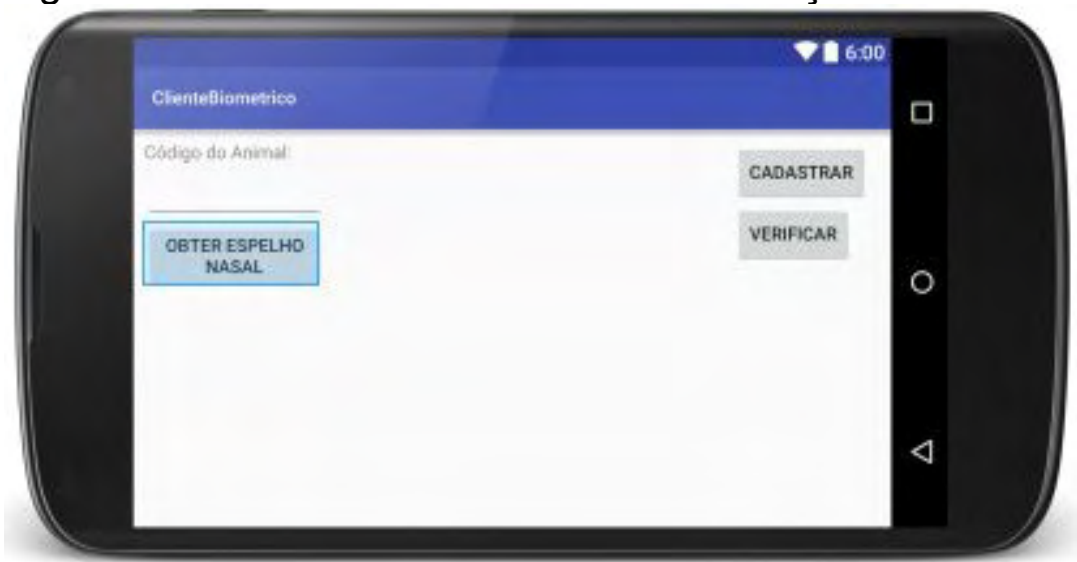

Fonte: Própria autoria.

Figura 7 - Tela de captura de imagem

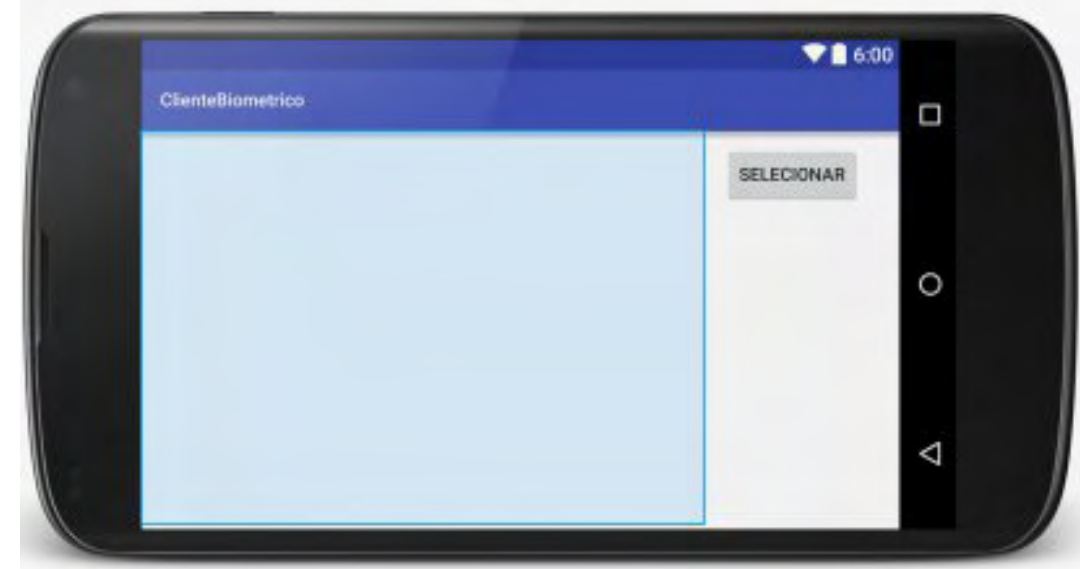

Fonte: Própria autoria. 
A apresentação da primeira tela foi disponibilizada através do arquivo de layout activty-main.xml (Figura 8) continuando na (Figura 9), enquanto que a segunda tela através do layout activy-camera.xml (Figura 10).

Figura 8 - Activity-main.xml

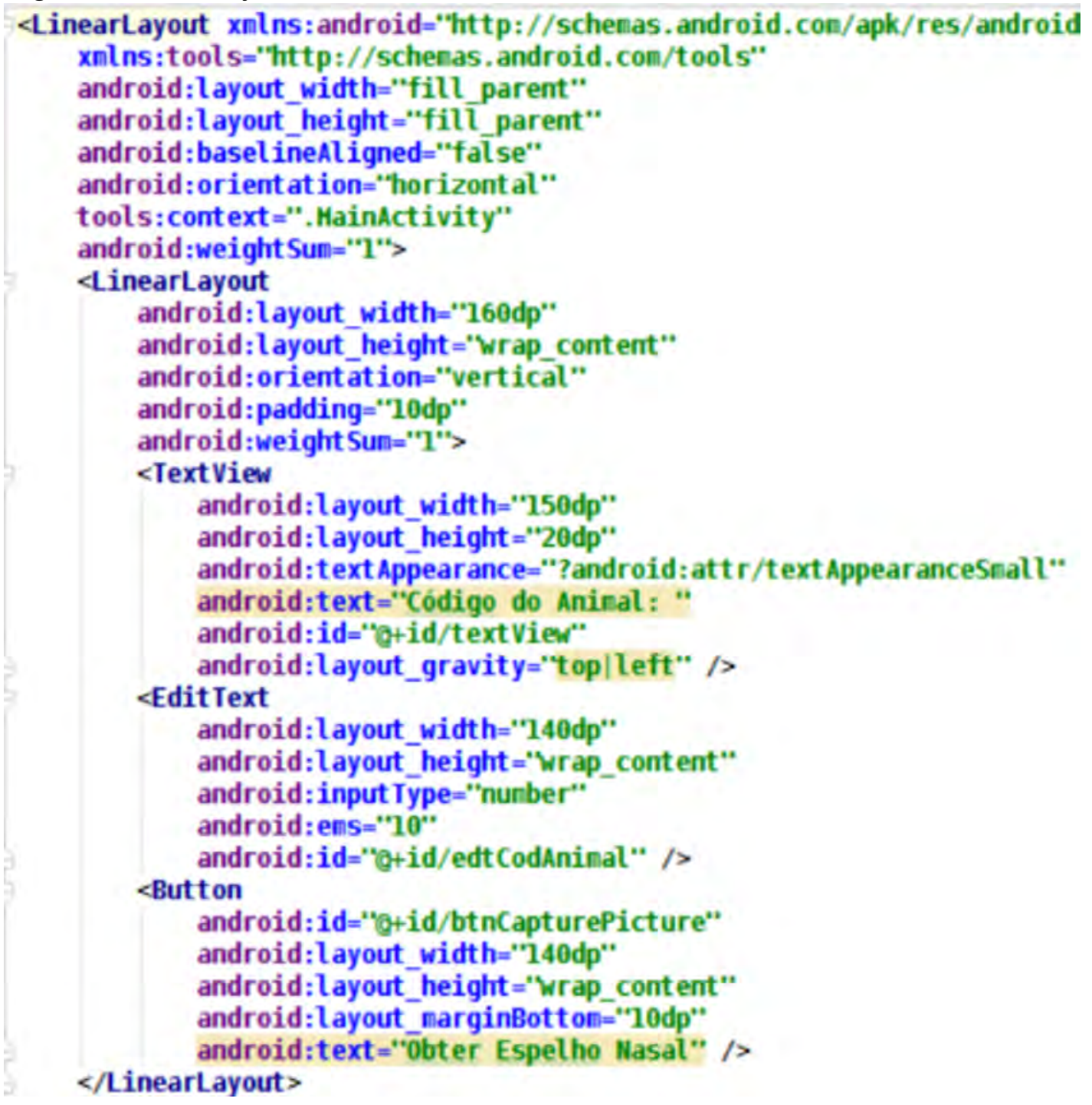

Fonte: Própria autoria. 
Figura 9 - activity-main.xml (continuação)

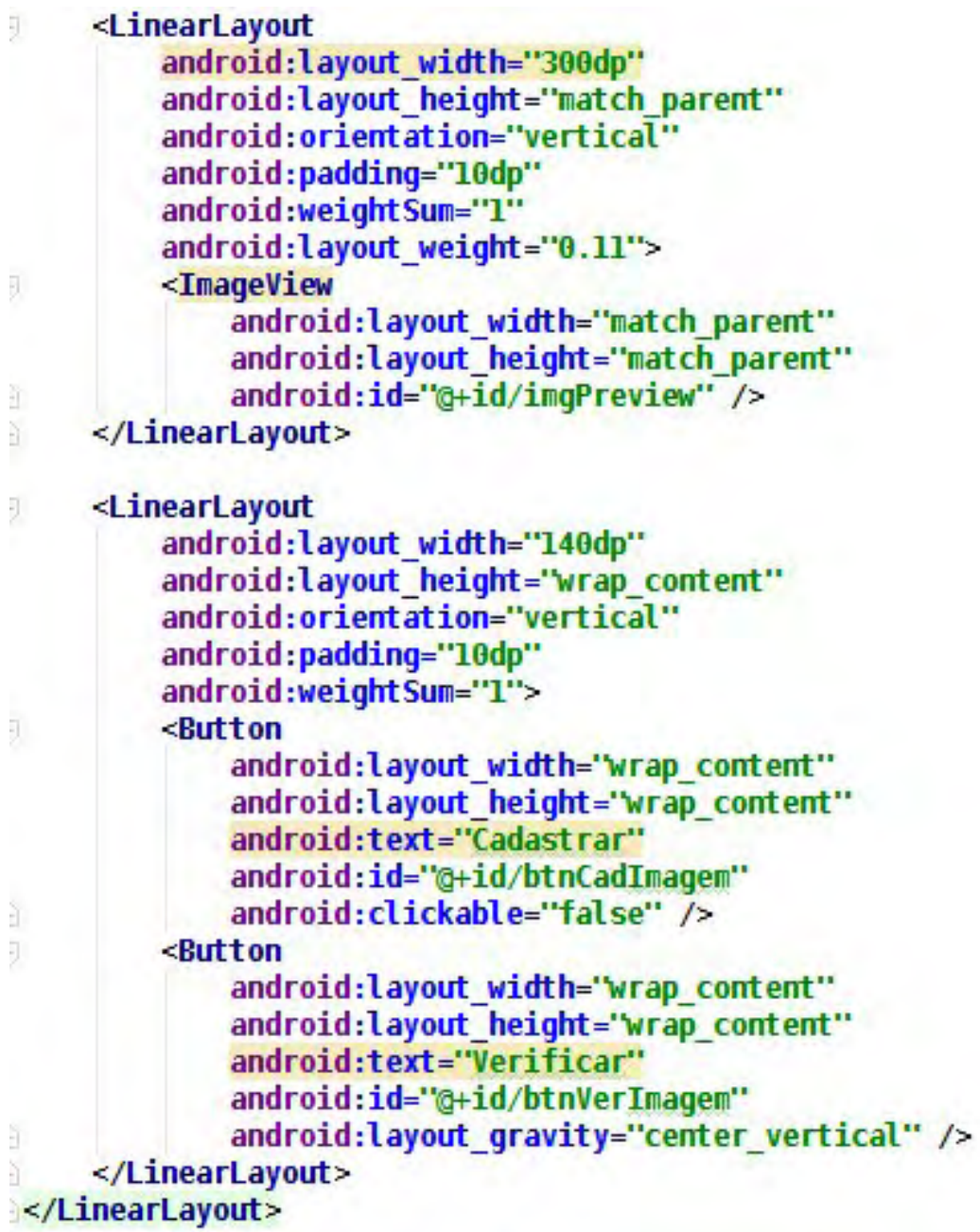

Fonte: Própria autoria. 
Figura 10 - activity-camera.xml

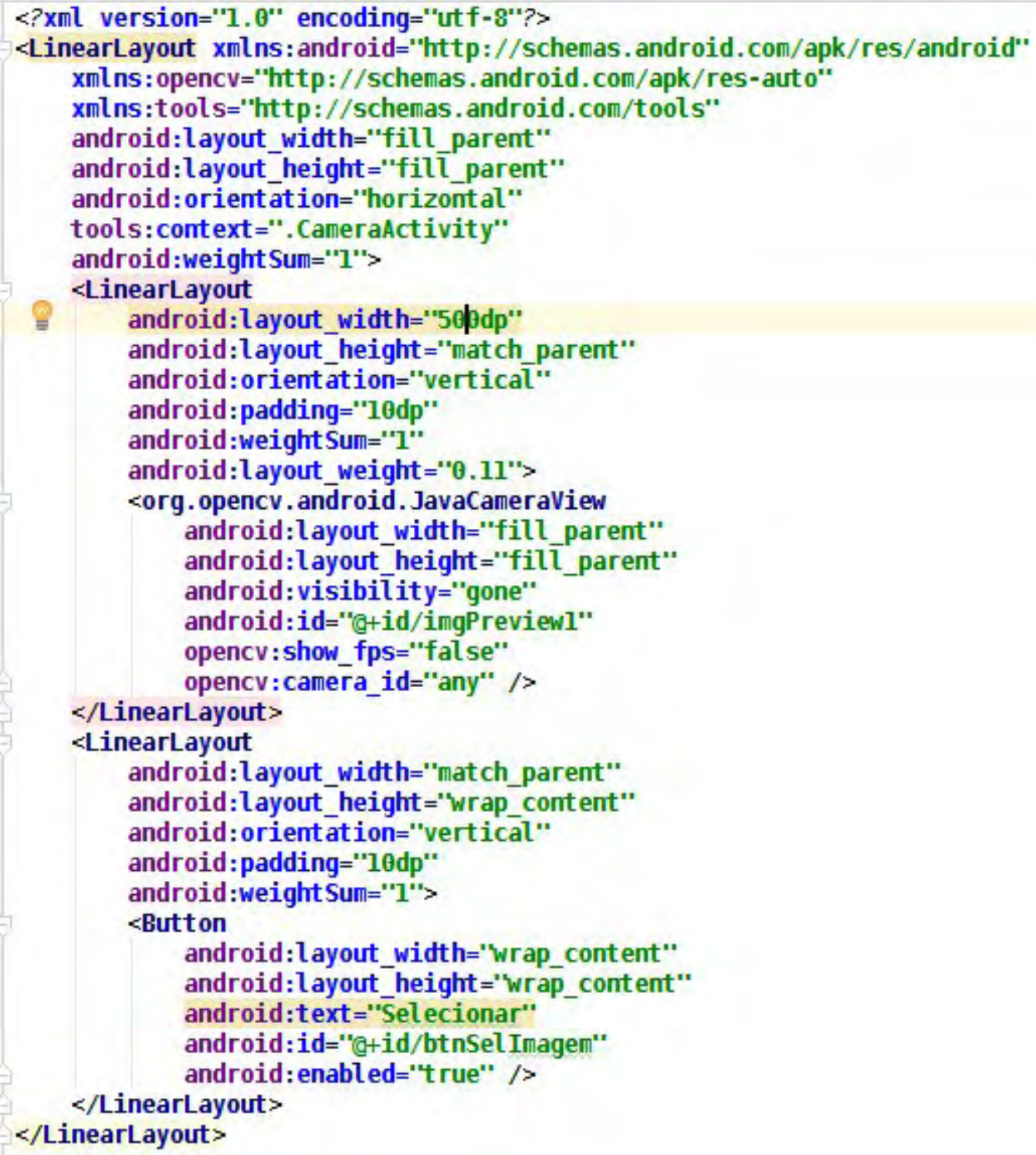

Fonte: Própria autoria.

\subsubsection{Camada Cliente}

Nesta camada desenvolveu-se duas rotinas importantes para a implementação. A primeira corresponde a obtenção da imagem conforme detalhado na metodologia e a segunda a comunicação do celular com o Web Service. 


\subsubsection{Obtenção do espelho nasal}

Para se obter o espelho nasal utilizou-se rotinas de apoio fornecidas pelo OpenCV e como explanado na Metodologia para que isso fosse possível foi necessário a criação de uma base de dados de imagens exemplos e contraexemplos. A especificação das imagens a serem coletadas seguiu o seguinte procedimento:

1. Como o trabalho partiu do princípio que a imagem mais ampla é a cabeça do bovino, seja por uma fotografia ou por aproximação de uma câmera, tevese que primeiramente localizar o focinho do animal (Figura 11) para desta forma reduzir-se o espaço de imagem a ser tratado.

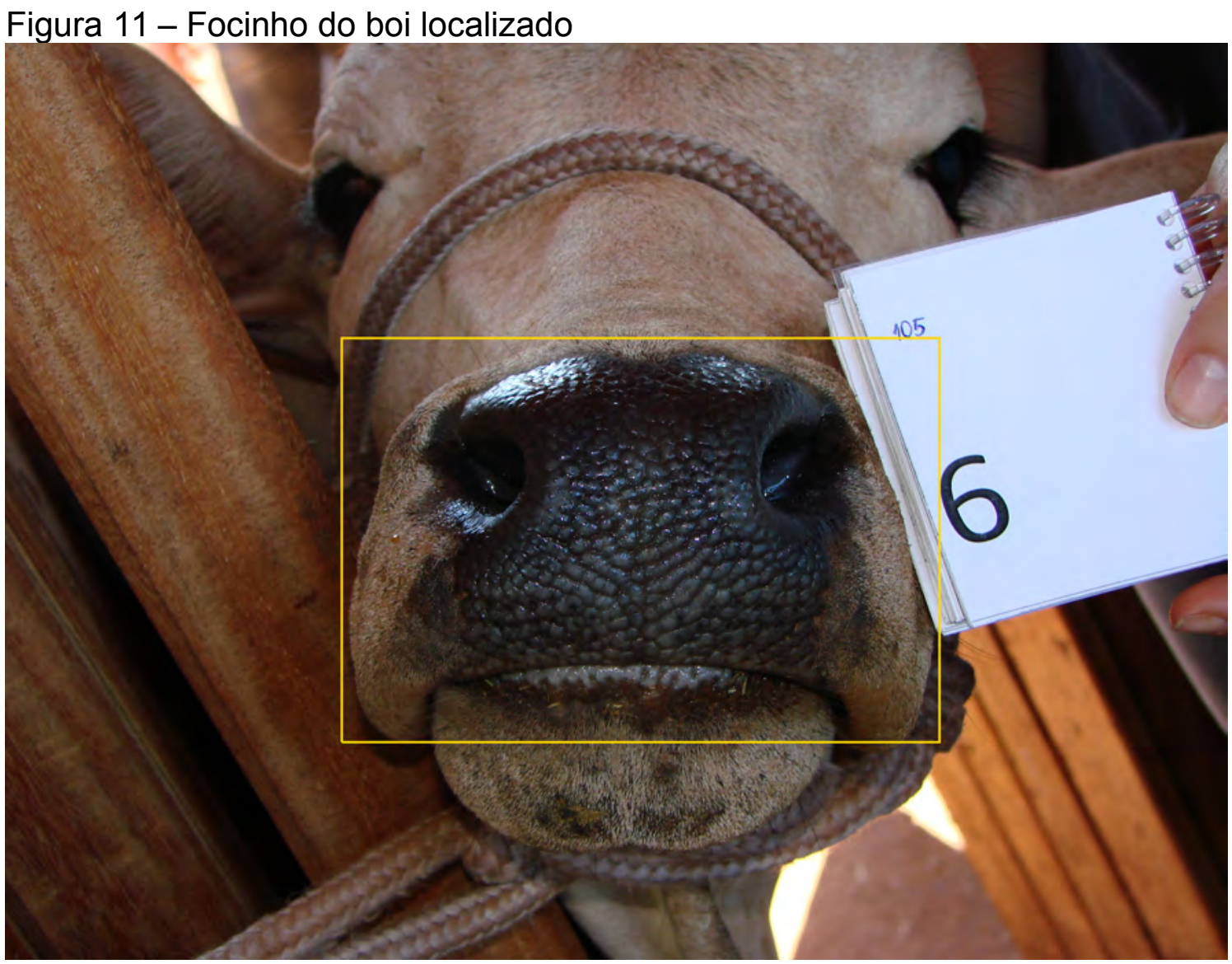

Fonte: Imagem alterada do Base de dados do Laboratório de Física Aplicada e Computacional, FZEAUSP, Pirassununga, SP, 2015. 
2. Após a localização do focinho do animal utilizou-se esta imagem como base para a localização das narinas esquerda e direita (Figura 12).

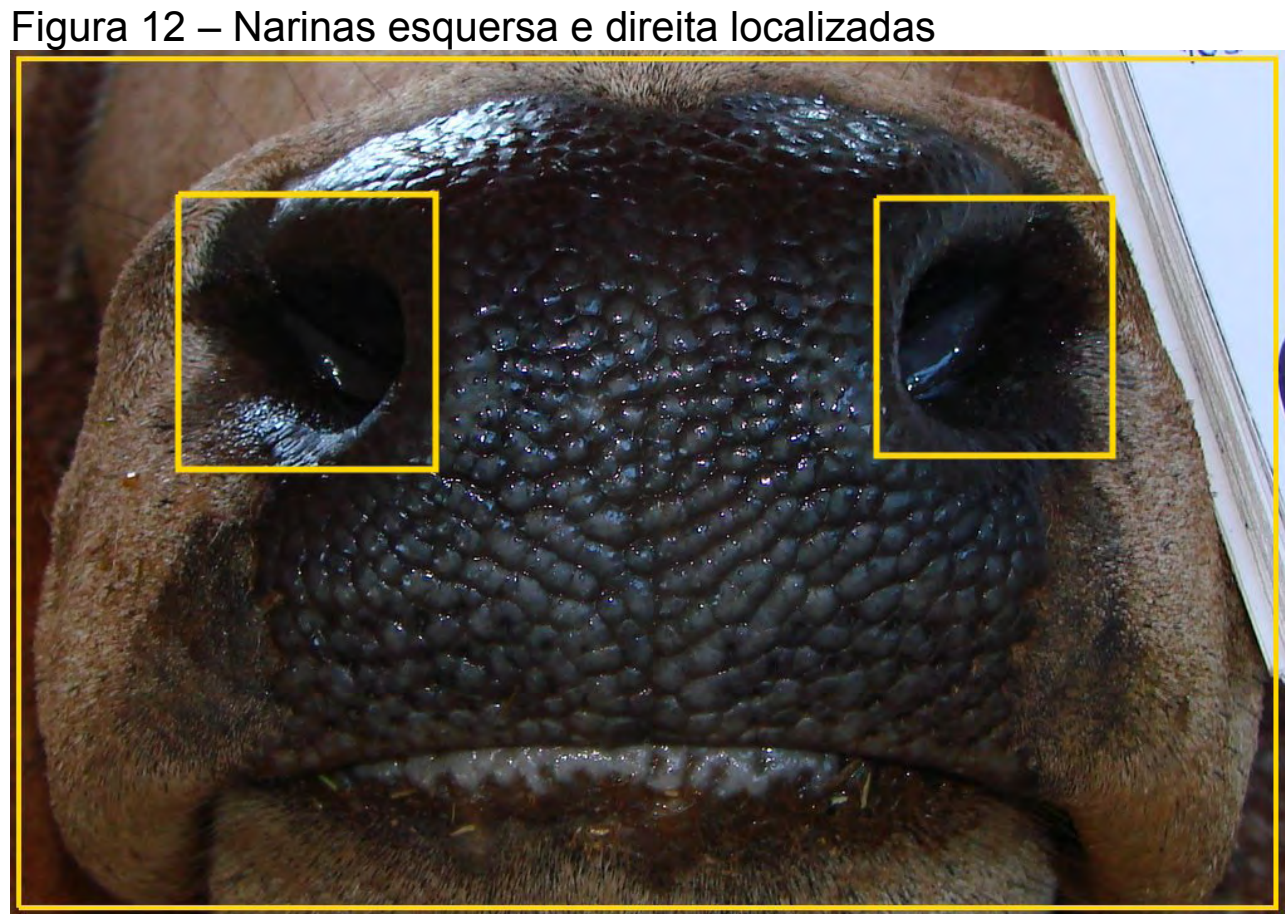

Fonte: Imagem alterada do Base de dados do Laboratório de Física Aplicada e Computacional, FZEAUSP, Pirassununga, SP, 2015.

3. Neste momento tem-se que certificar que a imagem está paralela ao eixo x para que a determinação da área correspondente ao espelho nasal fique correta. Podemos notar a seguir um exemplo de imagem inclinada (Figura 13). 
Figura 13 - Focinho inclinado

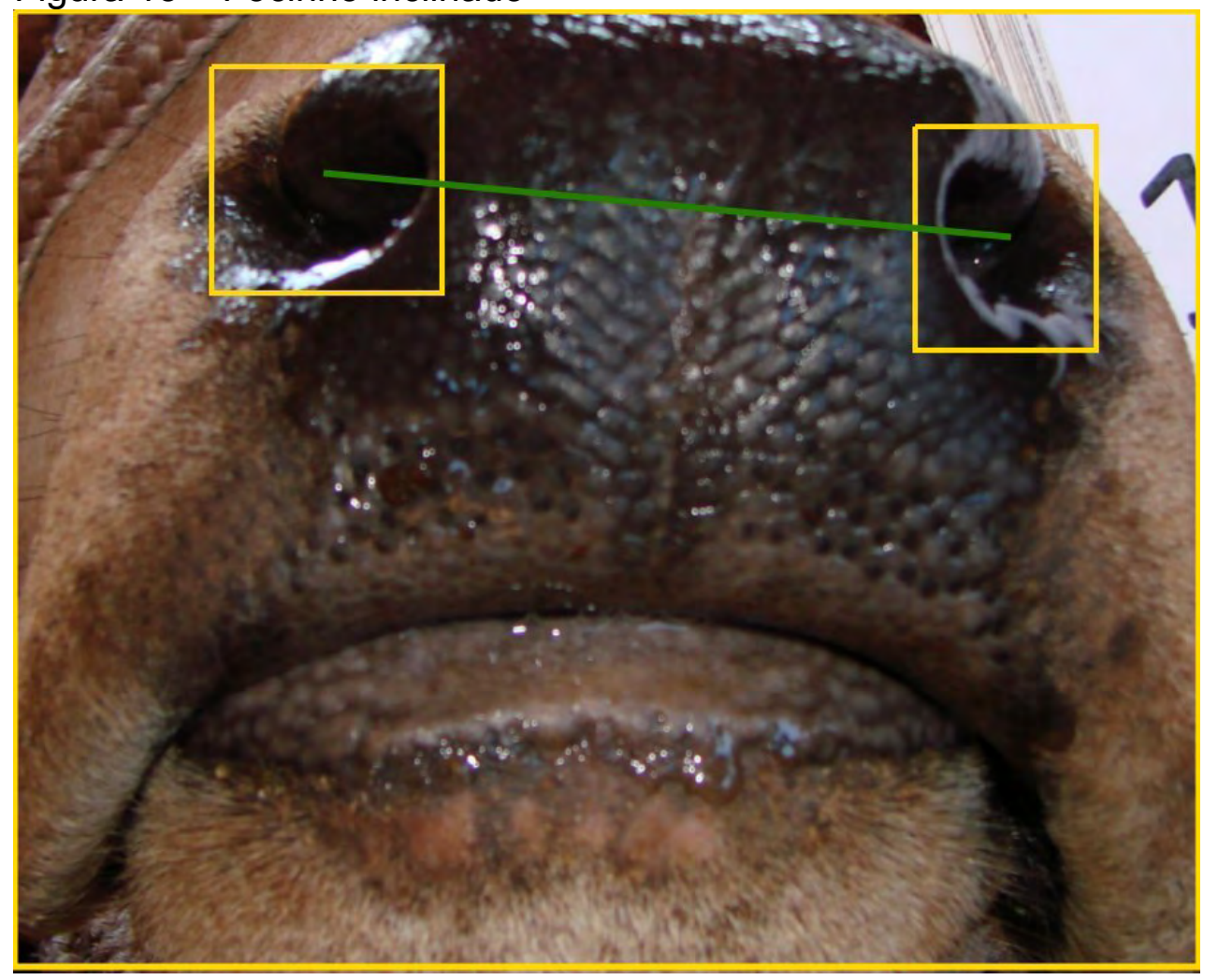

Fonte: Imagem alterada do Base de dados do Laboratório de Física Aplicada e Computacional, FZEAUSP, Pirassununga, SP, 2015. 
4. Após o ajuste da inclinação da imagem, se necessário, obter a imagem entre as narinas. Esta área é denominada espelho nasal (Figura 14).

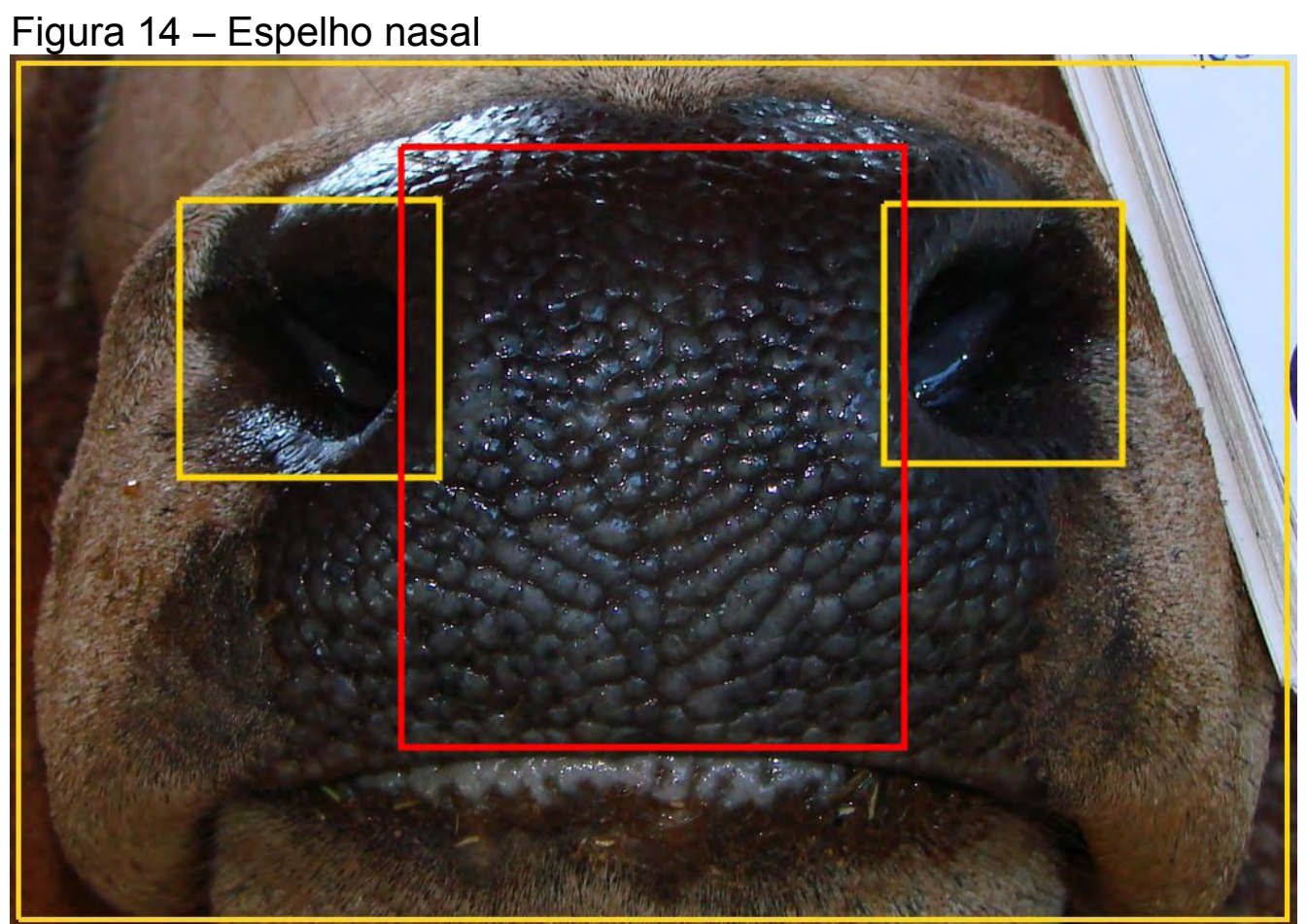

Fonte: Imagem alterada do Base de dados do Laboratório de Física Aplicada e Computacional, FZEAUSP, Pirassununga, SP, 2015.

5. Salvar esta imagem para que possa ser trabalhada pelo software. Importante relembrar que para o usuário apenas o retângulo de cor vermelha será visualizado pelo mesmo.

4.1.2.2 Identificação do espelho nasal pelo OpenCV

Todos os passos acima foram implementados com a utilização da biblioteca de funções do OpenCV. Para que isto fosse possível foi necessário a geração de arquivos XML que contém o padrão de cada objeto a ser localizado. Tem-se então um arquivo XML para o focinho e outros dois para as narinas esquerda e direita. Para que o OpenCV pudesse gerar estes arquivos XML criou-se várias imagens de 
exemplos de focinho (Figura 15), narina direita (Figura 17) e narina esquerda (Figura 19) assim como contraexemplos de focinho (Figura 16), narina direita (Figura 18) e narina esquerda (Figura 20).

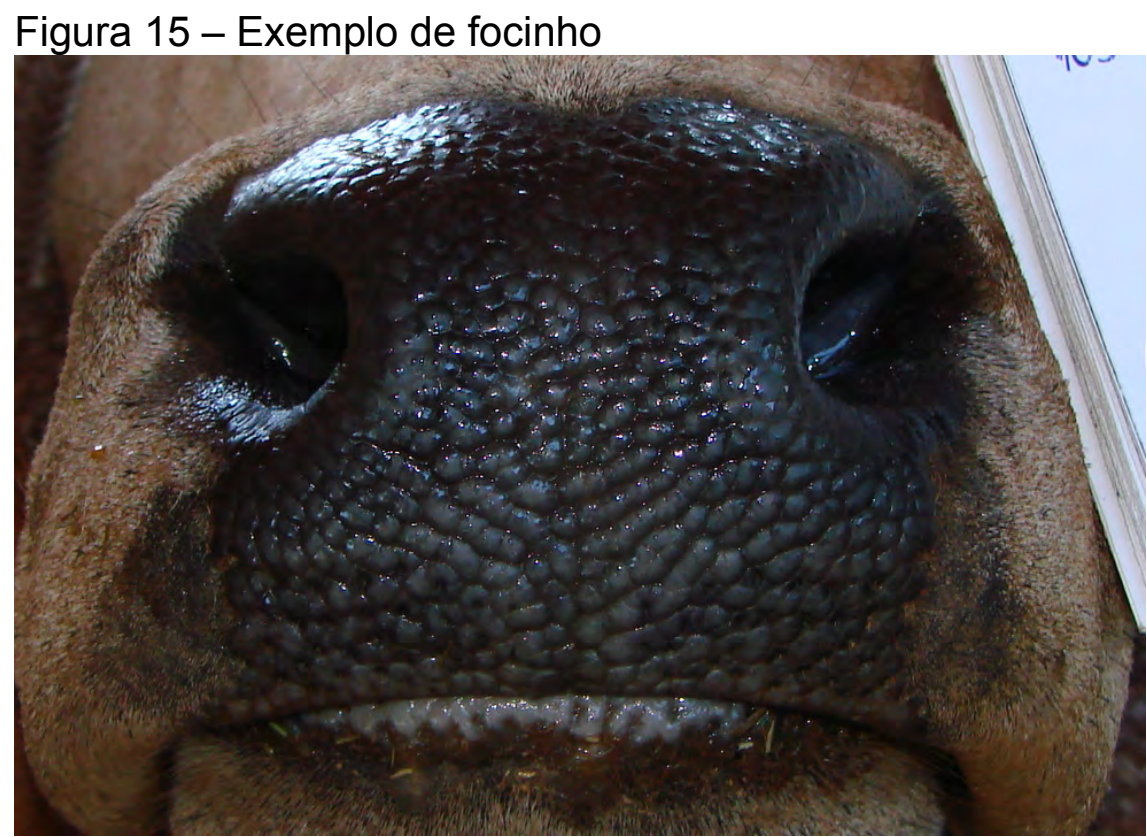

Fonte: Imagem alterada do Base de dados do Laboratório de Física Aplicada e Computacional, FZEAUSP, Pirassununga, SP, 2015. 
Figura 16 - Contra exemplo de focinho

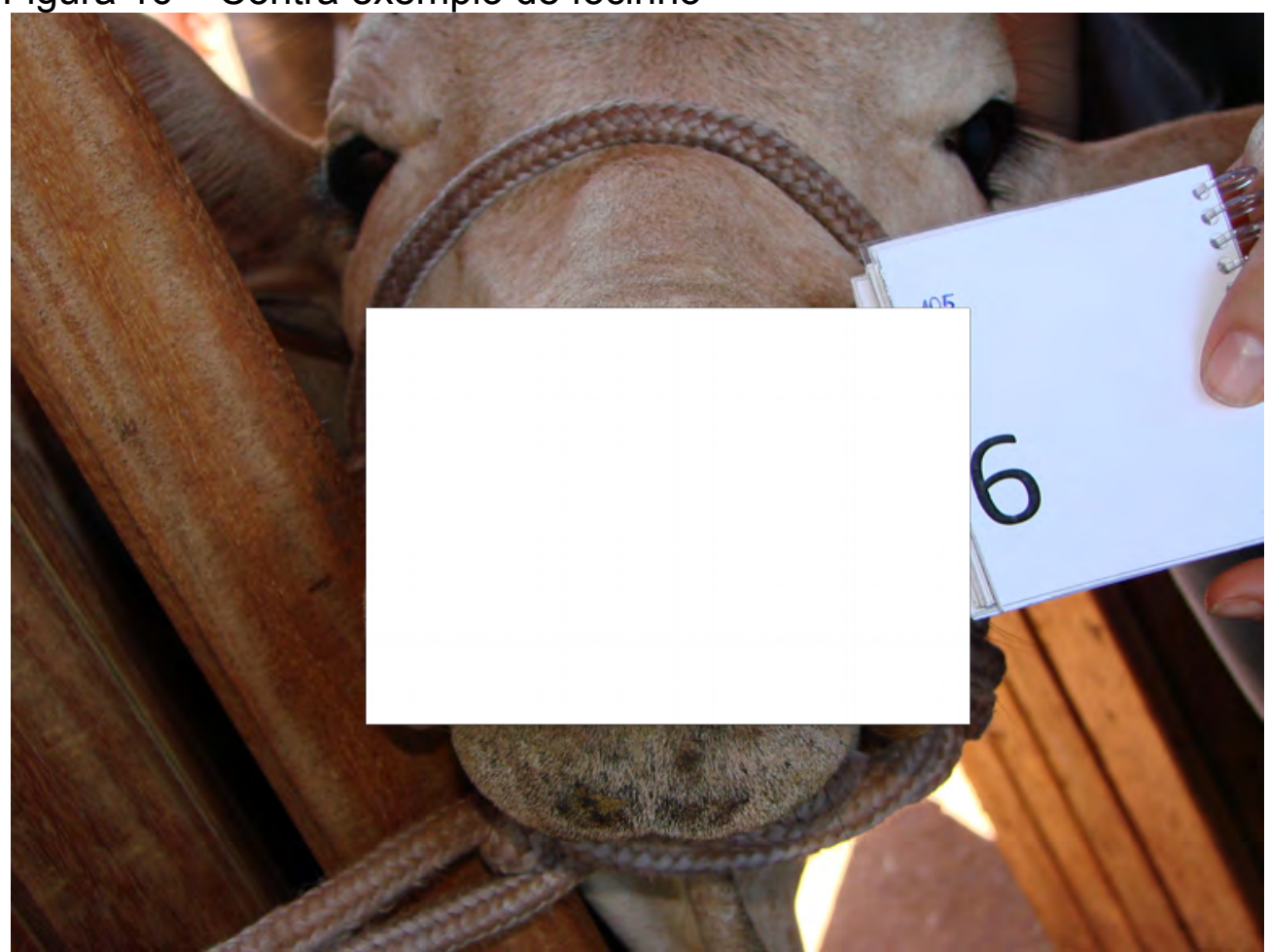

Fonte: Imagem alterada do Base de dados do Laboratório de Física Aplicada e Computacional, FZEAUSP, Pirassununga, SP, 2015.

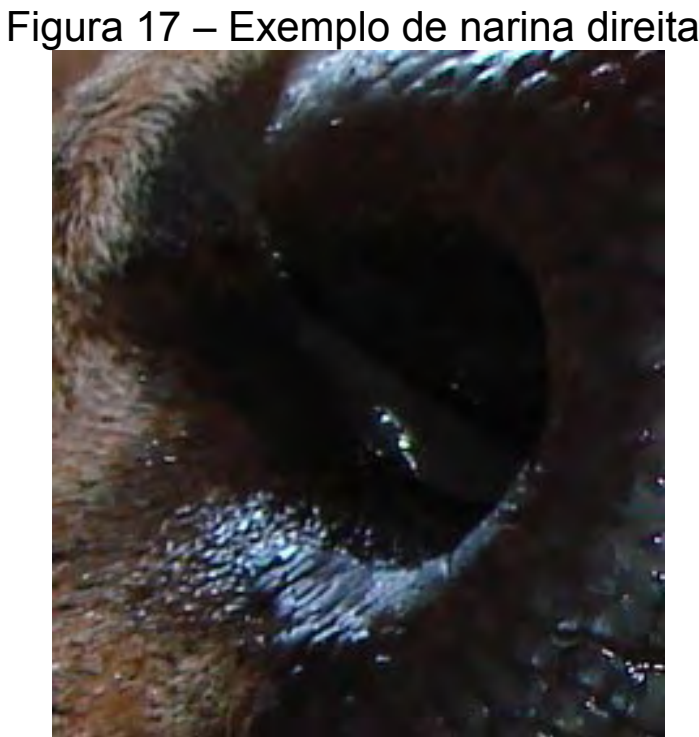

Fonte: Imagem alterada do Base de dados do Laboratório de Física Aplicada e Computacional, FZEAUSP, Pirassununga, SP, 2015. 
Figura 18 - Contra exemplo de narina direita

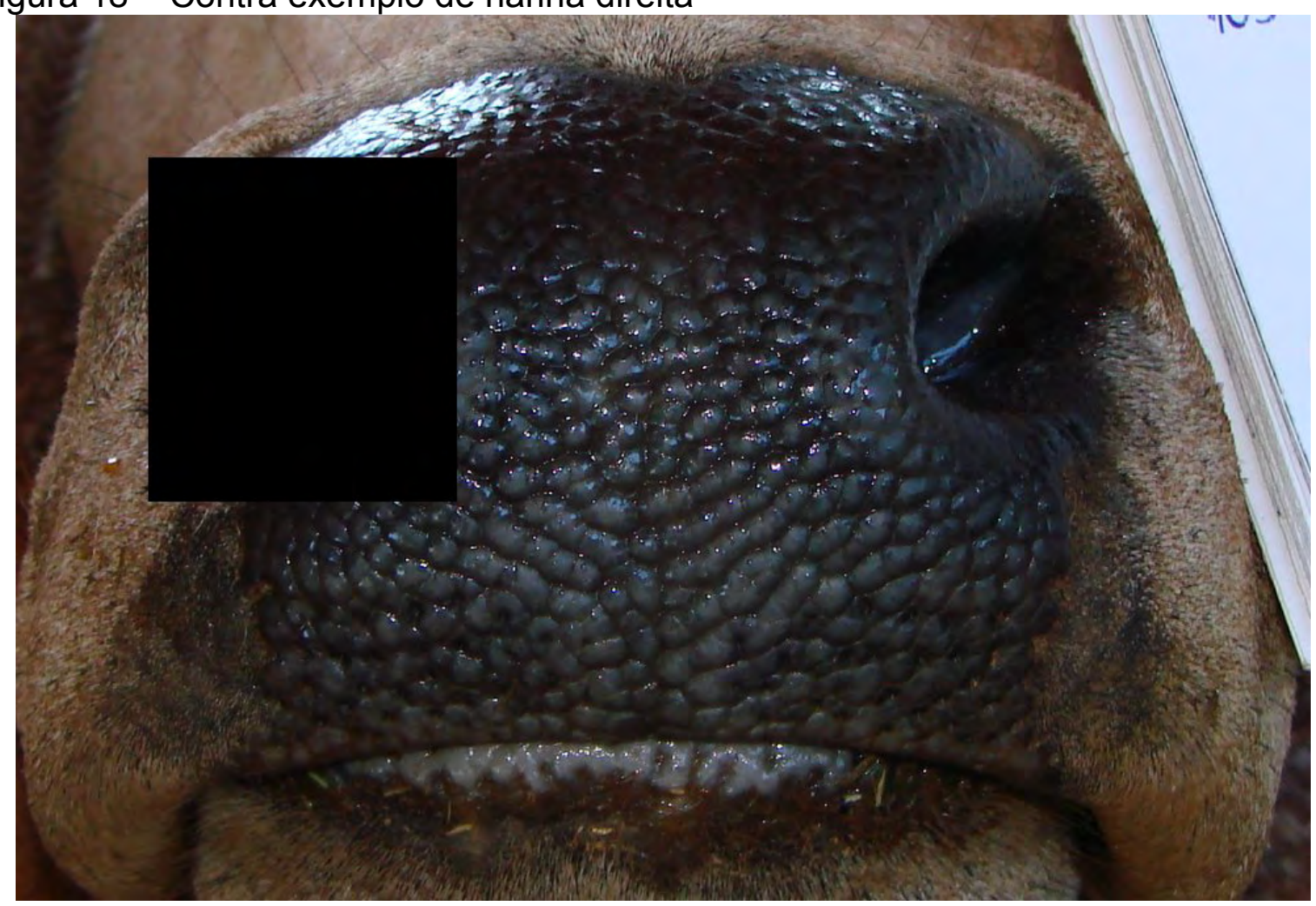

Fonte: Imagem alterada do Base de dados do Laboratório de Física Aplicada e Computacional, FZEAUSP, Pirassununga, SP, 2015.

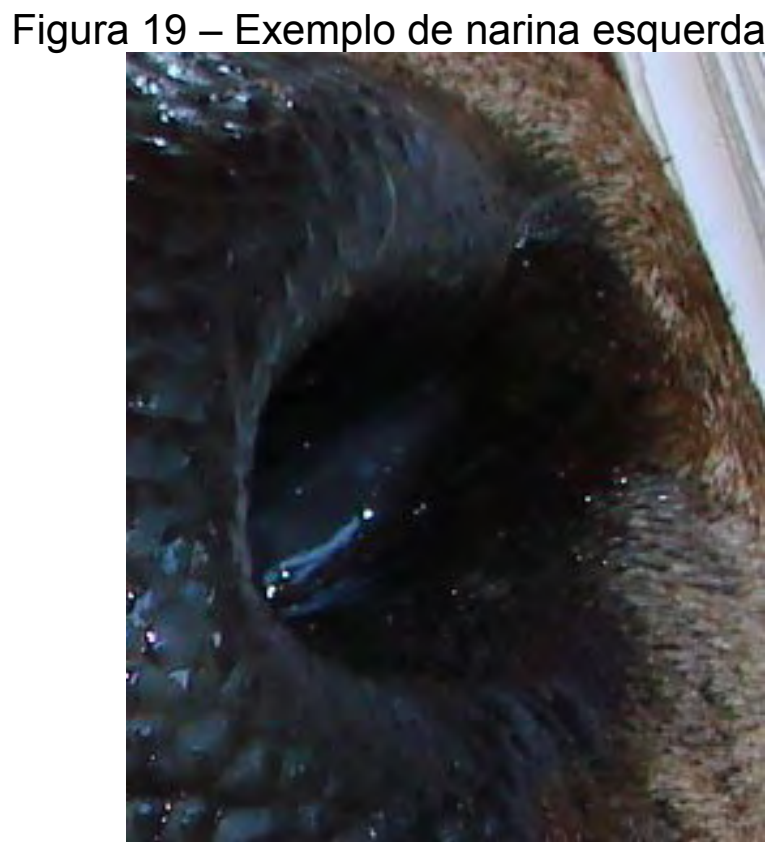

Fonte: Imagem alterada do Base de dados do Laboratório de Física Aplicada e Computacional, FZEAUSP, Pirassununga, SP, 2015. 
Figura 20 - Contra exemplo de narina esquerda

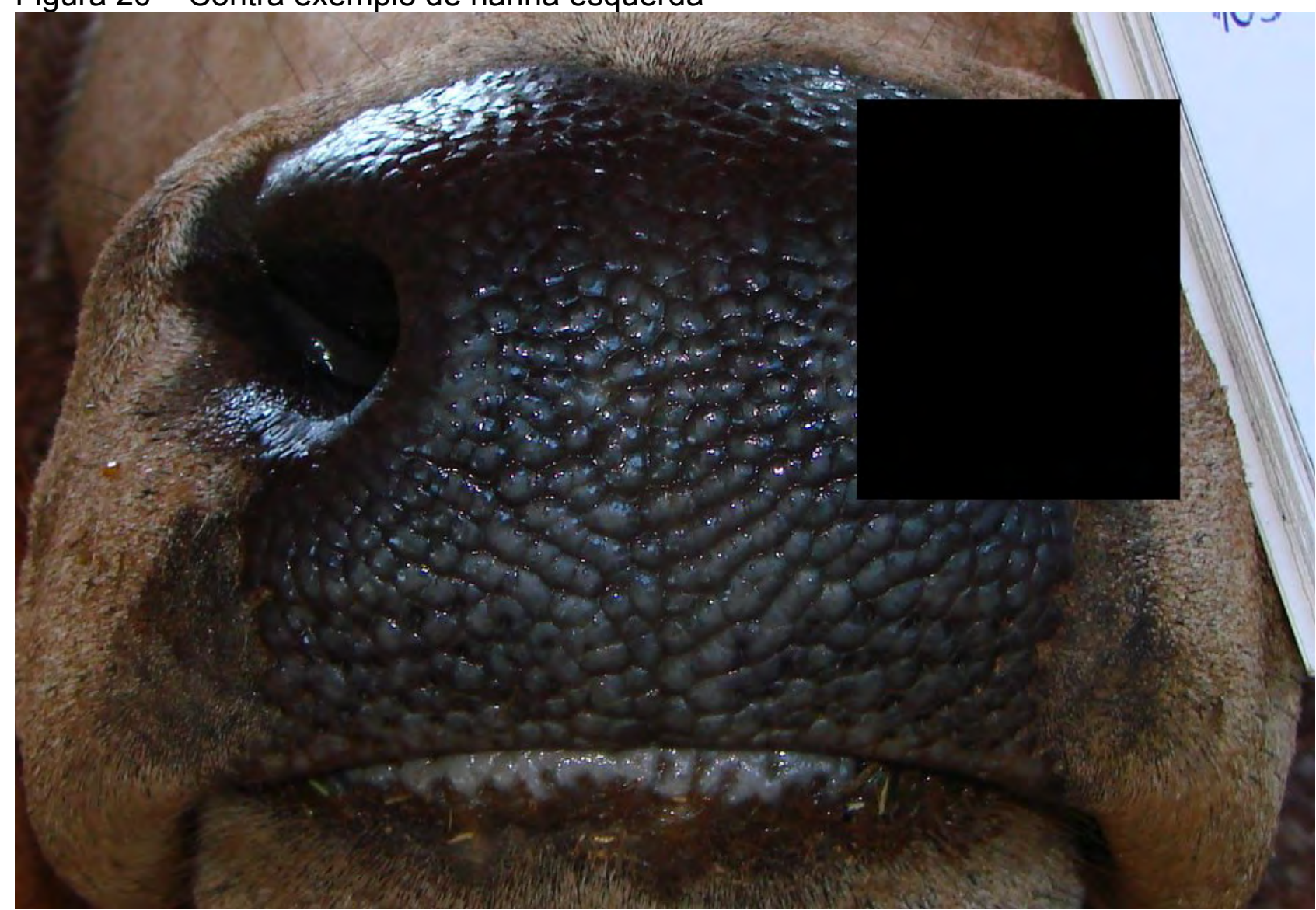

Fonte: Imagem alterada do Base de dados do Laboratório de Física Aplicada e Computacional, FZEAUSP, Pirassununga, SP, 2015.

Para a geração de um arquivo de configuração foram necessárias várias imagens exemplos e contraexemplos. Esta quantidade determina a qualidade do arquivo de configuração gerado. Nas descrições a seguir utilizou-se programas e scripts que podem ser encontrados no próprio site do produto (OpenCV). Nesta etapa foram usadas 101 imagens de exemplos para cada tipo de arquivo (focinho, narina direita e narina esquerda) e uma igual quantidade para os contraexemplos destes tipos de arquivos. Totalizando um total de 606 imagens trabalhadas.

\section{Passos:}

1. Criou-se uma pasta com nome "Treino LBP".

2. Dentro da pasta "Treino LBP" foram criadas as pastas "Focinho", "Narina Esquerda" e "Narina Direita".

3. Em cada uma delas criou-se as seguintes pastas. Uma pasta de nome 
"Positivo" para as imagens Exemplos e outra chamada "Negativo" para as imagens Contra exemplos. Uma pasta de nome "Exemplos" onde ficaram as imagens geradas em formato binário pelo OpenCV e outra chamada "Classificador" onde foi criado o arquivo "cascade.xml" com os padrões gerados e que foi inserido como parte do código fonte do programa que rodará no celular.

4. Inseriu-se nas pastas "Positivo" e "Negativo" as imagens produzidas manualmente conforme explicado anteriormente.

5. Através de um emulador de terminal, como este desenvolvimento ocorre em ambiente Linux utilizou-se o Gnome Terminal, executou-se os comandos a seguir:

5.1. Criação do arquivo "positivos.txt" que contem uma lista de todas as imagens inseridas na pasta "Positivo". Comando para criação:

find.$/$ Positivo/ ${ }^{*} . j p g>$ positivos.txt

5.2. Criação do aquivo "negativos.txt" que contem uma lista de todas as imagens inseridas na pasta "Negativo". Comando para criação:

find.$/$ Negativo/*.jpg > negativos.txt

5.3.Executar script "perl" que gera pasta com os exemplos criados pelo opencv_createsamples a partir da lista de positivos e negativos. Este comando gera uma pasta com arquivos de extensão .vec de formato binário contendo exemplos de imagens com e sem distorção.

perl /bin/createsamples.pl positivos.txt ./negativos.txt Exemplos 4000 "opencv_createsamples -bgcolor 0 -bgthresh 0 -maxxangle 1.1 -maxyangle 1.1 maxzangle 0.5 -maxidev 40 -w 24 -h 24"

5.4.Executar programa phyton que junta todos os .vec criados pelo item anterior em um arquivo .vec único. Este programa retorna o número de samples criados para utilização do opencv_traincascade.

python ../mergevecO.py -v samples -o exemplos.vec

5.5.Executar opencv_traincascade para gerar o arquivo .xml que será usado pelo OpenCV em seu programa. Este arquivo tem os dados já preparados para reconhecimento de uma determinada imagem.

opencv_traincascade -data Classificador -vec exemplos.vec -bg negativos.txt -numStages $20 \quad$-minHitRate 0.999 -maxFalseAlarmRate 0.5 -numPos 3885 
-numNeg 3885 -w 24 -h 24 -mode ALL -precalcValBufSize 4096 -precalcldxBufSize 4096 -featureType LBP

6. Como resultado da execução do item anterior para os focinhos, narinas direitas e narinas esquerdas, obteve-se os arquivos de configuração cascade.xml para cada um deles que foram renomeados para focinhocascade.xml, narinadireita.xml e narinaesquerda.xml respectivamente. Estes arquivos foram inseridos no aplicativo conforme identificação abaixo (Figura 21) extraída do Android Studio.

Figura 21 - Estrutura Android Studio - Realce para os cascades

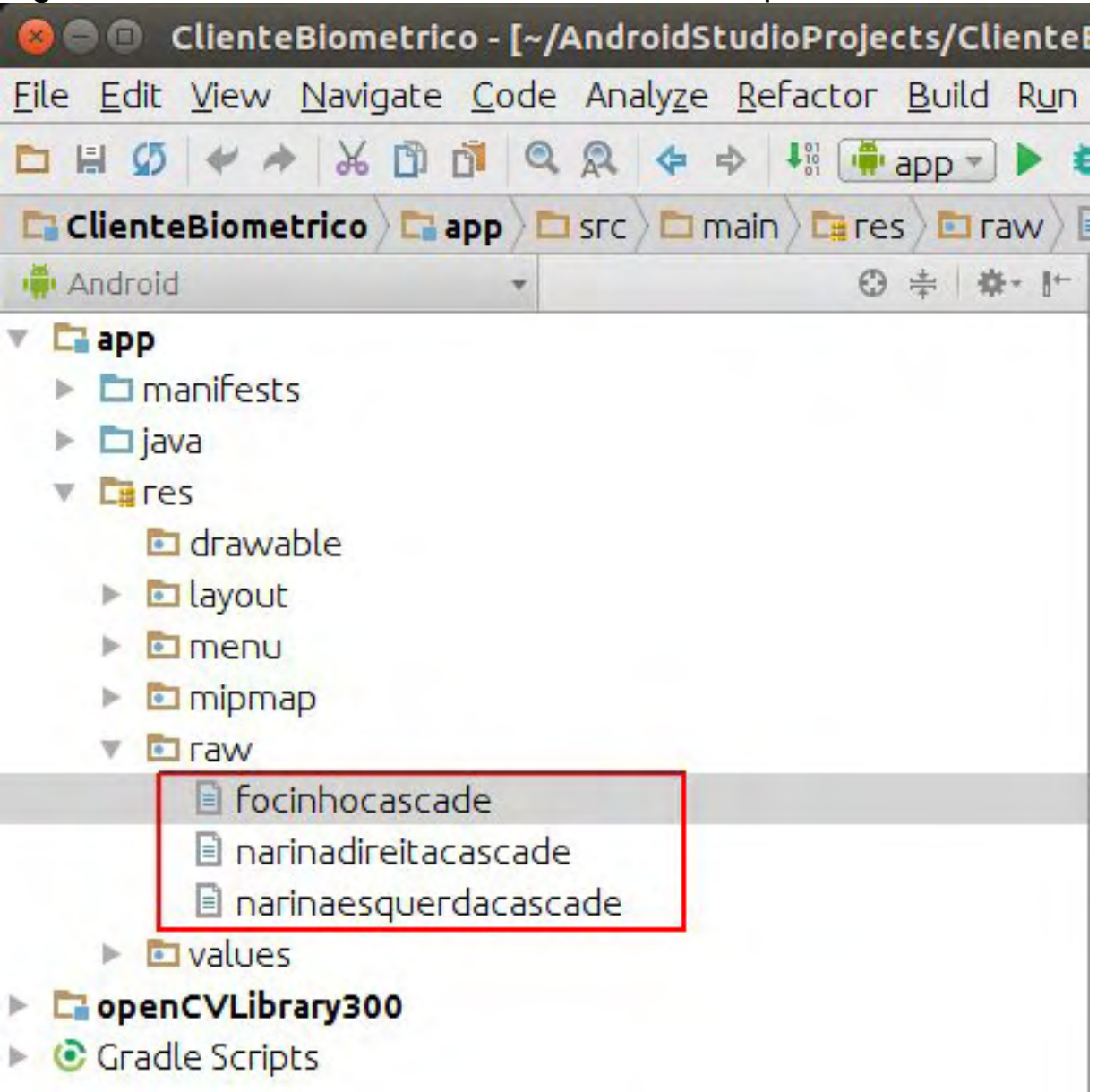

Fonte: Própria autoria

Para a camada cliente referente ao tratamento de imagem foi criado o arquivo-fonte "CameraActivity.java". Esta classe java é responsável pelo controle da câmera do celular e por selecionar a área que determina o espelho nasal do bovino. 
No código abaixo (Figura 22) interessante notar três funções grifadas que serão detalhadas a seguir. São elas: initializeOpenCVDependencies, onCreate e onCameraFrame.

Figura 22 - CameraActivity.java

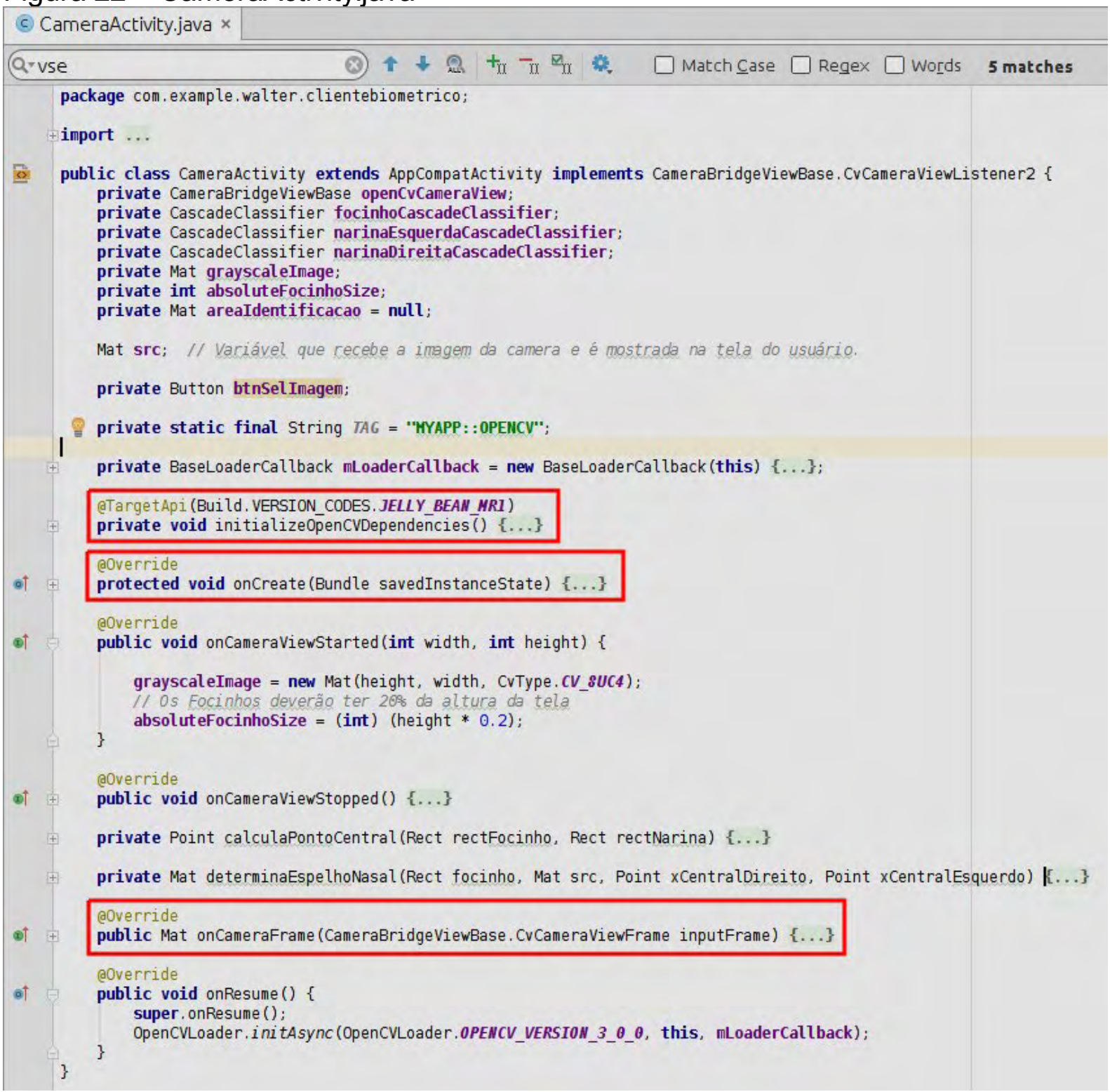

Fonte: Própria autoria.

A função initializeOpenCVDependencies (Figura 23) é responsável por carregar as variáveis que serão utilizadas para identificação do focinho, narina esquerda e narina direita com seus respectivos conteúdos localizados nos arquivos XML focinhocascade.xml, narinaesquerdacascade.xml e narinadireitacascade.xml. Ela também é responsável por ativar a câmera através do OpenCV. 
Figura 23 - Função initializeOpenCVDependencies

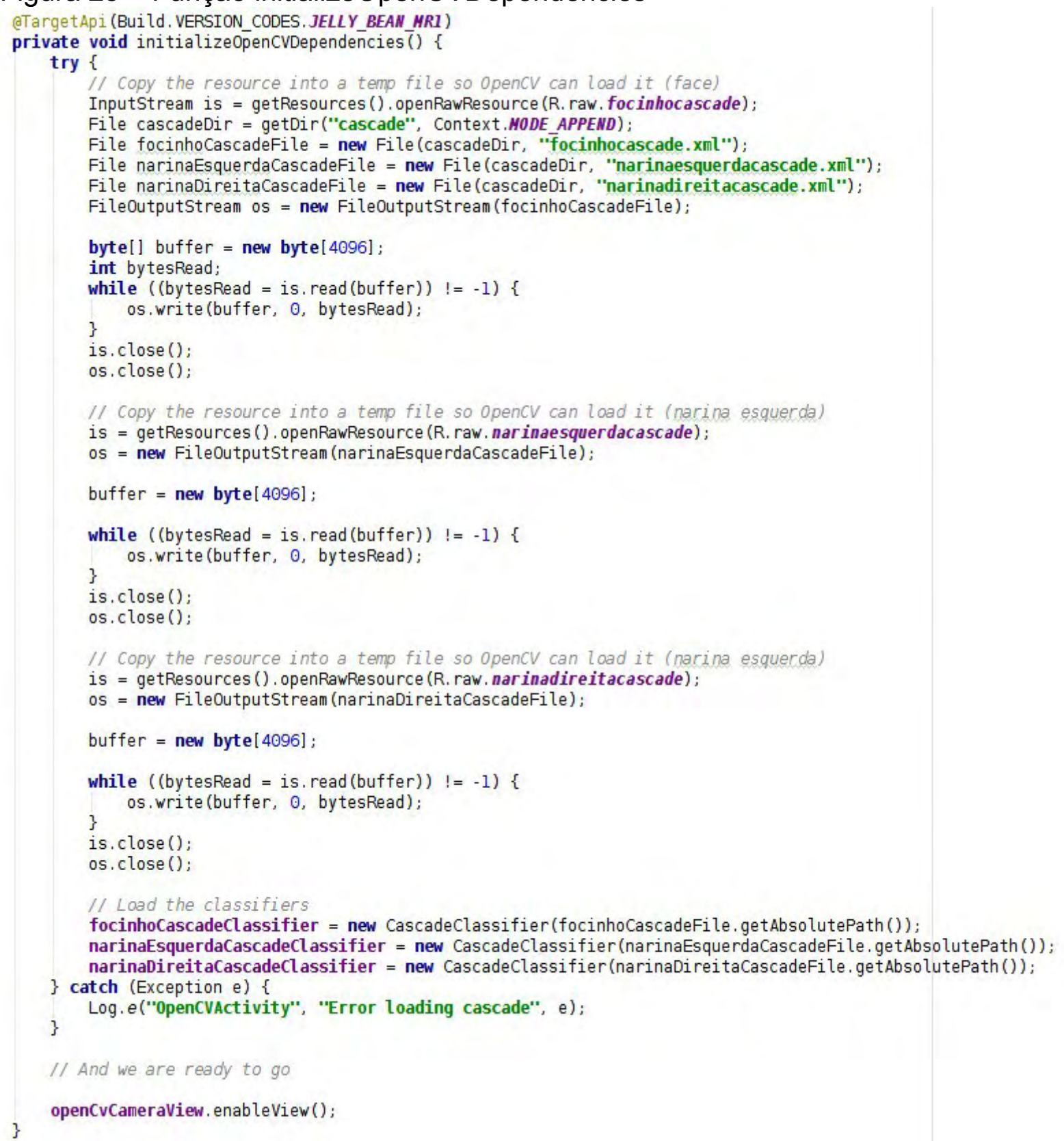

Fonte: Própria autoria.

No momento que é acionada a tela de captura da imagem automaticamente são executados os comandos inseridos na função onCreate (Figura 24). Nesta função direciona-se o que é capturado da câmera para a tela do celular e também associa-se ao click do botão "Selecionar" as ações responsáveis por salvar o espelho nasal identificado pela rotina onCameraFrame e retornar para a tela de cadastro e verificação. 


\section{Figura 24 - Função onCreate}

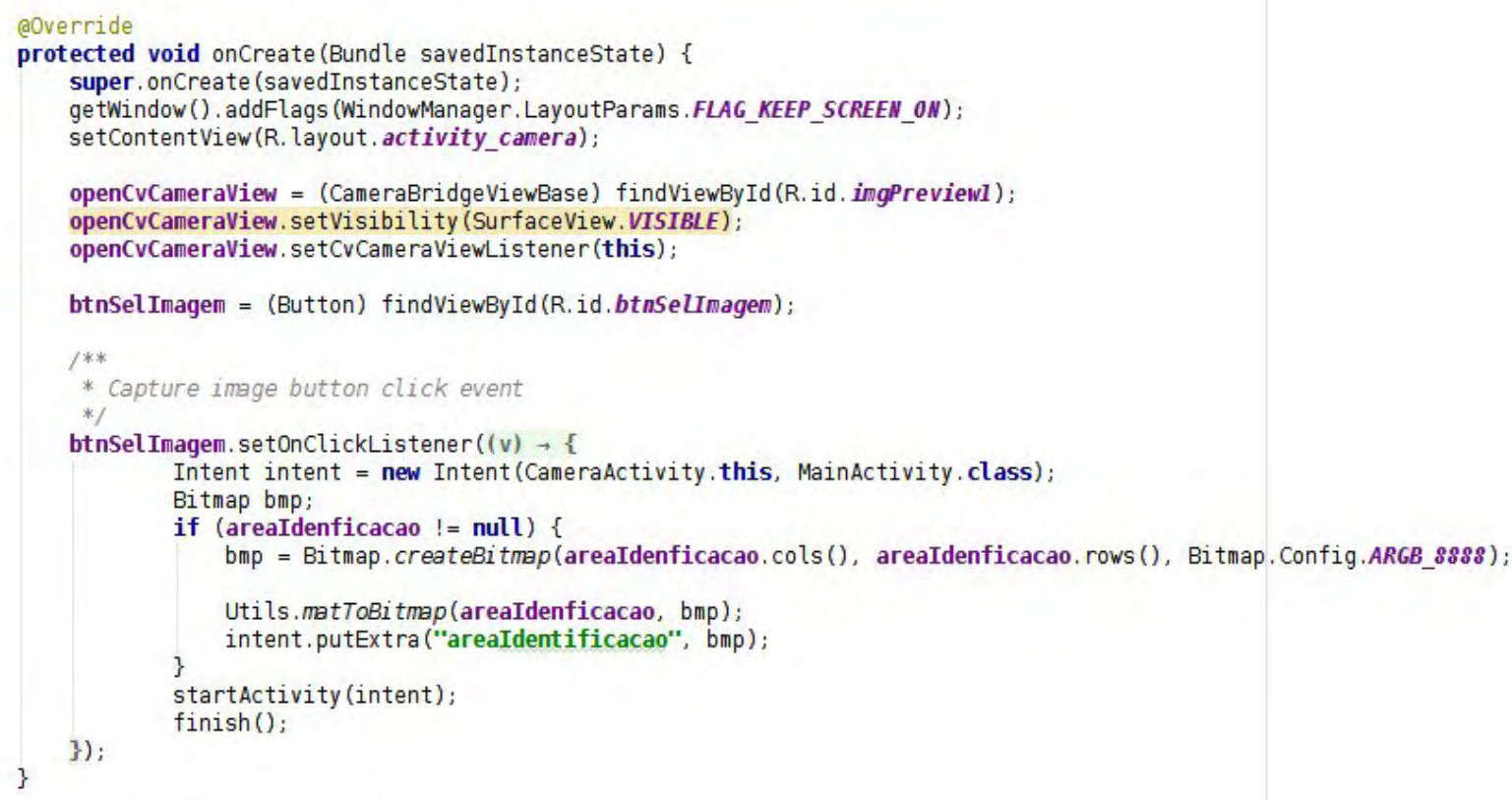

Fonte: Própria autoria.

$\mathrm{Na}$ rotina onCameraFrame (Figura 25) pode-se verificar o comando "detectMultiScale", demarcado no código abaixo em vermelho, que é responsável por localizar a imagem conforme os padrões armazenados nas variáveis focinhos, narinasDireitas e narinasEsquerdas. Importante perceber que apenas depois de encontrar apenas um focinho, uma narina direita e uma narina esquerda é que se procede os cálculos para identificação do espelho nasal. 
Figura 25 - Função onCameraFrame

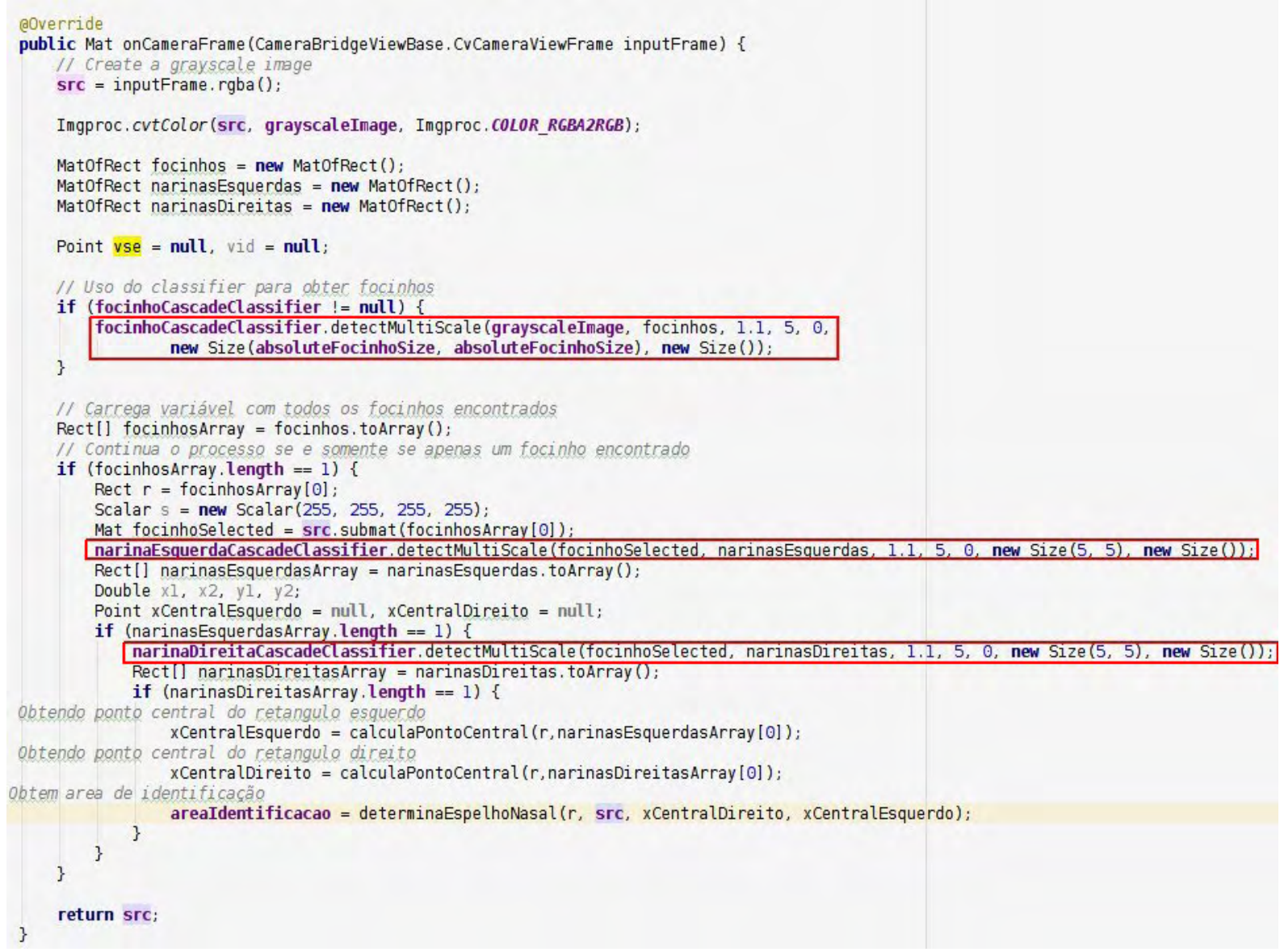

Fonte: Própria autoria.

Nota-se nos procedimentos para determinação do espelho nasal (Figura 26) que após identificar as narinas determina-se os centros das mesmas a fim de se obter o ângulo formado entre o seguimento de reta determinado por estes centros e uma linha imaginária paralela ao eixo x. Com este ângulo determinado procede-se o ajuste da figura e determina-se o retângulo que corresponde ao espelho nasal. 


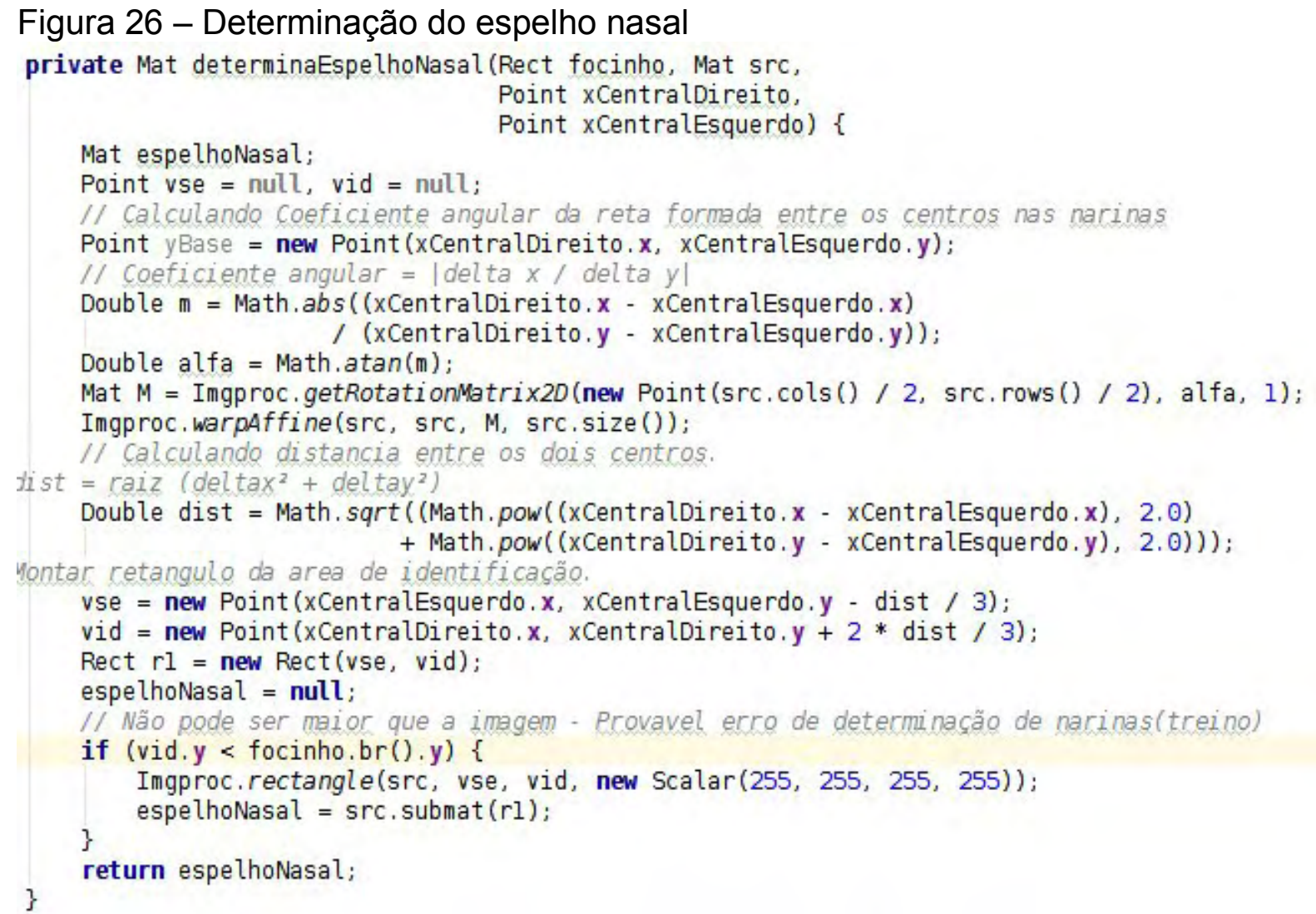

Fonte: Própria autoria. 


\subsubsection{Comunicação com Web Service.}

Para que se possa detalhar as rotinas de comunicação tem-se antes que mostrar como os dados foram passados para as mesmas. Na classe base da tela de cadastro e verificação, a classe MainActivity.java (Figura 27), criou-se as funções que preparam os dados a serem enviados para as rotinas do Web Service. Estas rotinas são acionadas pelos botões "Cadastrar" e "Verificar" cuja programação também é desenvolvida nesta classe na função "onCreate".

Figura 27 - Classe MainActivity.java

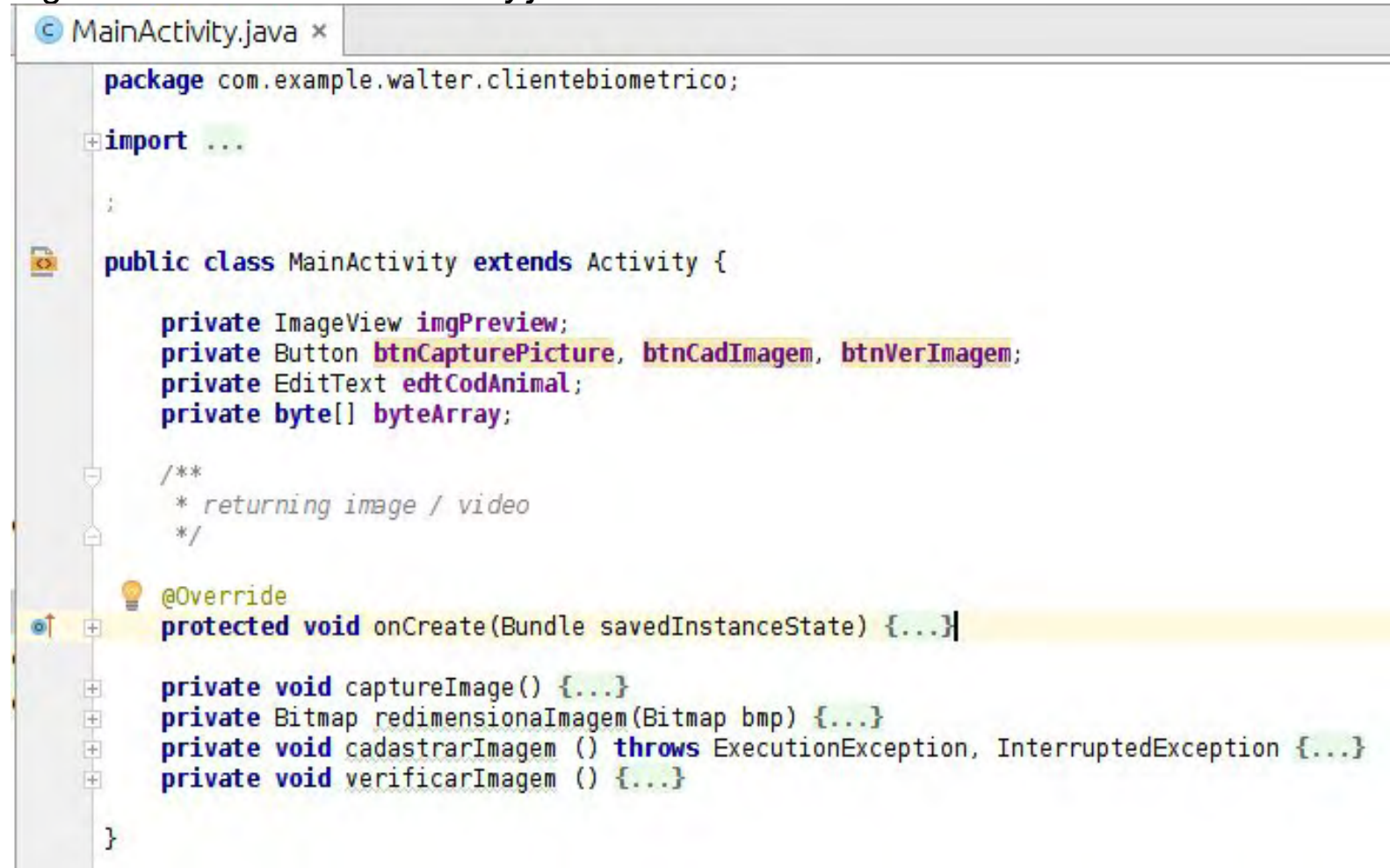

Fonte: Própria autoria.

$\mathrm{Na}$ função onCreate (Figura 28) verifica-se destacado em vermelho a associação dos eventos de click nos botões com suas respectivas rotinas. Permitindo assim que o usuário possa encaminhar através destas rotinas as informações para a camada Web Service ou para a camada de tratamento de imagens, ambas executadas no celular. 
Figura 28 - Função onCreate da classe MainAvtivity.java

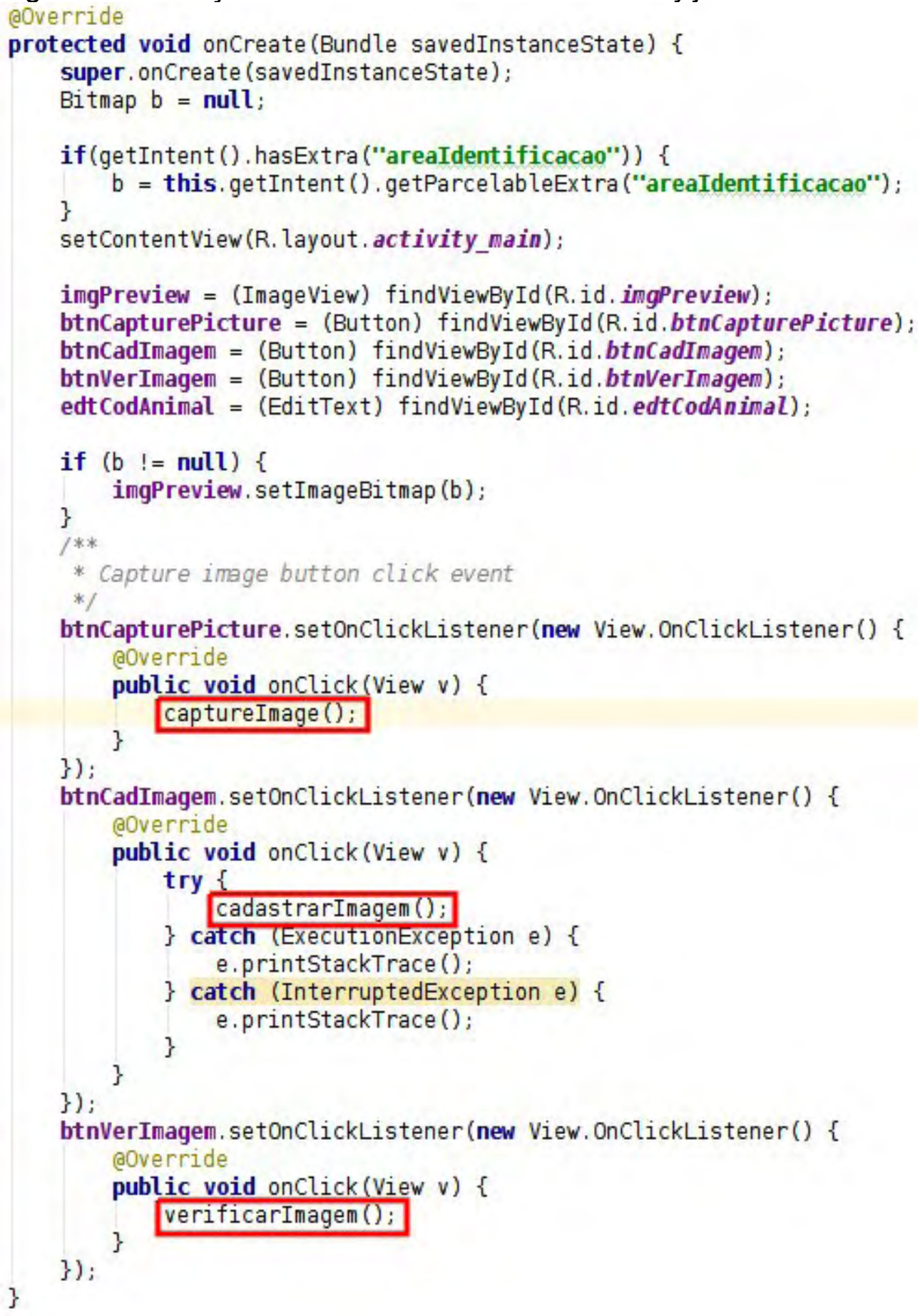

Fonte: Própria autoria.

A rotina capturelmage (Figura 29) é responsável por passar o controle do aplicativo para a classe de tratamento de imagem (CameraActivity) e que retorna como resultado o espelho nasal. 
Figura 29 - Função capturelmage

private void captureImage () \{

Intent intent $=$ new Intent (MainActivity, this, CameraActivity,class);

startactivity (intent):

\}

finish():

Fonte: Própria autoria.

Tanto no cadastramento da imagem (Figura 30) como na verificação (Figura 31) nota-se a preparação dos dados que é passado para a camada WebService através do comando "task.execute" grifado em vermelho.

Figura 30 - Função cadastrarlmagem

private void cadastrarImagem () throws ExecutionException, InterruptedException \{ AsyncCall task = new AsyncCall ():

String method = String.valueof(BiometricConstants, addAnimaLImage);

String idanimal $=$ edtCodAnimal $\cdot$ getText ().toString();

// Array que será enviado via WebService

ByteArrayOutputStream stream = new ByteArrayoutputStream ();

Bitmap bitmap $=(($ BitmapDrawable $)$ imgPreview, getDrawable ()$)$, getBitmap () ;

bitmap. compress (Bitmap. CompressFormat.JPEG, 100, stream);

byteArray = stream. toByteArray ();

String strImage $=$ Base64. encodeBytes (byteArray);

\}

task. execute (method, idAnimal, strImage);

Fonte: Própria autoria.

Figura 31 - Função verificarlmagem

private void verificarImagem () \{

AsyncCall task = new AsyncCall ();

String method = String, valueof (BiometricConstants, verAnimaLImage);

String idAnimal = edtCodAnimal $\cdot$ getText(), tostring();

// Array que será enviado via WebService

ByteArrayOutputStream stream = new ByteArrayOutputStream ();

Bitmap bitmap $=(($ BitmapDrawable $)$ imgPreview. getDrawable ()$)$, getBitmap () ;

bitmap $=$ redimensionaImagem (bitmap);

bitmap. compress (Bi tmap. CompressFormat. JPEG, 100, stream);

byteArray $=$ stream , toByteArray ();

String strImage = Base64. encodeBytes (byteArray);

\}

task. execute (method, idanimal, strImage);

Fonte: Própria autoria. 
Os dados coletados até agora pela camada cliente, ou seja, o código identificador e a imagem devem ser enviados ao servidor de aplicativos que providenciará o cadastro ou a verificação do bovino. Para esta implementação utilizou-se uma biblioteca chamada KSOAP que permite utilizar o protocolo SOAP na plataforma Android e como consequência a possibilidade de se implementar a camada cliente do Web Service. Ressalta-se no código inserido no arquivo WebService.java (Figura 32) uma variável declarada como URL que contém o endereço IP do servidor de aplicações, a porta (8080) que o mesmo atende as requisições e o serviço deste servidor (BiometricServer). As rotinas "involk" e "EnviaEnvelope" providenciam as requisições ao servidor e serão tratadas abaixo.

Figura 32 - WebService.java - Cliente

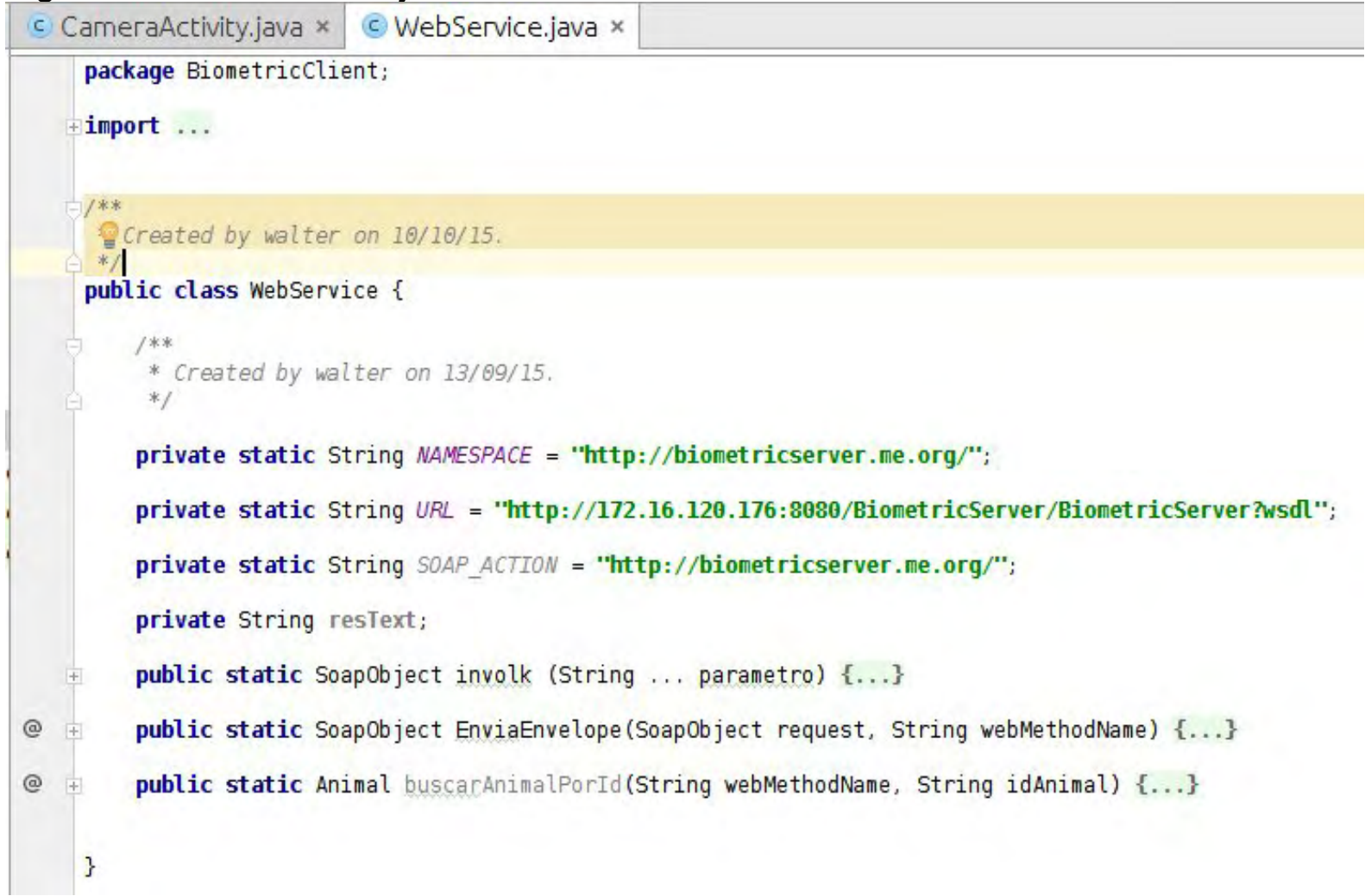

Fonte: Própria autoria.

A função "involk" (Figura 33) recebe como parâmetro o método a ser executado, a identificação do animal e a imagem do animal. Com estas informações esta rotina prepara os dados no formato esperado pelo Web Service e passa o controle para a rotina "enviaEnvelope" que enviará os dados ao servidor. 
Figura 33 - Função involk da classe WebService.java - Cliente public static Soapobject involk (String ... parametro) k

SoapObject request;

String webMethodNameInt $=$ parametro[0] tostring () ;

String webMethodName;

String resText;

PropertyInfo propertyBiometric = new PropertyInfo();

Soapobject resposta $=$ null;

RetornoAnimal retorno = new RetornoAnimal ():

Animal animal $=$ new Animal () :

switch (Integer,parseInt (webMethodNameInt)) \{

case BiometricConstants, addAnimalimage:

// Parametro idAnimal

webMethodName = "addAnimal Image";

request $=$ new SoapObject (NAMESPACE, webMethodName);

request.addProperty ("idAnimal", parametro[1].toString());

// Parametro image

request.addProperty ("image", parametro [2] .toString());

resposta $=$ EnviaEnvelope (request, webMethodName);

break;

case BiometricConstants. delAnimalimage:

// Parametro idAnimal

webMethodName = "del Animal Image";

request $=$ new Soap0bject (NAMESPACE, webMethodName):

request.addProperty ("idAnimal", parametro[1] . toString());

resposta $=$ EnviaEnvelope (request, webMethodName);

break;

case BiometricConstants, getAnimalimage:

// Parametro idAnimal

webMethodName = "getAnimal Image";

request $=$ new SoapObject (NAMESPACE, webMethodName);

request.addProperty ("idAnimal", parametro[1] . toString());

resposta $=$ EnviaEnvelope (request, webMethodName):

break;

case BiometricConstants, verAnimalimage:

// Parametro idAnimal

webMethodName = "verAnimal Image";

request $=$ new SoapObject (NAMESPACE, webMethodName);

request.addProperty ("idAnimal", parametro[1] , tostring ());

// Parametro image

request.addProperty ("image", parametro [2] .toString());

resposta $=$ EnviaEnvelope (request, webMethodName):

if (resposta.getProperty ("status") . toString(). equals ("Confere". toString())) \{ \} else \{

System , out.println ("Confere");

\}

System, out,println ("Não Confere");

break;

default:

break;

\}

return resposta;

Fonte: Própria autoria. 
Quando a rotina enviaEnvelope (Figura 34) recebe os dados preparados da rotina "involk" ela os envia para o destino especificado na variável URL citada anteriormente. Desta forma a mensagem incluindo seu método, identificação do animal e a imagem são enviadas ao Web Service localizado no servidor remoto.

Figura 34 - Função enviaEnvolope da classe WebService.java - Cliente public static SoapObject EnviaEnvelope (Soapobject request, String webMethodName) \{

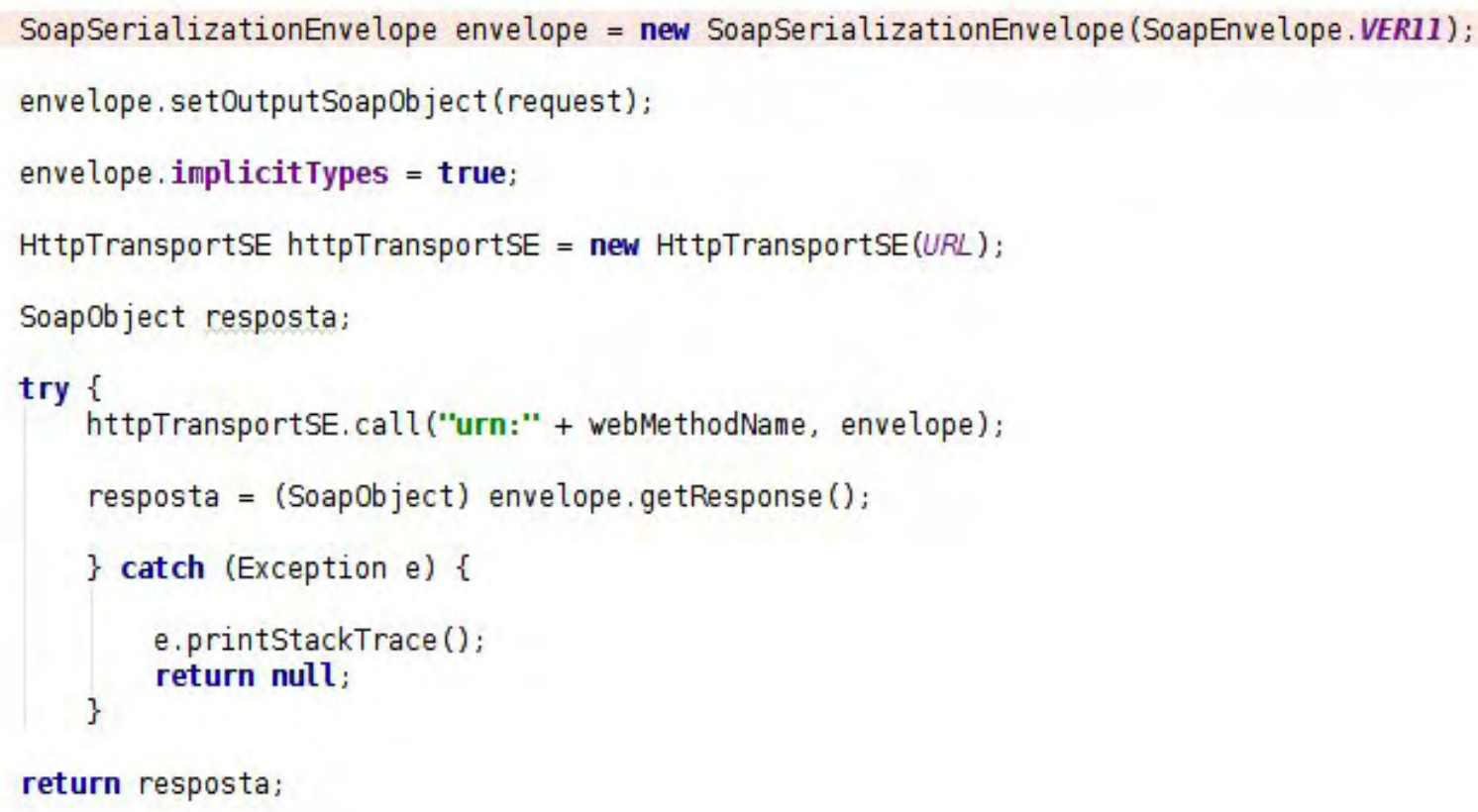

Fonte: Própria autoria.

\subsubsection{Camada Servidora}

Como sistema operacional base para o processo de desenvolvimento utilizase o Ubuntu 16.04 com o aplicativo NetBens Versão 8.1 e nele inclusos o framework de desenvolvimento para Java e o Servidor de Aplicativos GlassFish Server 4.1.1. Como Servidor de Banco de Dados instalado nesta mesma máquina foi utilizado o MySQL Versão 5.6.30. 


\subsubsection{Servidor de Aplicativos}

Como determinado na metodologia foi desenvolvido um aplicativo para atender as requisições da camada cliente na forma de Web Service. Este aplicativo foi nomeado com BiometricServer. Abaixo temos as estrutura do projeto (Figura 35) e demarca-se em vermelho dois pacotes criados com o objetivo de isolar as rotinas para acesso a dados e as rotinas do Web Service.

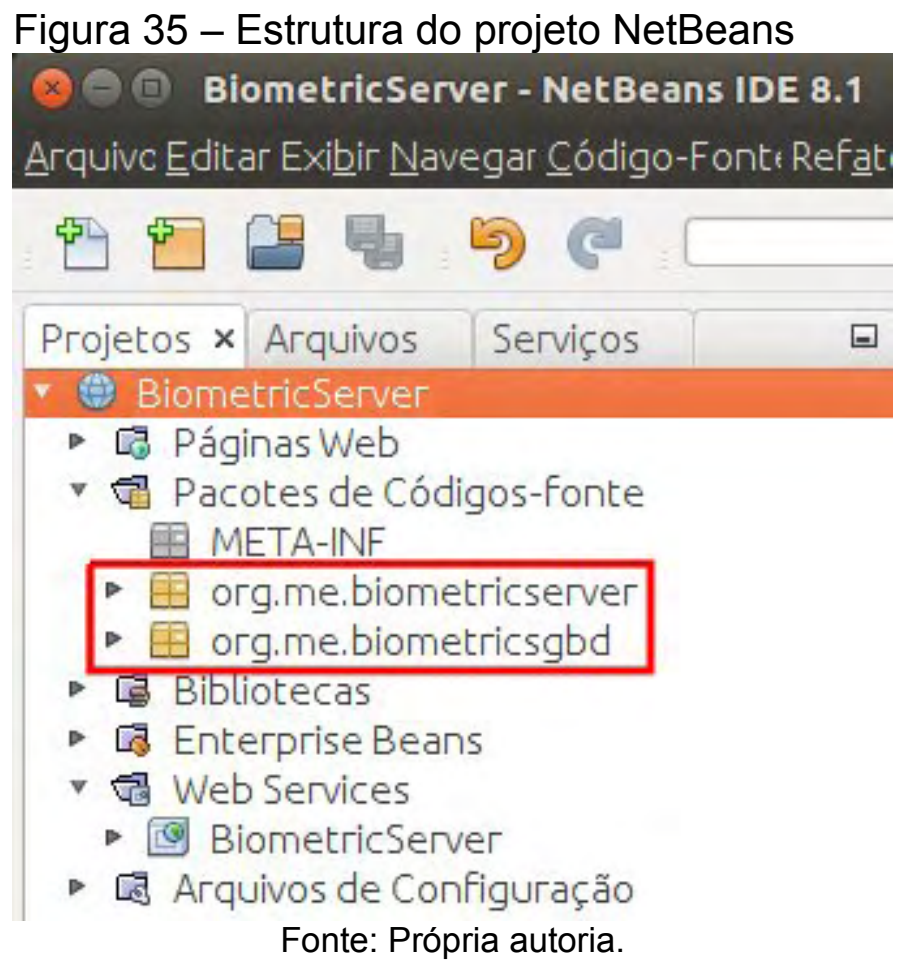

No pacote org.me.biometricserver estão todas as regras de negócio bem como as rotinas de comunicação para atender as requisições da camada cliente. $O$ pacote org.me.biometricsgbd contém as informações necessárias para o acesso ao servidor MySQL. 
Observando-se o pacote org.me.biometricserver (Figura 36) vê-se três classes onde uma delas grifada abaixo é o Web Service.

Figura 36 - Pacote org.me.biometricserver

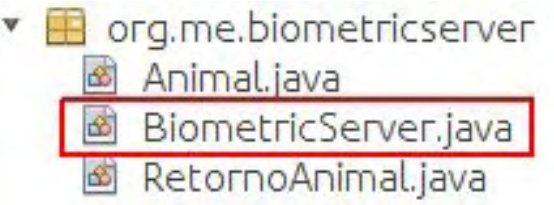

Fonte: Própria autoria.

No Web Service criado (Figura 37), conforme exposto na metodologia, existem os métodos que atendem as requisições da camada cliente. Nestes métodos, assim como os definidos na camada cliente, cada um deles possui uma identificação para o método e as identificações dos parâmetros correspondentes de cada um. Vale frisar aqui que os nomes dos métodos e os nomes dos parâmetros são os mesmos passados pela camada cliente, pois se assim não fosse ocorreria um erro de execução.

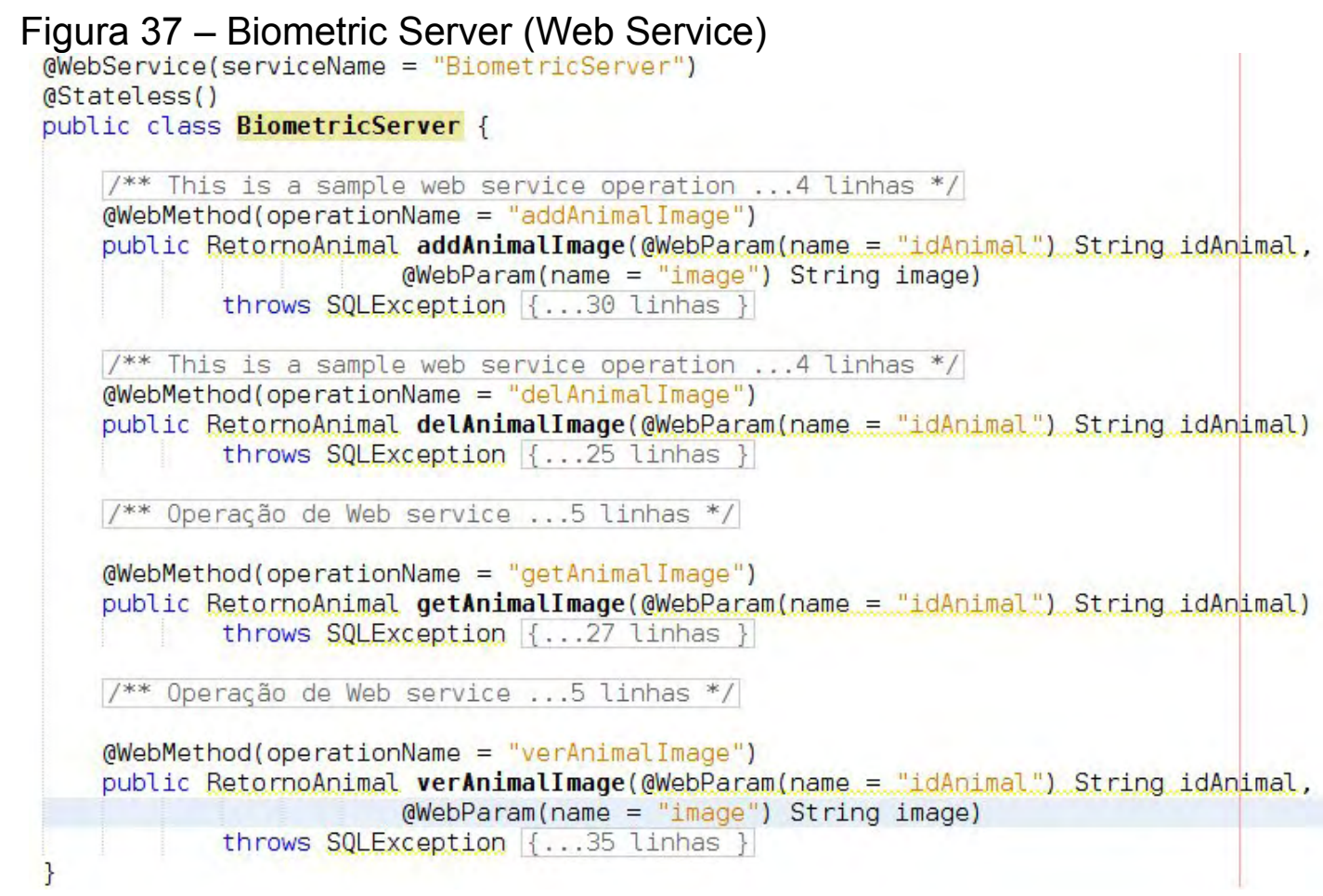

Fonte: Própria autoria. 
O método "addAnimallmage" (Figura 38) é responsável por cadastrar um animal na base de dados. Nota-se que este método, assim como os demais que acessam o Banco de Dados, faz referência a classe "DB" localizada no pacote "org.me.biometricsgbd". Esta classe possui os dados necessários para a comunicação com o Banco de Dados como endereço do servidor, porta de acesso, usuário e senha.

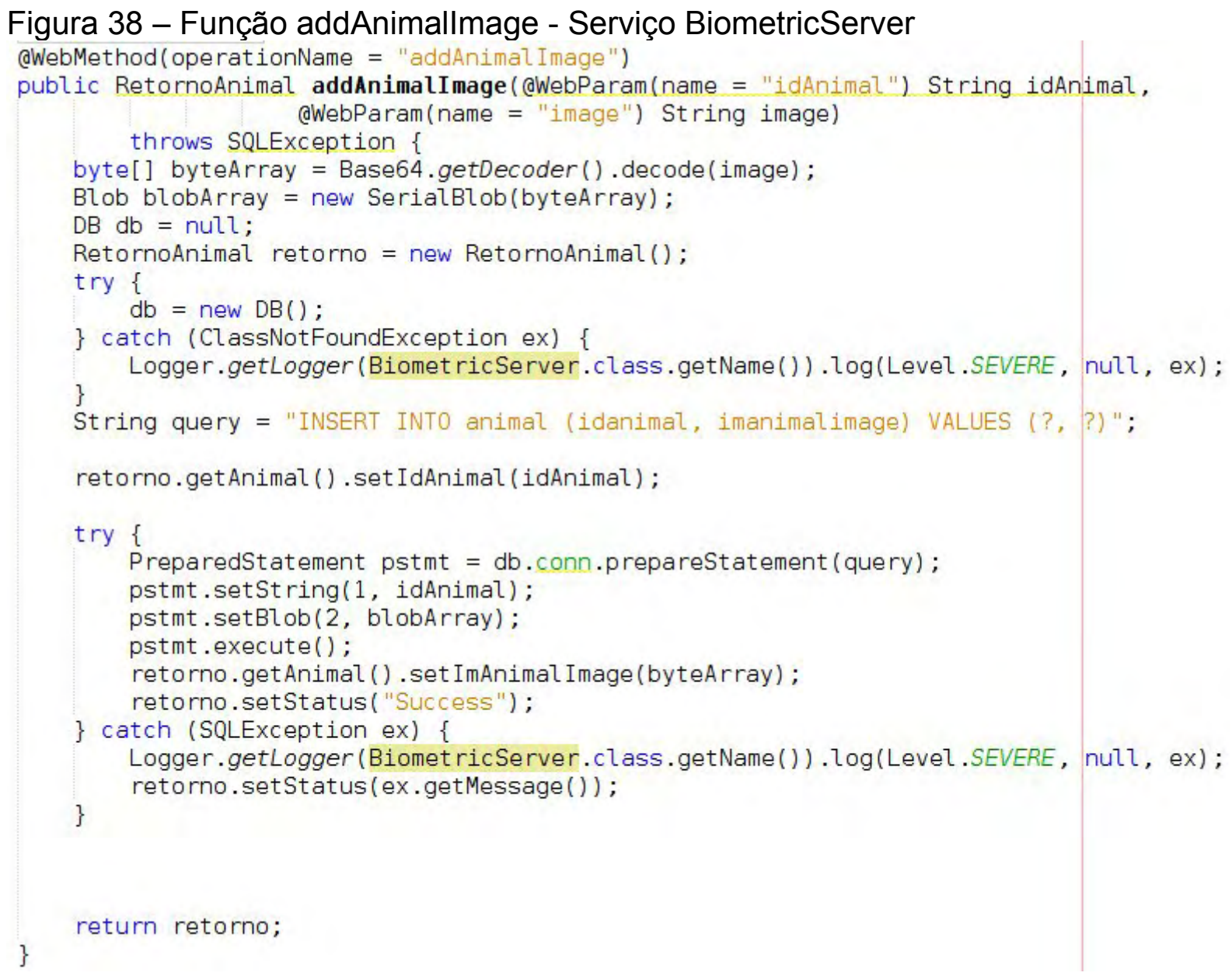

Fonte: Própria autoria. 


\subsubsection{Servidor de Banco de Dados}

No servidor MySQL instalado foi criado um Banco de Dados com nome "biometric" e neste banco de dados uma única tabela com as informações necessárias para demonstrar o processo. Pode-se ver a estrutura da tabela "animal" (Figura 39) através da ferramenta MySQL WorkBench instalada na máquina de desenvolvimento para manipulação do Banco de Dados.

Figura 39 - Estrutura da tabela "animal"

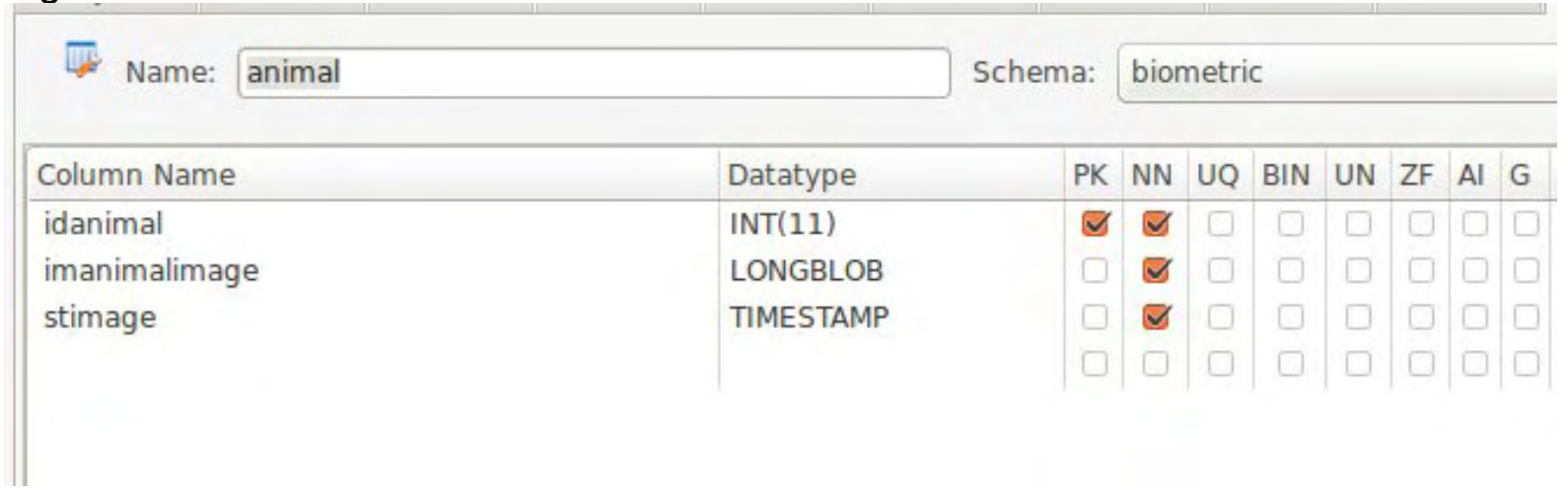

Fonte: Própria autoria.

\subsection{TESTE DO APLICATIVO}

Para que se pudesse fazer os testes foi necessário a geração do instalador do aplicativo ClienteBiometrico que roda no celular e construir e implantar o aplicativo WebService que roda no servidor. Para a geração do instalador do ClienteBiometrico basta abrir o aplicativo pelo Android Studio, entrar no menu "Build" e clicar em "Generated Signed APK ...". Após clicar no botão o Android Studio retorna mensagem informando que gerou o arquivo e disponibiliza o caminho para o mesmo (Figura 40). 
Figura 40 - Retorno Geração APK

\begin{tabular}{|c|c|c|c|c|}
\hline \multicolumn{5}{|c|}{ - Build Run Iools VCS $\underline{\text { Window }}$ Help } \\
\hline$a p p=$ & 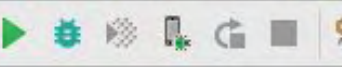 & 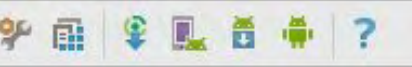 & & Q $P$ \\
\hline y.java $x$ & (c) WebService.java $x$ & (c) CameraActivity.java $\times$ & ( Generate Signed APK & \\
\hline $2=$ & le. valueof (rectFocinho. & tl ()$\cdot y)+$ Double valueof $(r$ & $\begin{array}{l}\text { APK(s) generated successfully. } \\
\text { Show in Files }\end{array}$ & \\
\hline
\end{tabular}

Fonte: Própria autoria.

No caminho acima grifado em azul com as palavras "Show in Files" encontrase o arquivo "app-release.apk" (Figura 41) que deverá ser enviado para o celular que fará a instalação do aplicativo através dele.

Figura 41 - Pasta contendo app-release.apk

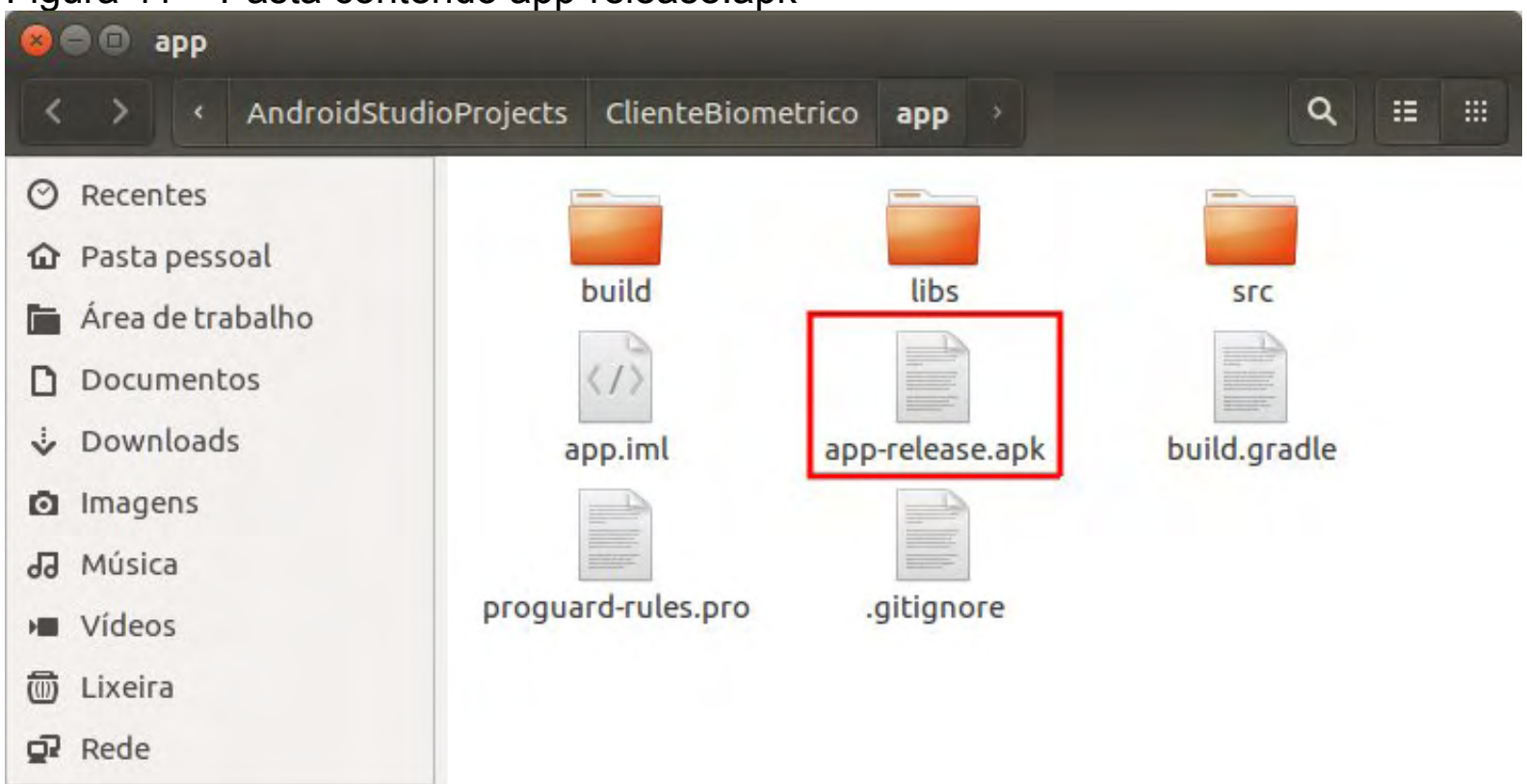

Fonte: Própria autoria.

Deve-se lembrar que após a instalação do ClienteBiometrico deve-se dar permissão de acesso à câmera do celular.

Para esta dissertação o servidor GlassFish foi instalado juntamente com o NetBeans. Através do NetBeans faz-se o deploy do aplicativo no Servidor e executase o aplicativo que atenderá as requisições como Web Service. Para isto devemos 
abrir o projeto BiometricServer pelo NetBeans, entrar no item de menu "Executar" e clicar em "Limpar e Construir". Esta ação fará a criação do aplicativo "BiometricServer.war" que poderá ser implantado no servidor GlassFish. Para a implantação (deploy) do serviço no servidor de aplicações deve-se clicar com o botão direito do mouse em cima do nome do projeto (Figura 42) e depois selecionar "Implantar".

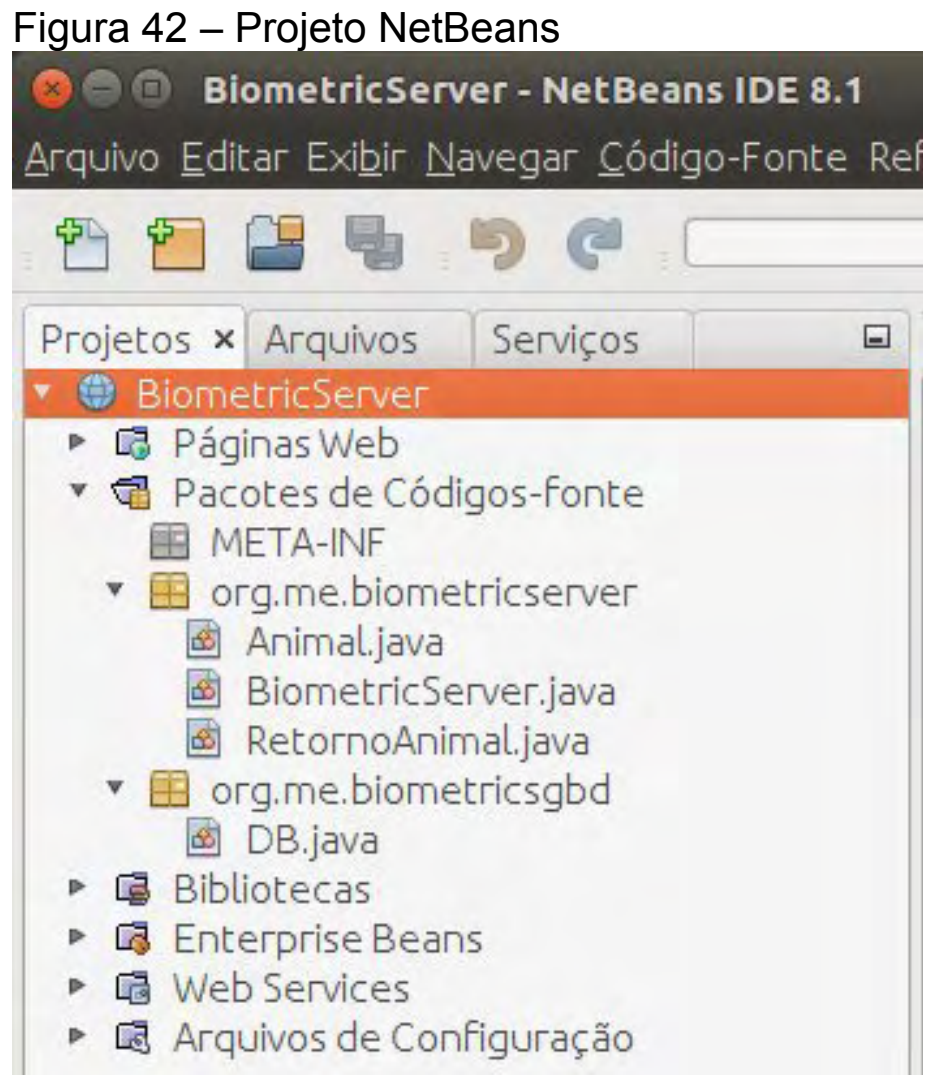

Fonte: Própria autoria.

Quando se faz isso o Netbens verifica se o servidor GlassFish está no ar e caso não esteja o próprio NetBeans inicializa o mesmo. Após este passo ele implanta o serviço no servidor como pode-se observar na aba "Serviços" (Figura 43). 
Figura 43 - BiometricServer na aba Serviços do Netbeans

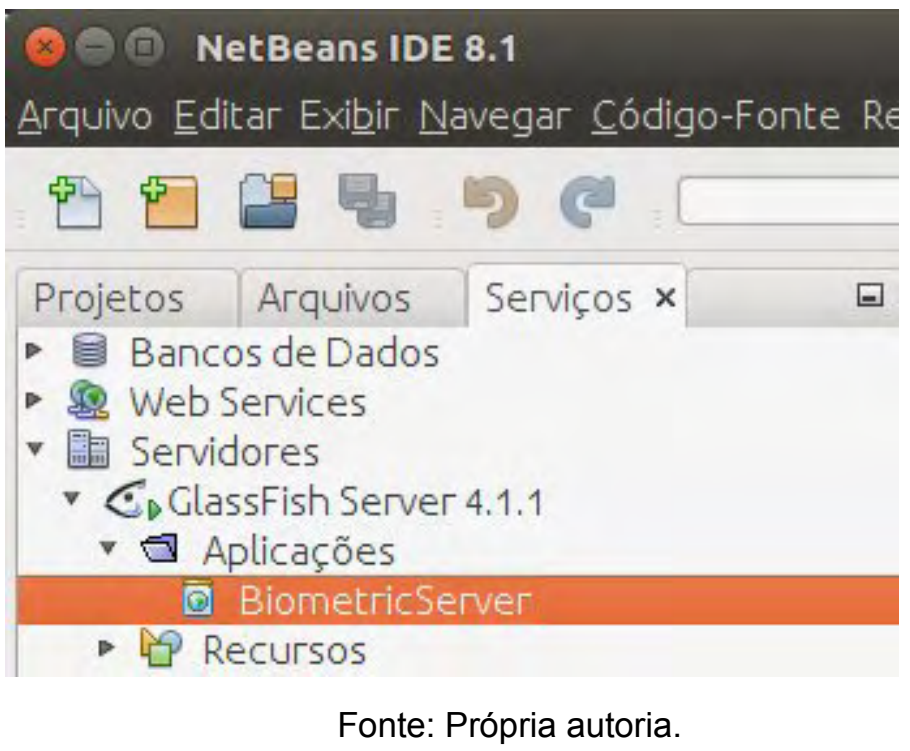

Com o programa no celular instalado e nosso servidor funcionando faz-se agora o teste no aplicativo. Toma-se uma fotografia de um boi (Figura 44) e então aciona-se o aplicativo no celular. Para a obtenção do espelho nasal deve-se clicar no botão "OBTER ESPELHO NASAL", neste momento abre-se a tela do ClienteBiometrico e quando se foca o focinho do boi pode-se verificar um retângulo branco demonstrando a área que será capturada (Figura 45). 
Figura 44 - Imagem da cabeça do boi

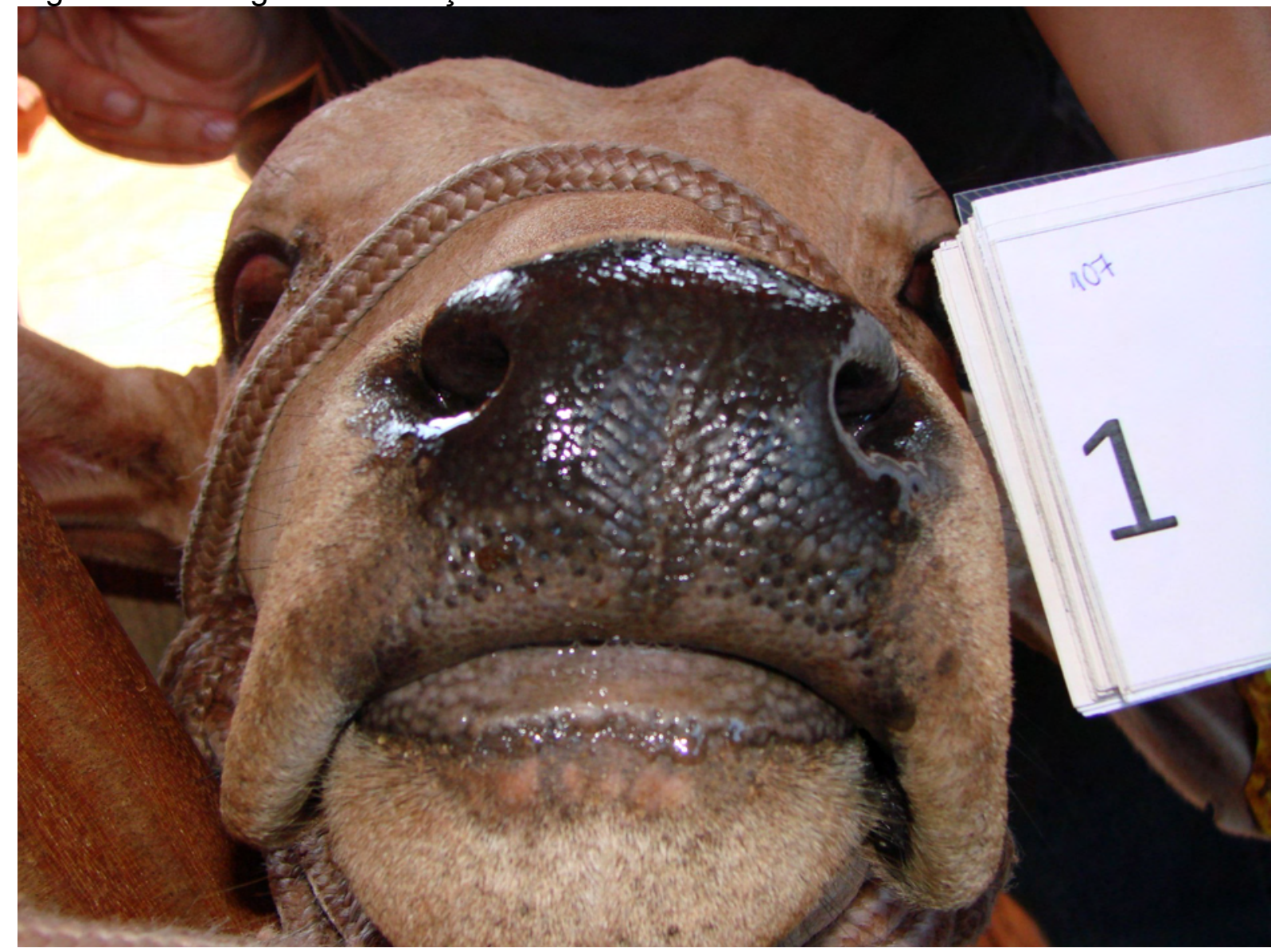

Fonte: Base de dados do Laboratório de Física Aplicada e Computacional, FZEA-USP, Pirassununga, SP, 2015.

Figura 45 - Imagem da tela do celular focando o espelho nasal

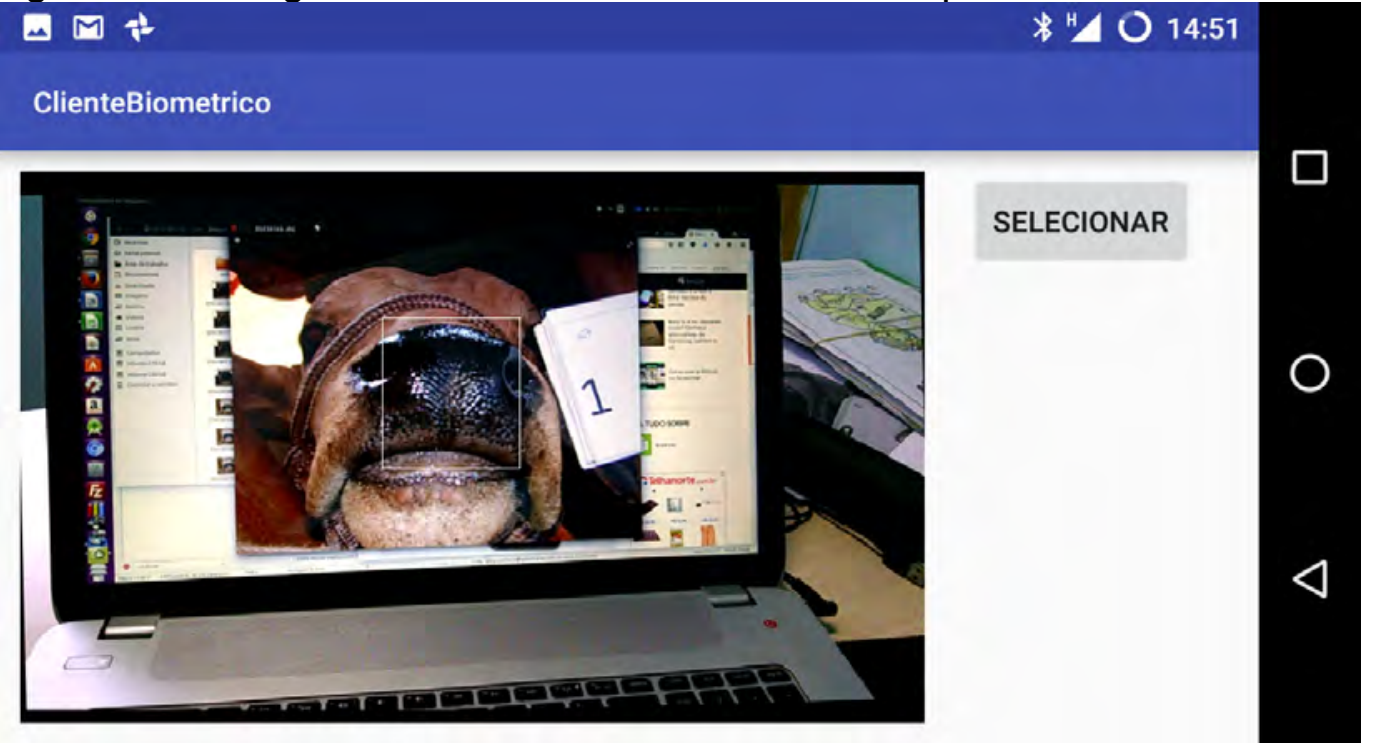

Fonte: Própria autoria. 
Após o foco do espelho nasal clica-se no botão "SELECIONAR" que fará a captura da área selecionada e retornará para a tela inicial (Figura 46) com o espelho nasal do animal.

Figura 46 - Tela do celular com espelho nasal capturado

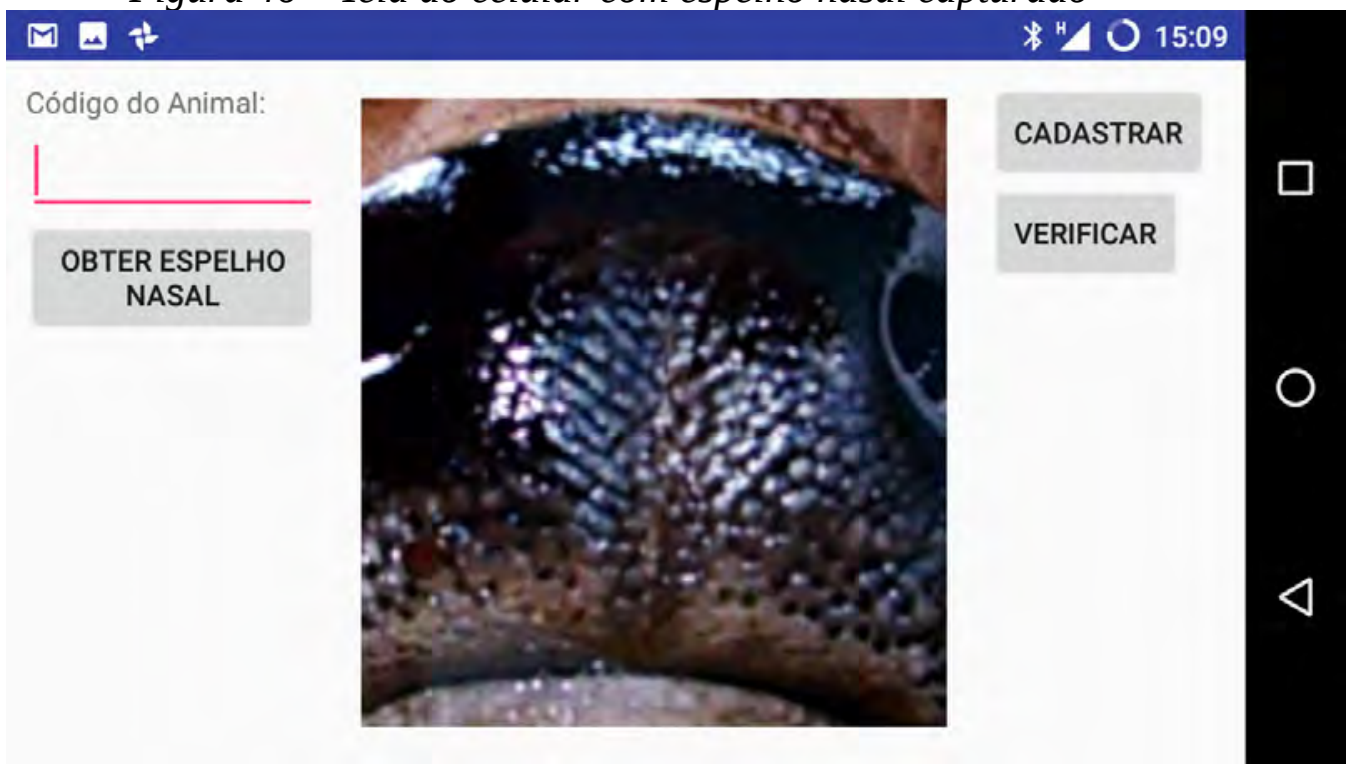

Fonte: Própria autoria.

Agora tem-se o espelho nasal capturado e pode-se tomar uma das duas ações disponibilizadas no aplicativo cliente. No teste de cadastramento informa-se o código do animal que neste teste é "56" e então clica-se no botão "CADASTRAR". Neste momento o aplicativo cliente abre uma comunicação SOAP com o Web Service e passa para o mesmo a mensagem solicitando o cadastramento do animal. O Servidor identifica a mensagem e com os parâmetros recebidos procede a inclusão no servidor de banco de dados MySQL. Para verificar se o processo ocorreu como esperado entra-se no aplicativo MySQL WorkBench e através dele acessamos a tabela animal e identifica-se uma linha contendo o campo "idanimal" com o valor "56" e o campo "imanimalimage" contendo o termo "BLOB" (Figura 47). 
Figura 47 - Linha da tabela "animal"

\section{$\otimes \ominus$ (D) MysQL Workbench}

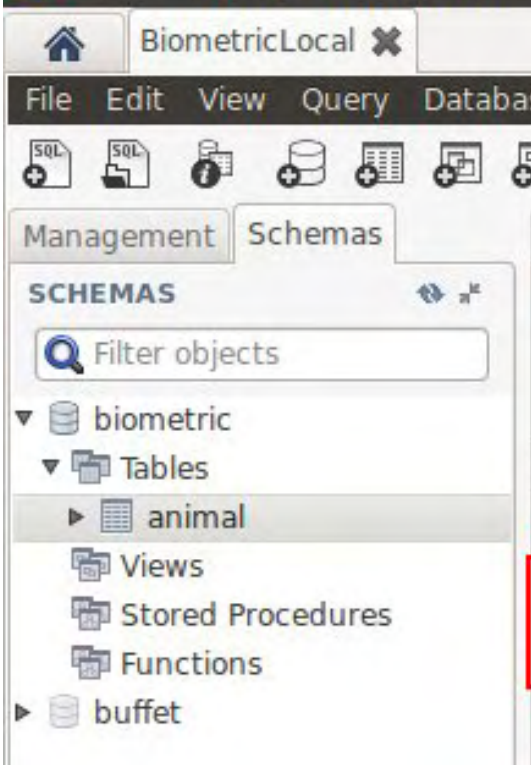

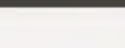

(n) 
Percebe-se desta forma que os dados enviados pelo celular foram armazenados no servidor com sucesso. 


\section{DISCUSSÃO E CONSIDERAÇÕES FINAIS}

O projeto desenvolvido para esta dissertação foi concebido como planejado, utilizando-se de ferramentas de código aberto e gratuitas e que está de acordo com os trabalhos de Mantas; Liu; Pereira (2015). Durante o desenvolvimento da camada cliente que envolvia o treinamento dos arquivos de configuração para a localização do focinho e narinas percebeu-se nitidamente que a quantidade de imagens exemplos e contra exemplos é fundamental para a qualidade dos arquivos e assim do processo de identificação este fato também foi observado por Abraham et al (2016). Outro aspecto importante foi a definição de narina esquerda e direita, pois elas possuem características diferentes que poderiam atrapalhar o processo caso se optasse por uma identificação geral. Este método de identificar pontos importantes na imagem já foi observado na literatura por Okabe e Carro (2015). O desenvolvimento da camada servidora mostrou-se muito eficiente com as ferramentas adotadas tanto de construção (NetBeans) como os servidores de apoio, servidor de aplicações GlassFish e de banco de dados MySQL. Pode-se citar como exemplo de utilização do Servidor GlassFish e MySQL o trabalho de prontuário eletrônico distribuído de Neto e Oliveira (2014). Para o desenvolvimento da camada cliente e servidora fez-se uso da linguagem Java, seja através do NetBeans para a camada servidora ou através do Android Studio na camada cliente.

As ferramentas de desenvolvimento, ou seja, o Android Studio e o NetBeans foram escolhidas por serem ferramentas reconhecidas no mercado e cujo conhecimento básico era de domínio do desenvolvedor. Fica claro com o projeto concluído que deve-se procurar uma ferramenta única que atenda as duas plataformas (servidora e cliente) para que possa ser mais facilmente mantido a fim de uma comercialização. Podendo ser o próprio NetBeans com plugins para Android e outras plataformas de celulares ou o Eclipse que também havia sido cogitado como plataforma de desenvolvimento. Como exemplo de utilização da plataforma NetBeans podemos citar Araújo e Silva (2016).

Quando da identificação do espelho nasal o mesmo foi determinado utilizando-se como base o centro das narinas sendo necessário para sua 
implementação comercial uma evolução na forma de localização das narinas e para isso uma base muito maior de imagens exemplos e contra exemplos que garantam a determinação das extremidades internas de cada uma, assim garantindo com precisão a coleta do espelho nasal.

Nos testes executados a identificação do espelho nasal como determinado acima mostrou-se regular e a imagem gravada no servidor com qualidade suficiente para comparação.

Com tudo o que foi exposto conclui-se que é viável o uso de técnicas de biometria em softwares de rastreabilidade, uma vez que se pode coletar informações com um celular e remotamente através do Web Service integrar este serviço com outros já existentes ou em implementações novas. Neste sentindo fica claro o aspecto comercial que pode ser explorado a partir dos estudos e desenvolvimentos realizados nesta dissertação. 


\section{REFERENCIAS}

\section{ABRAHAM, A. et al. Proceedings of the Second International Afro-European Conference for Industrial Advancement AECIA 2015. Springer, 2016.}

AMARAL, V; GIRALDI, G.A; THOMAZ, C.E. LBP Estatística Aplicada ao Reconhecimento de Expressões Faciais. In: ENCONTRO NACIONAL DE INTELIGENCIA ARTIFICIAL E COMPUTACIONAL, ENIAC, 13., 2013, Fortaleza, Ceara. Anais... Fortaleza, 2013.

ARAÚJO, A. J. C.; SILVA, L. C. J. BIOMÓVEL: aplicativo com tecnologia WebService para auxiliar o processo de ensino de aulas de campo em Botânica. In: SIMPÓSIO DE INFORMÁTICA DO IFNMG, 2., 2016, Januária, MG. Anais... Januária, 2016.

BARRY, B. et al. Using muzzle pattern recognition as a biometric approach for cattle identification. American Society of Agricultural an Biological Engineers, v.50, n.3, p. 1073-1080, 2007.

BRASIL. Portal Brasil. Disponível em <http://www.brasil.gov.br/economia-eemprego/2015/10/rebanho-bovino-brasileiro-cresce-e-chega-a-212-3-milhoes-decabecas-de-gado>. Acesso em: 28 maio 2016.

BRASIL. Ministério da Agricultura, Pecuária e Abastecimento. Disponível em <http://www.agricultura.gov.br/animal/exportacao>. Acesso em: 28 maio 2016.

DIAS, M, L, R, P. Cadeia Logística Segura Brasileira: Suprimento Internacional de Carne Bovina Industrializada e Rastreabilidade. Dissertação (Mestrado). Escola Politécnica da Universidade de São Paulo, Departamento de Engenharia de Energia e Automação Elétricas, 2012.

EBERT, B. Identification of beef animals. Extension Animal Scientist, Animal Sciences, Auburn University.YANR-0170, Reprinted July 2006. Disponível em: $<$ http://www.aces.edu/pubs/docs/Y/YANR-0170/index2.tmpl>. Acesso em : 27 jan. 2015.

FEDOTOV, N.G; MOKSHANINA, D.A. General Problems of Metrology and Measurement Technique: Recognition of Images with Complex Half-tone Texture. Measurement Techniques, Penza, Russia, v. 53, n. 11, p. 27, fev. 2011.

FERREIRA, L. C. L.; MEIRELLES, M. B. Avaliação da eficiência de quatro métodos para identificação de bovinos. Campo Grande: UFMS, 60 p., 2002.

FRANCO, M. Especial rastreabilidade. DBO Rural, São Paulo, n. 255, p. 102-117, fev. 2002.

FURQUIM, N.F. Alimento Seguro: Uma Análise do Ambiente Institucional Para Oferta de Carne Bovina no Brasil. Tese (Doutorado). Faculdade de Ciências Farmacêuticas da Universidade de São Paulo, Curso Interunidades em Nutrição 
Humana Aplicada, 2012.

GIMENEZ, C.M. Identificação de bovinos através de reconhecimento de padrões do espelho nasal utilizando redes neurais artificiais. Dissertação (Mestrado). Faculdade de Zootecnia e Engenharia de Alimentos da Universidade de São Paulo, Pirassununga, 2011.

GRAÇA, P.L.M; TOMÉ, A.M.P; LOPES, L.F.D.S. Detecção e Localização de Faces em Imagens. Dissertação (Mestrado). Universidade de Aveiro, Mestrado em Engenharia Electrónica e Telecomunicações, Aveiro, Portugal, 2008.

JENQ et al. Pratical Design and Implementation of Recognition Assisted Dynamic Surveillance System. Computers and Electrical Engineering, Taipei, n. 37, p. 1182-1192, Jul. 2011. Disponível em:

<http://www.sciencedirect.com/science/article/pii/S004579061100084X>. Acesso em: 24 jun. 2016.

KANESHIMA, E. Utilização de Serviços na Integração de Aplicações

Empresariais. Dissertação (Mestrado). Instituto de Ciências Matemáticas e de Computação da Universidade de São Paulo, Programa de Pós-Graduação em Ciências de Computação e Matemática Computacional, 2012.

MAHMOUD, H. A; HADAD, H. M. R. E. Automatic cattle muzzle print classification system using multiclass support vector machine. International Journal of Image Mining, v. 1, n. 1, p. 126-139, 2015.

MANTAS, V. M.; LIU, Z.; PEREIRA, A. J. S. C. A web service and android application for the distribution of rainfall estimates and Earth observation data. Computers \&

Geosciences, v. 77, p. 66-76, 2015.

NETO, J. S. A.; OLIVEIRA, H. J. Q. Modelo de banco de dados distribuido para o prontuário eletrônico único do paciente. In: CONGRESSO BRASILEIRO DE ENGENHARIA BIOMÉDICA - CBEB, 24., 2014, Mogi das Cruzes. Anais... Mogi das Cruzes, 2014.

OKABE, R. K.; CARRO, A. S. Reconhecimento facial em imagens capturadas por câmeras digitais de rede. In: COLLOQUIUM EXACTARUM, 2015. Presidente Prudente. Anais... Presidente Prudente, p. 106-119, 2015.

PAZ, A, R.; MENEZES, S. M.; CAMPION, A.; ZEN, S. Simpósio Internacional de Iniciação Científica da Universidade de São Paulo (13. 2005 Piracicaba, SP), 2005.

PINTAPROJECT. Pinta. Disponível em <http://pinta-project.com/pintaproject/pinta/>. Acesso em: 02 ago. 2016.

PORTO, S.M.C et al. A Computer Vision-based System for the Automatic Detection of Lying Behavior of Dairy Cows in Free-stall Barns. Biosystems Engineering, v. 115, n. 2, p. 184-194, 2013. 
VISHWAKARMA, S.K; AKASH; YADAV, D.S. Analysis of lane detection techniques using OpenCV. India Conference (INDICON), India, 2015, p. 1-4.

WEISSBROD, A. et. al. Automated long-term tracking and social behavioural phenotyping of animal colonies within a semi-natural environment. Nature communications, Beijing, China, v. 4, 2013.

ZAORÁLEK, L; PRILEPOK, M; SNÁŠEL, V. Cattle Identification Using Muzzle Images. In: INTERNATIONAL AFRO-EUROPEAN CONFERENCE FOR INDUSTRIAL ADVANCEMENT AECIA, 2., 2015, Villejuif. Proceedings... Villejuif: Springer International Publishing, 2016. p. 105-115. 